\title{
Synthesis and transport properties of 2D transition metal carbides (MXenes)
}

\author{
Joseph Halim
}

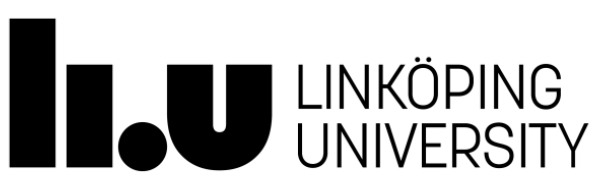

Thin Film Physics Division

Department of Physics, Chemistry and Biology (IFM) Linköping University, SE-581 83, Linköping, Sweden Linköping 2018 

The cover image shows schematics of single flakes of the transition metal carbide, $\mathrm{Ti}_{3} \mathrm{C}_{2}$ (MXene) depicting the electronic conduction mechanisms, that include interflake and intraflake hopping. Several flakes together form a free-standing thin film. STEM image shows a $\mathrm{Nb}_{2} \mathrm{CT}_{Z}$ epitaxially grown thin film.

(J)oseph Halim, 2018

ISBN 978-91-7685-219-4

ISSN 0345-7524

Printed by LiU-Tryck, Linköping, 2018. 



\section{ABSTRACT}

Since the isolation and characterization of graphene, there has been a growing interest in 2D materials owing to their unique properties compared to their $3 \mathrm{D}$ counterparts. Recently, a family of 2D materials of early transition metal carbides and nitrides, labelled MXenes, has been discovered $\left(\mathrm{Ti}_{2} \mathrm{CT}_{\mathrm{z}}, \mathrm{Ti}_{3} \mathrm{C}_{2} \mathrm{~T}_{\mathrm{z}}, \mathrm{Mo}_{2} \mathrm{TiC}_{2} \mathrm{~T}_{\mathrm{z}}, \mathrm{Ti}_{3} \mathrm{CNT}_{\mathrm{z}}, \mathrm{Ta}_{4} \mathrm{C}_{3} \mathrm{~T}_{\mathrm{z}}, \mathrm{Ti}_{4} \mathrm{~N}_{3} \mathrm{~T}_{\mathrm{z}}\right.$ among many others), where $\mathrm{T}$ stands for surface-terminating groups $(\mathrm{O}, \mathrm{OH}$, and $\mathrm{F})$. MXenes are mostly produced by selectively etching A layers (where A stands for group A elements, mostly groups 13 and 14) from the MAX phases. The latter are a family of layered ternary carbides and/or nitrides and have a general formula of $M_{n+1} A X_{n}(\mathrm{n}=1-3)$, where $M$ is a transition metal and $X$ is carbon and/or nitrogen. The produced MXenes have a conductive carbide core and a non-conductive $\mathrm{O}-$, $\mathrm{OH}$ - and/or F-terminated surface, which allows them to work as electrodes for energy storage applications, such as Li-ion batteries and supercapacitors.

Prior to this work, MXenes were produced in the form of flakes of lateral dimension of about 1 to 2 microns; such dimensions and form are not suitable for electronic characterization and applications. I have synthesized various MXenes $\left(\mathrm{Ti}_{3} \mathrm{C}_{2} \mathrm{~T}_{\mathrm{z}}, \mathrm{Ti}_{2} \mathrm{CT}_{\mathrm{z}}\right.$ and $\mathrm{Nb}_{2} \mathrm{CT}_{z}$ ) as epitaxial thin films, a more suitable form for electronic and photonic applications. These films were produced by $\mathrm{HF}, \mathrm{NH}_{4} \mathrm{HF}_{2}$ or $\mathrm{LiF}+\mathrm{HCl}$ etching of magnetron sputtered epitaxial $\mathrm{Ti}_{3} \mathrm{AlC}_{2}, \mathrm{Ti}_{2} \mathrm{AlC}$, and $\mathrm{Nb}_{2} \mathrm{AlC}$ thin films. For transport properties of the Ti-based MXenes, $\mathrm{Ti}_{2} \mathrm{CT}_{\mathrm{z}}$ and $\mathrm{Ti}_{3} \mathrm{C}_{2} \mathrm{~T}_{\mathrm{z}}$, changing $n$ from 1 to 2 resulted in an increase in conductivity but had no effect on the transport mechanism (i.e. both $\mathrm{Ti}_{3} \mathrm{C}_{2} \mathrm{~T}_{\mathrm{x}}$ and $\mathrm{Ti}_{2} \mathrm{CT}_{\mathrm{x}}$ were metallic). In order to examine whether the electronic properties of MXenes differ when going from a few layers to a single flake, similar to graphene, the electrical characterization of a single $\mathrm{Ti}_{3} \mathrm{C}_{2} \mathrm{~T}_{\mathrm{z}}$ flake with a lateral size of about $10 \mu \mathrm{m}$ was performed. These measurements, the first for MXene, demonstrated its metallic nature, along with determining the nature of the charge carriers and their mobility. This indicates that $\mathrm{Ti}_{3} \mathrm{C}_{2} \mathrm{~T}_{\mathrm{z}}$ is inherently of $2 \mathrm{D}$ nature independent of the number of stacked layers, unlike graphene, where the electronic properties change based on the number of stacked layers.

Changing the transition metal from Ti to $\mathrm{Nb}$, viz. comparing $\mathrm{Ti}_{2} \mathrm{CT}_{\mathrm{Z}}$ and $\mathrm{Nb}_{2} \mathrm{CT}_{\mathrm{Z}}$ thin films, the electronic properties and electronic conduction mechanism differ. $\mathrm{Ti}_{2} \mathrm{CT}_{\mathrm{z}}$ showed metallic-like behavior (resistivity increases with increasing temperature) unlike $\mathrm{Nb}_{2} \mathrm{CT}_{\mathrm{z}}$ where the conduction occurs via variable range hopping mechanism (VRH) where resistivity decreases with increasing temperature. 
Furthermore, these studies show the synthesis of pure $\mathrm{Mo}_{2} \mathrm{CT}_{\mathrm{z}}$ in the form of single flakes and freestanding films made by filtering $\mathrm{Mo}_{2} \mathrm{CT}_{\mathrm{z}}$ colloidal suspensions. Electronic characterization of free-standing films made from delaminated $\mathrm{Mo}_{2} \mathrm{CT}_{\mathrm{z}}$ flakes was investigated, showing that a VRH mechanism prevails at low temperatures ( 7 to $\approx 60 \mathrm{~K}$ ). Upon vacuum annealing, the room temperature, RT, conductivity of $\mathrm{Mo}_{2} \mathrm{CT}_{\mathrm{x}}$ increased by two orders of magnitude. The conduction mechanism was concluded to be VRH most likely dominated by hopping within each flake.

Other Mo-based MXenes, $\mathrm{Mo}_{2} \mathrm{TiC}_{2} \mathrm{~T}_{\mathrm{z}}$ and $\mathrm{Mo}_{2} \mathrm{Ti}_{2} \mathrm{C}_{3} \mathrm{~T}_{\mathrm{z}}$, showed VRH mechanism at low temperature. However, at higher temperatures up to RT, the transport mechanism was not clearly understood. Therefore, a part of this thesis was dedicated to further investigating the transport properties of Mo-based MXenes. This includes $\mathrm{Mo}_{2} \mathrm{CT}_{\mathrm{z}}$, out-of-plane ordered $\mathrm{Mo}_{2} \mathrm{TiC}_{2} \mathrm{~T}_{\mathrm{z}}$ and $\mathrm{Mo}_{2} \mathrm{Ti}_{2} \mathrm{C}_{3} \mathrm{~T}_{\mathrm{z}}$, and vacancy ordered $\mathrm{Mo}_{1.33} \mathrm{CT}_{\mathrm{z}}$. Magneto-transport of free-standing thin films of the Mo-based MXenes were studied, showing that all Mo-based MXenes have two transport regimes: a VRH mechanism at lower temperatures and a thermally activated process at higher temperatures. All Mo-based MXenes except $\mathrm{Mo}_{1.33} \mathrm{CT}_{\mathrm{Z}}$ show that the electrical transport is dominated by inter-flake transfer. As for $\mathrm{Mo}_{1.33} \mathrm{CT}_{\mathrm{z}}$, the primary electrical transport mechanism is more likely to be intra-flake.

The synthesis of vacancy ordered MXenes $\left(\mathrm{Mo}_{1.33} \mathrm{CT}_{\mathrm{Z}}\right.$ and $\left.\mathrm{W}_{1.33} \mathrm{CT}_{\mathrm{z}}\right)$ raised the question of possible introduction of vacancies in all MXenes. Vacancy ordered MXenes are produced by selective etching of $\mathrm{Al}$ and (Sc or $\mathrm{Y}$ ) atoms from the parent 3D MAX phases, such as $\left(\mathrm{Mo}_{2 / 3} \mathrm{Sc}_{1 / 3}\right)_{2} \mathrm{AlC}$, with in-plane chemical ordering of $\mathrm{Mo}$ and $\mathrm{Sc}$. However, not all quaternary parent MAX phases form the in-plane chemical ordering of the two M metals; thus the synthesis of the vacancy-ordered MXenes is restricted to a very limited number of MAX phases. I present a new method to obtain MXene flakes with disordered vacancies that may be generalized to all quaternary MAX phases. As proof of concept, I chose $\mathrm{Nb}-\mathrm{C}$ MXene, as this 2D material has shown promise in several applications, including energy storage, photothermal cell ablation and photocatalysts for hydrogen evolution. Starting from synthetizing $\left(\mathrm{Nb}_{2 / 3} \mathrm{Sc}_{1 / 3}\right)_{2} \mathrm{AlC}$ quaternary solid solution and etching both the $\mathrm{Sc}$ and $\mathrm{Al}$ atoms resulted in $\mathrm{Nb}_{1.33} \mathrm{C}$ material with a large number of vacancies and vacancy clusters. This method may be applicable to other quaternary or higher MAX phases wherein one of the transition metals is more reactive than the other, and it could be of vital importance in applications such as catalysis and energy storage. 


\section{POPULÄRVETENSKAPLIG SAMMANFATTNING}

Tvådimensionella (2D) material har en oändlig utsträckning i x- och y-riktningen och en tjocklek av ett enda atomlager. Sådana material uppvisar nya egenskaper som skiljer sig från deras 3D-motsvarigheter. De optiska och elektriska egenskaperna är vanligtvis olika på grund av att elektronerna endast kan röra sig i ett plan. Andra egenskaper, till exempel mekaniska och kemiska, förändras också, vilket huvudsakligen beror på det höga förhållandet mellan yta och volym.

Under 2010 tilldelades Andre Geim och Konstantin Novoselov Nobelpriset i fysik för att de isolerat ett atomärt tunt skikt av kol (grafén) och mätt dess elektroniska egenskaper. Grafén visade sig ha imponerande egenskaper jämfört med grafit: hög mekanisk styrka, ballistisk ledningsförmåga, lika bra elektrisk ledningsförmåga som silver, och hög värmeledningsförmåga. Det är nästan genomskinligt för ljus $(97,7 \%)$, medan små atomer som helium kan inte tränga igenom ett enda lager av grafen. Dessa egenskaper gör grafén till ett lovande material för olika tillämpningar, såsom elektriska och optoelektroniska anordningar som transistorer och transparenta ledande elektroder som används i pekskärmar, samt elektrokemiska och biologiska sensorer.

Men grafén var bara toppen av isberget. Efter grafen har man upptäckt en rad andra 2D-material. För att nämna några: hexagonal bornitrid, $\mathrm{MoS}_{2}$, övergångsmetalloxider och hydroxider. Under 2011 upptäcktes en ny familj 2D-material av övergångsmetallkarbider och nitrider, vilken benämndes "MXene". MXener produceras genom att kemiskt avlägsna "A" -skikten från de lagrade övergångsmetallkarbider och nitrider som är kända som MAX-faser. De senare har den allmänna formeln $\mathrm{M}_{n+1} \mathrm{AX}_{\mathrm{n}}(\mathrm{n}=1,2$ eller 3), där $\mathrm{M}$ är en övergångsmetall, $\mathrm{A}$ är huvudsakligen grundämnen från grupp 13 och 14 i periodiska systemet (t.ex. Al, Ga, Si eller Ge) och X är C och / eller N.

MXenes har främst undersökts för energilagring där de visar lovande resultat. Innan det här arbetet påbörjades producerades MXenes i form av små flingor med en storlek på en till två mikrometer, vilket inte är lämpligt för att karakterisera elektroniska egenskaper. Därför är syftet med denna studie att tillverka MXene som enskilda flak stora nog för att mäta elektroniska egenskaper, liksom i tunnfilmform av mer än ett lager. Tunna filmer upp till $50 \mathrm{~nm}$ av MXene, $\mathrm{Ti}_{3} \mathrm{C}_{2}$, syntetiserades och deras elektroniska egenskaper karakteriserades, och påvisade ett metalliskt beteende. Vidare visade elektroniska mätningar för ett enda flak av $\mathrm{Ti}_{3} \mathrm{C}_{2}$ också metalliska egenskaper. De elektroniska egenskaperna hos $\mathrm{Ti}_{3} \mathrm{C}_{2}$ är alltså oberoende av tjockleken. På samma sätt förändras inte 
de elektroniska egenskaperna av stökiometrin hos de Ti-baserade MXenerna i det avseendet att de är metalliska, men den elektriska ledningsförmågan hos $\mathrm{Ti}_{2} \mathrm{C}$ är lägre än $\mathrm{Ti}_{3} \mathrm{C}_{2}$. Byter man däremot övergångsmetall från $\mathrm{Ti}$ till $\mathrm{Nb}$ eller $\mathrm{Mo}$ ändras det elektroniska beteendet till en variabel hoppningsmekanism. Utöver det har jag också undersökt den elektroniska ledningsmekanismen för Mo-baserade $\mathrm{MXener:} \mathrm{Mo}_{2} \mathrm{C}$, med vakanser på Mo-platser $\left(\mathrm{Mo}_{1.33} \mathrm{C}\right)$ och ordnade MXener $\left(\mathrm{Mo}_{2} \mathrm{TiC}_{2}\right.$ och $\left.\mathrm{Mo}_{2} \mathrm{Ti}_{2} \mathrm{C}_{3}\right)$. Fristående tunna filmer av flera mikrometer tjocka Mo-baserade MXener visade en variabel hoppmekanism vid låga temperaturer (2 till $100 \mathrm{~K}$ ) och en termisk aktiverad process vid högre temperatur upp till rumstemperatur. Alla Mo-baserade MXener utom $\mathrm{Mo}_{1.33} \mathrm{C}$ visar att den elektriska transporten domineras av transport mellan 2D-flaken. När det gäller Mo1.33 $\mathrm{C}$ är den elektriska transportmekanismen mer sannolikt dominerad av transport inom varje flak.

Syntesen av vakans-ordnade MXener, som Mo1.33 C, ledde till frågan: är det möjligt att införa ordnade vakanser i alla MXener? Vakansordnade MXener produceras genom att kemiskt avlägsna Al- och Sc-atomer från ordnade 3D MAX-faserna som $(\mathrm{MoSc})_{2} \mathrm{AlC}$, där Mo- och Sc-atomerna har specifika positioner inom samma lager av atomer (kemisk ordning i planet). Dock bildar inte alla kvaternära MAX-faser kemisk ordning i de två Mmetallerna, varför syntesen av vakansordnade MXener är begränsad. Här presenterar jag en ny metod för att få MXene-flak med oordnade vakanser. Detta kan sannolikt generaliseras till alla kvartenära MAX-faser. Som bevis på konceptet valde jag Nb-C MXene, eftersom detta 2D-material är intressant inom flera tillämpningar, inklusive energilagring, fototermisk cellablation och fotokatalysatorer för väteutveckling. Detta gjordes med början i de första syntetiserande kvaternära faserna $(\mathrm{NbSc})_{2} \mathrm{AlC}$, där $\mathrm{Nb}$ - och $\mathrm{Sc}$-atomer fördelas slumpmässigt inom samma atomlager. Etsning av både Sc och Alatomer resulterar i materialet $\mathrm{Nb}_{1.33} \mathrm{C}$ med ett stort antal vakanser. Denna metod är högst sannolikt tillämplig på alla kvaternära (eller högre) MAX-faser där en av övergångsmetallerna är mer reaktiv än den andra. Detta kan vara av avgörande betydelse vid tillämpningar såsom katalys och energilagring.

Den viktigaste delen av denna studie är därigenom att den för första gången undersöker de elektroniska egenskaperna hos denna nya familj 2D-material, vilket öppnar dörren för användning i elektroniska och optoelektroniska applikationer. 


\section{PREFACE}

This thesis summarizes my research work done primarily in the Thin Film Physics Division, Department of Physics, Chemistry and Biology (IFM), Linköping University, Linköping, Sweden from January 2012 to October 2018. The main focus of this work was to synthesize MXenes in the form of nanocrystals and epitaxial thin films and investigate their electronic properties. Part of the work presented herein was published in my licentiate thesis in October 2014, Synthesis and Characterization of 2D Nanocrystals and Thin Films of Transition Metal Carbides (MXenes) (Linköping Studies in Science and Technology, Licentiate Thesis No. 1679).

During the period from January 2012 to June 2016, I worked on another PhD thesis, primarily in the Materials and Engineering Department at Drexel University, Philadelphia, Pennsylvania, United States of America. This work resulted in a separate published PhD thesis, An X-Ray Photoelectron Spectroscopy Study of Multilayered Transition Metal Carbides (MXenes).

Pages XI and XII list the papers included in this thesis and my contributions to them. Pages XIII and XIV list the papers related to this thesis. Page XV lists my other papers, including those related to my Drexel University thesis.

The work presented herein has been funded by the Swedish Research Council (VR), Grant Nos. 621-2012-4430 and 621-2011-4420, the VR Linnaeus Strong Research Environment LiLi-NFM, and the Swedish Foundation for Strategic Research (SSF) through the Synergy Grant FUNCASE. 



\section{ACKNOWLEDGEMENTS}

I would like to express my genuine gratitude and appreciation to everyone who supported me and/or contributed to this work. In particular, I acknowledge:

Michel Barsoum, my supervisor; for supporting me and pushing my boundaries of science towards more research of quality and quantity. Most importantly, I am in his debt for giving me the freedom to express my scientific ideas, as well as to perform them.

Lars Hultman, my co-supervisor at Linköping University; for all his helpful constructive criticism of my work, as well as for finding the time for me despite being extremely busy. Although he is currently working at IFM for only one day a week, he always finds the time for discussions and feedback on my research and articles.

Per Eklund, my co-supervisor at Linköping University; for his outstanding help during my stay in Linköping, as well as for being very patient and helpful throughout the process of manuscripts preparation.

Johanna Rosén, my co-supervisor at Linköping University; for her continuous support, and encouragement, as well as for finding the time for a progress meeting once a week, despite being extremely busy.

Martin Magnuson, my co-supervisor at Linköping University; for his help with the theoretical calculations portion of my research. I am looking forward to the synchrotron addition work on MXenes.

Jun Lu (my co-supervisor), Ingemar Persson, Justinas Palisaitis, and Per Persson; for their help with TEM characterizations and TEM micrographs analysis.

Lars-Åke and Kevin Cook, my two XPS masters; no words can express my sincere gratitude for all the knowledge and experience you continuously provide.

Hossein Fashandi and Andrejs Petruhins; for the time and effort to train me on the deposition system.

Michael Naguib, my friend, and officemate at Drexel University. It has been a great pleasure working with you, and I have learnt a lot from you. 
Maria Lukatskaya, my friend, and labmate at Drexel University. I enjoyed working with you as much as I enjoyed our hiking trips to the parks in Philadelphia.

Árni Sigurður Ingason; for introducing me to the XRD characterization of thin films, as well as for helping me achieve the best quality deposited films. I have learnt a lot from you, and I enjoyed our fruitful discussions while having beer in Italy.

Yury Gogotsi, Alessio Miranda, Axel Lorke, El'ad Caspi, Philipp Kühne, Eun Ju Moon, Marian Precner, Thierry Ouisse, and Thierry Cabioch; for their collaborations. I have enjoyed working with you, and I learned a lot from all of you.

Marlene Mühlbacher, my Austrian friend, and office mate at Linköping University; for making working in the summer at Linköping endurable. I really enjoyed our books discussions, going to the movies and ice cream trips.

Rahele Meshkian and Jimmy Thörnberg; for making lab work fun and exciting.

Ildiko Farkas; for all the help regarding the chemical experiments in the HF lab.

Thomas Lingefelt, Harri Savimaki, and Sven Andersson the best and most helpful technicians ever; for your patience and help with purchasing laboratory equipment and making my lab work easier.

Michael Ghidiu, Sankalp Kota Elisa Mayerberger; for being awesome office and labmates while I was at Drexel University. I truly appreciate your efforts and Kira Wojack's in proofreading this thesis.

Kirstin Kahl, Malin Wahlberg, and Anette Frid administrators at Linköping University, Keiko Nakazawa, Sarit Kunz, and Yenneeka West, administrators at Drexel University. Thank you all for your help with all the administrative work, you really made my life much easier.

All my friends and colleagues in Drexel University and Linköping University; Thank you for your support and help.

Last but not least, my family. Thank you for your never-ending support for all my decisions and your encouragement to always follow my dreams.

Joseph Halim

Linköping, October 2018 


\section{INCLUDED PAPERS AND AUTHOR'S CONTRIBUTION}

\section{Paper I}

Transparent Conductive Two-Dimensional Titanium Carbide Epitaxial Thin Films

J. Halim, M.R. Lukatskaya, K.M. Cook, J. Lu, C.R. Smith, L.-Å. Näslund, S.J. May, L. Hultman, Y. Gogotsi, P. Eklund, and M.W. Barsoum

Chemistry of Materials 26, $2374-2381$ (2014)

I planned and performed the thin film depositions; performed and developed the etching process; performed XRD and XRR of the films before and after etching; measured the room temperature resistivities; performed UV-Vis characterization; and analyzed the produced data. I also analyzed the TEM micrographs and the XPS results. I wrote the manuscript.

\section{Paper II}

Electronic Properties of Freestanding $\mathrm{Ti}_{3} \mathrm{C}_{2} \mathrm{~T}_{x}$ MXene Monolayer

A. Miranda, J. Halim, M.W. Barsoum, and A. Lorke

Applied Physics Letters 108, 033102 (2016)

I synthesized the samples; was involved in data analysis and discussions; and took part in the writing of the manuscript.

\section{Paper III}

Electronic and Optical Characterization of $2 \mathrm{D} \mathrm{Ti}_{2} \mathrm{C}$ and $\mathrm{Nb}_{2} \mathrm{C}$ (MXene) Thin Films

J. Halim, I. Persson, E.J. Moon, P. Kühne, V. Darakchieva, S.J. May, P.O.Å Persson, P. Eklund, J. Rosen, and M.W. Barsoum

In manuscript

I planned and performed the thin film depositions; performed and developed the etching process; performed the XRD, XPS measurements; and analyzed the produced data. I also analyzed the transport data, including $\mathrm{R}$ vs. $\mathrm{T}$ and magnetoresistance. I took part in writing the manuscript. 


\section{Paper IV}

Synthesis and Characterization of 2D Molybdenum Carbide (MXene)

J. Halim, S. Kota, M.R. Lukatskaya, M. Naguib, M.Q. Zhao, E.J. Moon, J. Pitock, J. Nanda, S.J. May, Y. Gogotsi, and M.W. Barsoum

Advanced Functional Materials 26, 3118 - 3127 (2016)

I planned the experiments, synthesized the precursor $\left(\mathrm{Mo}_{2} \mathrm{Ga}_{2} \mathrm{C}\right)$; developed the etching process; performed the XRD, XPS measurements; and analyzed the produced data. I also analyzed the transport data, including $\mathrm{R}$ vs. $\mathrm{T}$ and magnetoresistance. I took part in writing the manuscript in cooperation with M. R. Lukatskaya, S. Kota and M. Naguib.

\section{Paper V}

Variable Range Hopping and Thermally Activated Transport in Molybdenum-based MXenes

J. Halim, E.J. Moon, P. Eklund, J. Rosen, M.W. Barsoum, and T. Ouisse

Physical Review B 98, 104202 (2018)

I planned the experiments, took part in producing the samples and analyzing the transport data. I took part in writing the manuscript along with T. Ouisse.

\section{Paper VI}

Synthesis of Two-Dimensional $\mathrm{Nb}_{1.33} \mathrm{C}$ (MXene) with Randomly Distributed Vacancies by Etching of the Quaternary Solid Solution $\left(\mathrm{Nb}_{2 / 3} \mathrm{Sc}_{1 / 3}\right)_{2} \mathrm{AlC} \mathrm{MAX}$ Phase

J. Halim, J. Palisaitis, J. Lu, J. Thörnberg, E.J. Moon, M. Precner, P. Eklund, P.O.Å. Persson, M.W. Barsoum, and J. Rosen

ACS Applied Nano Materials 1, 2455 - 2460 (2018)

I planned the experiments; synthesized the MAX phase; developed the etching process; performed the XRD, XPS measurements; and analyzed the produced data. I also analyzed the transport data, including $\mathrm{R}$ vs. $\mathrm{T}$ and magnetoresistance measurements. I wrote the manuscript. 


\section{RELATED PAPERS}

New Two-Dimensional Niobium and Vanadium carbides as Promising Materials for Li-ion Batteries

M. Naguib, J. Halim, J. Lu, K.M. Cook, L. Hultman, Y. Gogotsi, and M.W. Barsoum

Journal of the American Chemical Society 135, 15966 - 15969 (2013)

$\mathrm{Mo}_{2} \mathrm{Ga}_{2} \mathrm{C}$ : A New Ternary Nanolaminated Carbide

C. Hu, C-C. Lai, Q. Tao, J. Lu, J. Halim, L. Sun, J. Zhang, J. Yang, B. Anasori, J.

Wang, Y. Sakka, L. Hultman, P. Eklund, J. Rosen, M.W. Barsoum

Chemical Communications 51, 6560 - 6563 (2015)

$\mathrm{Mo}_{2} \mathrm{TiAlC}_{2}$ : A New Ordered Layered Ternary Carbide

B. Anasori, J. Halim, J. Lu, C.A. Voigt, L. Hultman, and M.W. Barsoum

Scripta Materialia 101, 5 - 7 (2015)

Experimental and Theoretical Characterization of Ordered MAX Phases

$\mathrm{Mo}_{2} \mathrm{TiAlC}_{2}$ and $\mathrm{Mo}_{2} \mathrm{Ti}_{2} \mathrm{AlC}_{3}$

B. Anasori, M. Dahlqvist, J. Halim, E.J. Moon, J. Lu, B. C. Hosler, E. N. Caspi, S. J.

May, L. Hultman, P. Eklund, J. Rosen, and M. W. Barsoum

Journal of Applied Physics 118, 094304 (2015)

Synthesis of Two-Dimensional Molybdenum Carbide, $\mathrm{Mo}_{2} \mathrm{C}$, from the Gallium Based Atomic Laminate $\mathrm{Mo}_{2} \mathrm{Ga}_{2} \mathrm{C}$

R. Meshkian, L.Å. Näslund, J. Halim, J. Lu, M.W. Barsoum, and J. Rosen

Scripta Materialia 108, 147 - 150 (2015)

Fabrication of $T_{3} C_{2} T_{x}$ MXene Transparent Thin Films with Tunable Optoelectronic Properties

K. Hantanasirisakul, M.Q. Zhao, P. Urbankowski, J. Halim, B. Anasori, S. Kota, C.E. Ren, M.W. Barsoum, and Yury Gogotsi

Advanced Electronic Materials 2, 1600050 (2016) 
Two-Dimensional Mo ${ }_{1.33} C$ MXene with Divacancy Ordering Prepared from Parent 3D Laminate with In-Plane Chemical Ordering

Q. Tao, M. Dahlqvist, J. Lu, S. Kota, R. Meshkian, J. Halim, J. Palisaitis, L. Hultman, M. W. Barsoum, P.O.A. Persson, J. Rosen

Nature Communications 8, 14949 (2017)

Rendering $\mathrm{Ti}_{3} \mathrm{C}_{2} \mathrm{~T}_{x}$ (MXene) Monolayers Visible

A. Miranda, J. Halim, A. Lorke, M.W. Barsoum

Materials Research Letters 5, 322 - 328 (2017) 


\section{LIST OF OTHER PAPERS}

X-ray Photoelectron Spectroscopy of Select Multi-layered Transition Metal Carbides (MXenes)

J. Halim, K.M. Cook, M. Naguib, P. Eklund, Y. Gogotsi, J. Rosen, and M.W. Barsoum

Applied Surface Science 362, 406 - 417 (2016).

Ion-Exchange and Cation Solvation Reactions in Ti ${ }_{3} C_{2}$ MXene Two-Dimensional M. Ghidiu, J. Halim, S. Kota, D. Bish, Y. Gogotsi, and M. W. Barsoum

Chemistry of Materials 28, $3507-3514$ (2016).

Alkylammonium Cation Intercalation into $\mathrm{Ti}_{3} \mathrm{C}_{2}$ (MXene): Effects on Properties and Ion-Exchange Capacity Estimation

M. Ghidiu, S. Kota, J. Halim, A. W. Sherwood, N. Nedfors, J. Rosen, V. N. Mochalin, and M. W. Barsoum

Chemistry of Materials 28, $3507-3514$ (2017)

Structure and Thermal Expansion of $\left(C r_{x}, V_{l-x}\right)_{n+l} A l C_{n}$ Phases Measured by $X$-Ray Diffraction

J. Halim, P. Chartier, T. Basyuk, T. Prikhna, E. N. Caspi, M. W. Barsoum and T. Cabioc'h

Journal of the European Ceramic Society 37, 15 - 21 (2017)

New Solid Solution MAX Phases: $\left(\mathrm{Ti}_{0.5}, \mathrm{~V}_{0.5}\right) \mathrm{AlC} \mathrm{C}_{2},\left(\mathrm{~N} b_{0.5}, \mathrm{~V}_{0.5}\right)_{2} \mathrm{AlC}$, $\left(\mathrm{Nb}_{0.5}, \mathrm{~V}_{0.5}\right) \mathrm{AlC}_{3}$ and $\left(\mathrm{Zr}_{0.8}, \mathrm{Zr}_{0.2}\right)_{2} \mathrm{AlC}$ M. Naguib, G.W. Bentzel, J. Shah, J. Halim, E.N. Caspi, J. Lu, L. Hultman, and M. W Barsoum

Materials Research Letters 2, 233 - 240 (2014)

Chemical Bonding in Carbide MXene Nanosheets M. Magnuson, J. Halim, and L.Å. Näslund

Journal of Electron Spectroscopy and Related Phenomena 224, 27 - 32 (2018) 



\section{TABLE OF CONTENTS}

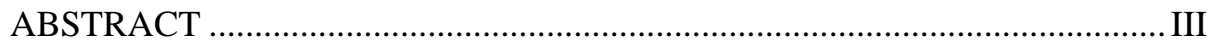

POPULÄRVETENSKAPLIG SAMMANFATTNING ...................................... V

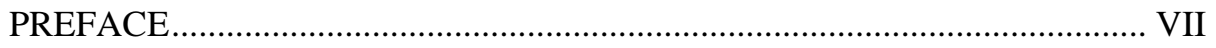

ACKNOWLEDGEMENTS ....................................................................

INCLUDED PAPERS AND AUTHOR'S CONTRIBUTION .............................

RELATED PAPERS ...............................................................................

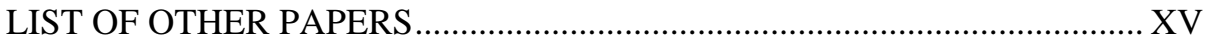

TABLE OF CONTENTS ………………………………............................

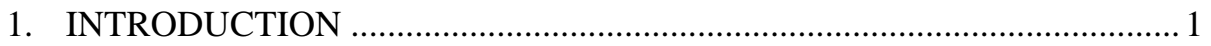

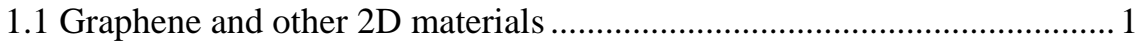

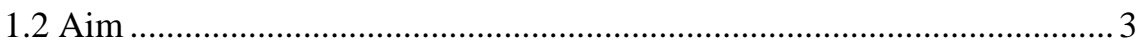

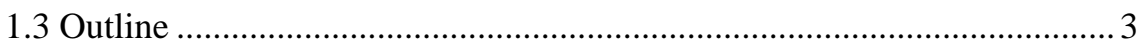

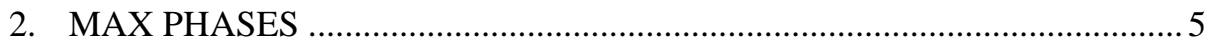

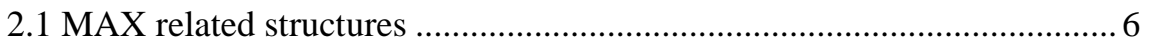

2.1.1 o-MAX

2.1.2

2.1.3 MAX phase like structures.............................................................. 7

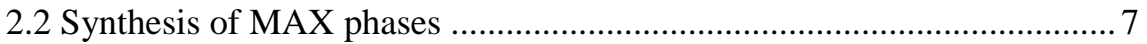

2.2.1 Bulk synthesis techniques .............................................................. 7

2.1.2 Thin film synthesis techniques...................................................... 10

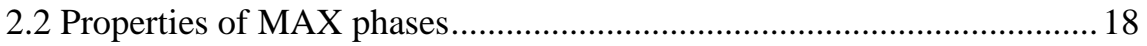

3. 2D TRANSITION METAL CARBIDES (MXENES) ………………............. 21

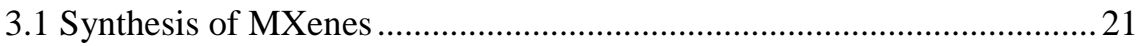

3.1.1 Factors Influencing the Production of MXenes ............................ 22

3.2 Exfoliation, Intercalation and Delamination of MXenes ..........................23

3.3 Structure of MXenes ................................................................................ 25

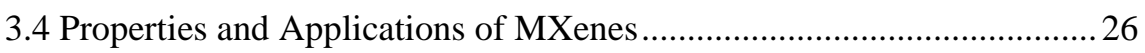

4. ELECTRONIC TRANSPORT PROPERTIES IN DISORDERED

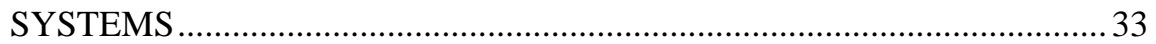

4.1 Conduction mechanisms in disordered systems ....................................... 34

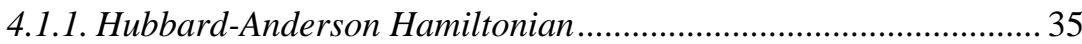


4.1.2. Weak localization in thin films and 2D materials ....................... 36

4.1.3. Variable range hopping (VRH) models ................................... 38

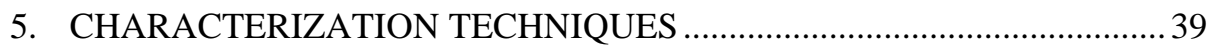

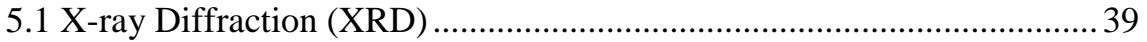

5.2 X-ray Reflectivity (XRR) ........................................................... 40

5.3 X-ray Photoelectron Spectroscopy (XPS) ............................................ 41

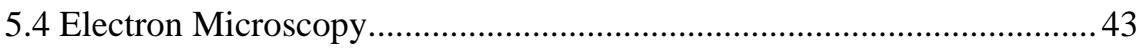

5.5 Ultraviolet-Visible Spectroscopy ................................................ 44

5.6 Electrical Characterization............................................................ 44

5.6.1 Four-point probe ............................................................... 44

5.6.1 Physical Properties Measurement System (PPMS)..................... 45

5.7 Electrochemical Characterization ...................................................... 46

5.7.1 Li-ion Batteries ........................................................................... 46

5.7.2 Supercapacitors ............................................................. 46

6. SUMMARY AND CONTRIBUTION TO THE FIELD .............................49

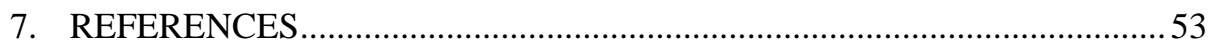




\section{INTRODUCTION}

\subsection{Graphene and other 2D materials}

In 2004, Novoselov et al. [1] managed to isolate a single atomic layer of graphene, measured its electronic properties and reported on its ballistic conductivity. This achievement continues to fascinate the scientific community to this day. It is worth noting that exfoliating 3D materials and converting them to 2D materials was already reported in 1859 by Brodie [2], who showed that the exfoliation of graphite to single sheets was possible. Furthermore, in 1986, Joensen et al. [3] reported on the exfoliation of $\mathrm{MoS}_{2}$ single layers. However, before 2004, no characterization of these single sheets was performed.

According to Geim et al. [4], a 2D crystal is a single atomic plane (monolayer). Graphene consists of one atomic layer of carbon $0.34 \mathrm{~nm}$ thick. In contrast, 100 atomic layers of carbon would constitute a thin film of graphite (3D material). The question is whether only a monolayer of material can be regarded as a 2D material or there is a certain range of thickness at which a material can be called 2D material? Bianco et al. [5] defined the range of graphene to be considered 2D material to be from 1 to 10 layers; whereas more than 10 layers would be considered 3D. This definition is based on the electronic structure of graphene, which changes from being a zero-gap semiconductor (often referred to as semimetal) for a monolayer of graphene to the graphitic 3D bulk electronic structure for more than 10 atomic layers thick. Thus, in general, one can define a range of thickness for 2D materials to be from one atomic layer to the extent that their electronic structure approaches that of the 3D bulk.

Owing to its ballistic conductivity, high thermal conductivity, high in-plane mechanical strength, optical transparency of $97.7 \%$ per monolayer of the visible spectrum and the possibility of tuning its properties, graphene is the most well-researched 2D material, thus finding its way into many applications [4, 6-7]. For example, the high mobility of charge carriers in graphene enabled it to be used in the field of transistors. Lin et al. were able to fabricate a 100-GHz transistor from wafer-scale epitaxial graphene [8]. Also, its high optical transparency combined with its high flexibility enabled flexible transparent electronic devices to be fabricated. For example, Eda et al. produced transparent flexible conductive films of reduced graphene oxides [9]. Kobayashi et al. developed an industrial method that can produce $100 \mathrm{~m}$ long high quality transparent conductive graphene [10]. Such transparent films can be used for multiple applications such as solar cells, light emitting devices, and touch sensitive screens [11]. 
The rapid advancement of graphene has encouraged several countries, funding agencies, and companies to focus their investments on graphene. In 2013, the European Commission awarded 1 billion euros to the Graphene Flagship for a duration of 10 years [12]. Interestingly, a large amount of investments came from private companies, such as Samsung [13]. In 2017, Samsung produced a Li-ion battery containing graphene-balls (silica with 1 wt.\% graphene coated on nickel-rich cathodes), providing improved cycle life and fast charging though the suppression of detrimental side reactions, as well as improving the efficiency of conductive pathways, leading to an increase in the volumetric energy density by $27 \%$ [14].

Despite the huge interest in graphene, it does have its drawbacks, such as hydrophobicity, the lack of a natural bandgap and the existence of very few methods to open a bandgap (e.g. such as functionalization [15-16] and/or the introduction of defects [17-19]). These drawbacks have encouraged scientists to explore other 2D materials, such as hexagonal BN [20], transition metal oxides and hydroxides [21], chalcogenides [22] and a new family of early transitional metal carbides and/or nitrides (MXenes) [23-27]. This large number of materials comes with a variety of properties, where each can be used for a certain application, it is also possible to combine several 2D materials to build heterostructure devices. For example, Bertolazzi et al. [28] took advantage of the ballistic conductivity and high mobility of charge carriers in graphene, as well as the natural bandgap of $\mathrm{MoS}_{2}$, and built a memory cell device. In that device, graphene is used as a conductive electrode, while $\mathrm{MoS}_{2}$ is used as the channel.

This thesis deals with one of the latest additions to the 2D family of materials (MXenes). They are primarily synthesized by selective etching of the "A" layers from generally layered transition metal carbides and/or nitrides known as the MAX phases. The latter have a general formula of $\mathrm{M}_{n+1} \mathrm{AX}_{\mathrm{n}}(\mathrm{n}=1,2$, or 3), where $\mathrm{M}$ stands for transition metals, A is mostly elements from group 13 and 14 , such as $\mathrm{Al}, \mathrm{Ga}, \mathrm{Si}$, or $\mathrm{Ge}$, and $\mathrm{X}$ is $\mathrm{C}$ and/or $N$ [29]. MXenes are synthesized by selective chemical etching of the A element (Al, Si or Ga) from the MAX phases to produce MXene [24-25, 30-31]. A mixture of elements and chemical groups terminate the surface of MXenes after the removal of the A element; those are called surface terminations. MXenes are readily functionalized with a formula of $\mathrm{M}_{\mathrm{n}+1} \mathrm{X}_{\mathrm{n}} \mathrm{T}_{\mathrm{z}}$, where $\mathrm{T}$ stands for surface termination groups $(\mathrm{O}, \mathrm{OH}$ and/or $\mathrm{F})$ [32-33]. 


\subsection{Aim}

This thesis aims to synthesize 2D transition metal carbides in the form of thin films on a substrate, as well as free-standing thin films, and to experimentally explore their electronic properties. This was done by producing MXene in the form of $2 \mathrm{D}$ epitaxial thin films, single flakes, and as free-standing thin films. Electronic properties were studied through showing the effect of several parameters, such as the stoichiometry $(n)$, number of flakes, and substitution of the M elements and the introduction of vacancies (whether they are ordered or randomly distributed), on the magneto-transport properties. The MXenes produced and studied herein include: $\mathrm{Ti}_{3} \mathrm{C}_{2} \mathrm{~T}_{\mathrm{z}}, \mathrm{Ti}_{2} \mathrm{CT}_{\mathrm{z}}, \mathrm{Nb}_{2} \mathrm{CT}_{\mathrm{z}}, \mathrm{Nb}_{1.33} \mathrm{CT}_{\mathrm{z}}$, $\mathrm{Mo}_{2} \mathrm{TiC}_{2} \mathrm{~T}_{\mathrm{z}}, \mathrm{Mo}_{2} \mathrm{Ti}_{2} \mathrm{C}_{3} \mathrm{~T}_{\mathrm{z}}$, and $\mathrm{Mo}_{1.33} \mathrm{CT}_{\mathrm{z}}$.

\subsection{Outline}

The thesis begins with a general introduction to 2D materials. Chapter 2 discusses the structure, synthesis techniques, properties and applications of MAX phases which are the MXene precursors. Chapter 3 is concerned with MXenes, illustrating their synthesis methods, effects of processing parameters, structure, exfoliation and intercalation, and properties and applications. Chapter 4 reviews the electronic properties of disordered materials. Chapter 5 discusses the main characterization techniques used in this work. Chapter 6 summarizes the main results in the appended papers. 



\section{MAX PHASES}

The MAX phases - layered transition metal ternary carbides and/or nitrides - constitute a large family of more than 100 phases, having the general formula of $M_{n+1} A X_{n}$, where $n$ $=1,2$ or $3, \mathrm{M}$ is an early transition metal, $\mathrm{A}$ is an A-group element, and $\mathrm{X}$ is $\mathrm{C}$ and/or $\mathrm{N}$ [29]. The elements constituting the MAX phases are shown in Figure 1.

\begin{tabular}{|c|c|c|c|c|c|c|c|c|c|c|c|c|c|c|c|c|c|}
\hline \multirow{3}{*}{$\begin{array}{c}\mathrm{H} \\
\mathrm{Li} \\
\mathrm{Na}\end{array}$} & \multirow{3}{*}{$\begin{array}{l}\mathbf{B e} \\
\mathbf{M}\end{array}$} & \multirow{3}{*}{\multicolumn{3}{|c|}{$\begin{array}{c}\text { Early transi- } \\
\text { tion metal }\end{array}$}} & \multirow{3}{*}{\multicolumn{2}{|c|}{$\begin{array}{c}\text { A } \\
\text { Group A } \\
\text { element }\end{array}$}} & \multirow{3}{*}{\multicolumn{5}{|c|}{$\mathrm{C}$ and/or $\mathrm{N}$}} & \multirow{3}{*}{$\begin{array}{c}\text { B } \\
\text { Al }\end{array}$} & \multirow{3}{*}{$\begin{array}{l}\mathrm{C} \\
\mathrm{Si}\end{array}$} & \multirow{3}{*}{$\begin{array}{l}\mathbf{N} \\
\mathbf{P} \\
\end{array}$} & \multirow{3}{*}{$\begin{array}{l}\mathbf{O} \\
\mathrm{S} \\
\end{array}$} & \multirow{3}{*}{\begin{tabular}{|c|}
$\mathbf{F}$ \\
$\mathbf{C l}$ \\
\end{tabular}} & \multirow{3}{*}{$\begin{array}{l}\mathrm{He} \\
\mathrm{Ne} \\
\mathrm{Ar}\end{array}$} \\
\hline & & & & & & & & & & & & & & & & & \\
\hline & & & & & & & & & & & & & & & & & \\
\hline $\mathbf{K}$ & $\mathrm{Ca}$ & Sc & $\mathrm{Ti}$ & V & $\mathrm{Cr}$ & Mn & $\mathrm{Fe}$ & Co & $\mathrm{Ni}$ & $\mathbf{C u}$ & Zn & Ga & Ge & As & Se & $\mathrm{Br}$ & $\mathbf{K r}$ \\
\hline $\mathbf{R b}$ & $\mathrm{Sr}$ & $\mathbf{Y}$ & $\mathbf{Z r}$ & $\mathrm{Nb}$ & Mo & Tc & $\mathbf{R u}$ & $\mathbf{R h}$ & Pd & Ag & Cd & In & Sn & Sb & Te & I & $\mathbf{X e}$ \\
\hline Cs & $\mathbf{B a}$ & Lu & Hf & Ta & $\mathbf{W}$ & $\operatorname{Re}$ & Os & Ir & $\mathbf{P t}$ & Au & $\mathrm{Hg}$ & Tl & $\mathbf{P b}$ & $\mathbf{B i}$ & Po & At & Rn \\
\hline Fr & $\mathbf{R a}$ & $\mathbf{L r}$ & Rf & Db & $\mathrm{Sg}$ & Bh & Hs & Mt & Ds & $\mathbf{R g}$ & Cn & Uut & Fl & Uup & $\mathbf{L v}$ & Uus & Uuo \\
\hline
\end{tabular}

Figure 1. Periodic table showing elements from which the MAX phases are composed: M: early transition metal (red), A: group A element (blue) and X: C and/or N (black) [3441].

These phases have a layered hexagonal crystal structure with two formula units per unit cell. The near-close-packed M-layers are interleaved with pure A-group element layers, with the X-atoms occupying the octahedral sites between the M layers (Figure 2). This structure provides these compounds with anisotropic behavior.
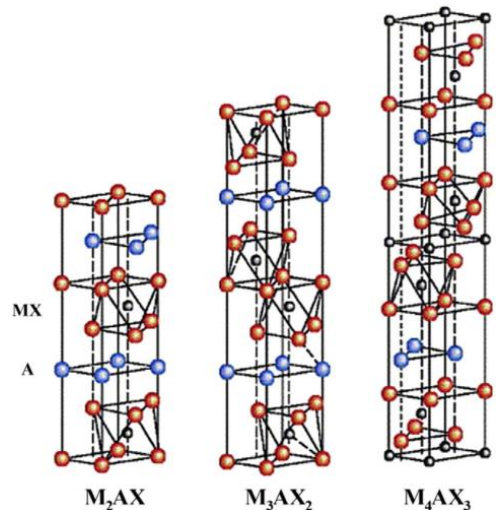

Figure 2. Crystal structure unit cells of various $M A X$ phases: $M_{2} A X(211), M_{3} A X_{2}$ (312) and $\mathrm{M}_{4} \mathrm{AX}_{3}$. Reprinted with permission from Elsevier, Thin Solid Films (Ref. [42]), copyright (2010) and adapted with permission from Elsevier, Progress in Solid State Chemistry (Ref. [43]), copyright (2000). 
The MAX phases family can be expanded beyond single $\mathrm{M}, \mathrm{A}$ and $\mathrm{X}$ elements by alloying on the three sites. Quaternaries such as $\left(\mathrm{Nb}_{0.5}, \mathrm{~V}_{0.5}\right)_{2} \mathrm{AlC}$ and $\left(\mathrm{Nb}_{0.5}, \mathrm{~V}_{0.5}\right)_{4} \mathrm{AlC}_{3}$ and $\left(\mathrm{Nb}_{0.8}, \mathrm{Zr}_{0.2}\right)_{2} \mathrm{AlC}$ [44] are examples of alloying on the M-site. $\mathrm{Ti}_{3} \mathrm{Sn}_{(1-x)} \mathrm{Al}_{x} \mathrm{C}_{2}$ compounds, where $x=0,0.25,0.38,0.4,0.5,0.8$, and 1 [45], are examples of alloying on the A site. Alloying on the $\mathrm{X}$ site includes $\mathrm{Ti}_{2} \mathrm{Al}\left(\mathrm{C}_{0.5}, \mathrm{~N}_{0.5}\right)_{2}$ and $\mathrm{Ti}_{2} \mathrm{Al}\left(\mathrm{C}_{0.5}, \mathrm{~N}_{0.5}\right)$ [46].

\subsection{MAX related structures}

As mentioned above, alloying on various sites has expanded the family of the MAX phases. In most cases, the alloying elements are randomly distributed [44-45]. However, in special cases, ordering on the $\mathrm{M}$ sites can be achieved. There are two ways of ordering on the M sites. The first is out-of-plane ordering, henceforth labelled $o$-MAX; the second is in-plane ordering, henceforth referred to as $i$-MAX.

\subsection{1 o-MAX}

Examples of the $o$-MAX phases are $\mathrm{Mo}_{2} \mathrm{TiAlC}_{2}$ and $\mathrm{Mo}_{2} \mathrm{Ti}_{2} \mathrm{AlC}_{3}$ [40-41]. These two quaternaries serve as precursors for the $\mathrm{Mo}_{2} \mathrm{TiC}_{2} \mathrm{~T}_{\mathrm{z}}$ and $\mathrm{Mo}_{2} \mathrm{Ti}_{2} \mathrm{C}_{3} \mathrm{~T}_{\mathrm{z}}$ MXenes discussed in paper V. In both compounds, the Mo atoms are mainly bonded to the $\mathrm{Al}$ layers. The $\mathrm{Ti}$ atoms are mainly bonded to the $\mathrm{C}$ atoms and are positioned away from the Al layers. The general stacking sequence of elemental planes along the $c$ direction is Mo-Ti-Mo-Al-Mo-Ti-Mo for $\mathrm{Mo}_{2} \mathrm{TiAlC}_{2}$ and Mo-Ti-Ti-Mo-Al-Mo-Ti-Ti-Mo for $\mathrm{Mo}_{2} \mathrm{Ti}_{2} \mathrm{AlC}_{3}$. In both cases, the $\mathrm{C}$ atoms occupy the octahedral sites between the transition metals. The $o$-MAX phases preserve the same crystal structure of the MAX phases, viz. $\mathrm{P}_{3} / \mathrm{mmc}$. The reason behind the ordering is due to the high energy needed for Mo to occupy sites in which the $\mathrm{C}$-atoms are in FCC arrangement. Therefore, the Mo atoms are forced to be positioned in the sites where they are bonded to Al, thus forming the ordering. Such ordering is not possible for all M elements and it is restricted to MAX phases with $n=2$ or higher.

\subsection{2 $i$-MAX}

Unlike the $o$-MAX phases, the $i$-MAX so far are restricted to quaternary MAX phases with $n=1$. The first discovered phase of that group is $\left(\mathrm{Mo}_{2 / 3}, \mathrm{Sc}_{1 / 3}\right)_{2} \mathrm{AlC}$ [37]. $\left(\mathrm{Mo}_{2 / 3}, \mathrm{Sc}_{1 / 3}\right)_{2} \mathrm{AlC}$ is the precursor of $\mathrm{Mo}_{1.33} \mathrm{CT}_{\mathrm{z}}$, discussed in paper $\mathrm{V}$. In $\left(\mathrm{Mo}_{2 / 3} \mathrm{Sc}_{1 / 3}\right)_{2} \mathrm{AlC}$, the Mo and $\mathrm{Sc}$ atoms are ordered within the $\mathrm{M}$ plane. This alters the hexagonal symmetry to either a monoclinic structure $(\mathrm{C} 2 / \mathrm{c})$, as in $\left(\mathrm{Mo}_{2 / 3} \mathrm{Sc}_{1 / 3}\right)_{2} \mathrm{AlC}$, or an orthorhombic structure $(\mathrm{Cmcm})$, as in $\left(\mathrm{Mo}_{2 / 3} \mathrm{Sc}_{1 / 3}\right) \mathrm{GaC}$ and $\left(\mathrm{Mo}_{2 / 3} \mathrm{Y}_{1 / 3}\right) \mathrm{GaC}$ [47]. The formation of the chemical in-plane ordering is most likely due to the larger atomic size mismatch of the two metals in the mentioned cases Mo and Sc or Y, in addition to decreasing the size of the A element. Therefore, the $i$-MAX phases are more likely to 
form quaternary MAX compounds containing $\mathrm{A}$ element as $\mathrm{Al}, \mathrm{Ga}$ or $\mathrm{In}$, than from compounds containing A elements as $\mathrm{Si}, \mathrm{Ge}$ and $\mathrm{Sn}$ [47].

\subsubsection{MAX phase like structures}

Other layered structures similar to the MAX phases were also discovered. One particular example germane to this thesis is $\mathrm{Mo}_{2} \mathrm{Ga}_{2} \mathrm{C}$, which also has a hexagonal structure but contains two A layers instead of one [48]. $\mathrm{Mo}_{2} \mathrm{Ga}_{2} \mathrm{C}$ was used as a precursor to produce $\mathrm{Mo}_{2} \mathrm{CT}_{\mathrm{z}}$ MXene, which is discussed in papers $\mathbf{I V}$ and $\mathbf{V}$.

\subsection{Synthesis of MAX phases}

The MAX phases can be synthesized in the form of bulk materials or thin films.

\subsubsection{Bulk synthesis techniques}

Several bulk synthesis techniques have been used to produce bulk MAX phases such as pressureless sintering [49], hot pressing [50], hot isostatic pressing (HIP) [51], self-propagating high-temperature synthesis [52], pulse discharge sintering [53], solid-liquid reaction synthesis [54] and most recently microwave sintering [55-56]. More details about pressureless sintering, HP and HIP techniques are discussed below, as they were used to produce the MAX phases used in papers II, IV, V, and VI.

Sintering is a common method for production of ceramics and pottery. Fine powders are mixed with water to form a slurry, which is formed into a desired shape. Then, the object is subjected to high temperature, which leads to the transformation of that mixture into a more compact and rigid object. That process is called sintering. If one of the components of the fine powders has a melting point lower than the sintering temperature, it will transform into a liquid while sintering. In that case, the process is called liquid-phase sintering (Figure 3.a). If no liquid phase occurs during the sintering process, it is referred to as solid-state sintering (Figure 3.b). 
(a)

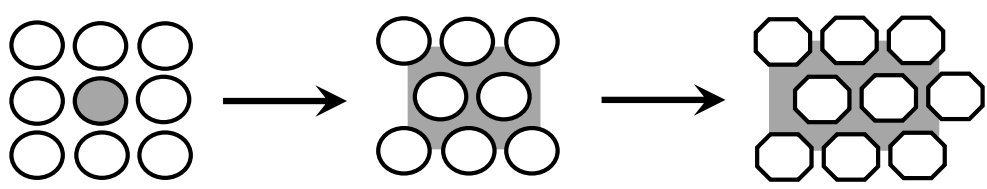

(b)
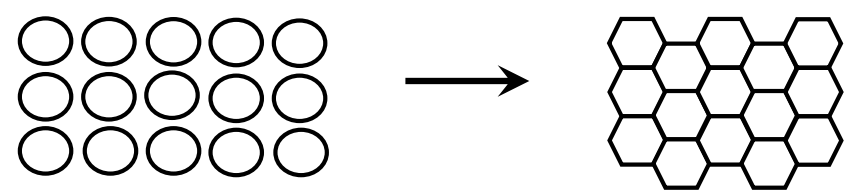

Figure 3. (a) Liquid-phase sintering; (b) Solid-state sintering.

Like any thermodynamically governed process, the driving force of sintering is reducing the Gibbs free energy. This can be achieved through either: (1) coarsening, where the total surface area is reduced by increasing the average particle size, and/or (2) densification followed by grain growth, where the free energy is decreased by the reduction and elimination of the pores between the particles, creating grain boundaries followed by grain growth. Densification and coarsening are two competing mechanisms. The first leads to shrinkage of the sintered object and to an increase of its density, while the latter leads to an increase of the pore size as well as the particle size.
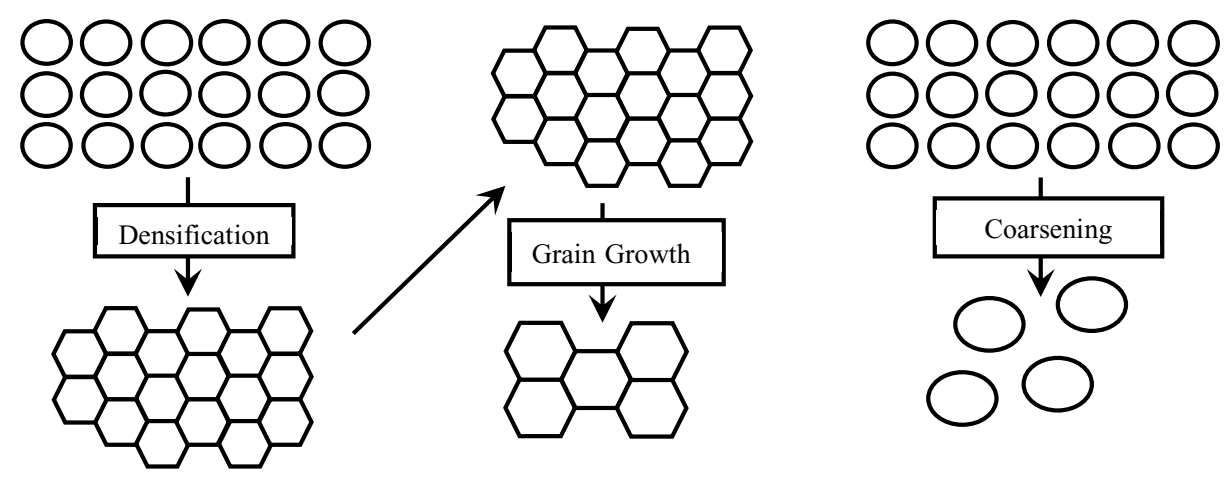

Figure 4. Schematic showing both routes for reduction of free energy during sintering: (a) densification and (b) coarsening.

For densification to take place, the grain boundary energy $\gamma_{\mathrm{gb}}$ must be less than twice the solid/vapor surface energy $\gamma_{\mathrm{sv}}$. This can take place when the angle, $\varnothing$, between the 2 $\gamma_{\mathrm{sv}}$ at the intersection between 2 particles (Figure 5) is less than $180^{\circ}$. 
The relationship between $\gamma_{\mathrm{gb}}$ and $\gamma_{\mathrm{sv}}$ can be described by the equation below [57]:

$$
\gamma_{g b}=2 \gamma_{s v} \cos \frac{\emptyset}{2}
$$

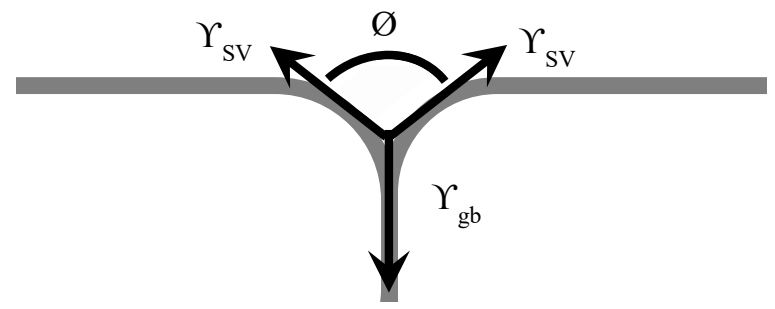

Figure 5. Equilibrium between grain boundary and solid/vapor energies.

There are several factors that can affect the solid-state sintering process and favor densification rather than coarsening. These factors are:

(1) Temperature: increasing the temperature leads to an increase in the diffusion rate, thus increasing the grain boundary diffusion and leading to the domination of the densification process over the coarsening process.

(2) Density of the object before sintering: increasing the density of the object before sintering can result in a decrease in the number/volume of pores that need to be eliminated.

(3) Atmosphere: Choosing the correct atmosphere for sintering is crucial. Certain gases might promote densification, while others might promote coarsening. The gas used can increase the diffusivity of the sintered species, thus promoting densification, or increase the vapor pressure, leading to coarsening.

(4) Size distribution: the narrower the particle size distribution is, the more homogenous the product is after sintering. Broad particle size distribution would lead to abnormal grain growth, which would result in a non-uniform grain size distribution after sintering.

Pressureless sintering has been used to produce $\mathrm{Nb}_{2} \mathrm{AlC}$ and $\mathrm{V}_{2} \mathrm{AlC}$ MAX phases from their elemental powders. $\mathrm{Mo}_{2} \mathrm{TiAlC}_{2}, \mathrm{Mo}_{2} \mathrm{Ti}_{2} \mathrm{AlC}_{3}, \mathrm{Mo}_{2} \mathrm{Ga}_{2} \mathrm{C}$ (a phase similar to MAX phases), ( $\left.\mathrm{Mo}_{2 / 3} \mathrm{Sc}_{1 / 3}\right)_{2} \mathrm{AlC},\left(\mathrm{Nb}_{2 / 3} \mathrm{Sc}_{1 / 3}\right)_{2} \mathrm{AlC}$, and $\mathrm{Nb}_{2} \mathrm{AlC}$ were used as precursor 
for synthesis of $\mathrm{Mo}_{2} \mathrm{TiC}_{2} \mathrm{~T}_{\mathrm{z}}, \mathrm{Mo}_{2} \mathrm{Ti}_{2} \mathrm{C}_{3} \mathrm{~T}_{\mathrm{z}}, \mathrm{Mo}_{2} \mathrm{CT}_{\mathrm{z}}, \mathrm{Mo}_{1.33} \mathrm{CT}_{\mathrm{z}}, \mathrm{Nb}_{1.33} \mathrm{CT}_{\mathrm{z}}$ and $\mathrm{Nb}_{2} \mathrm{CT}_{\mathrm{z}}$ respectively, as mentioned in papers $\mathbf{I V}, \mathbf{V}$, and, $\mathbf{V I}$.

Fully dense MAX phases can be achieved by applying pressure during sintering which leads to the decrease of the pore size and promotes the densification process. The relationship between the stress $\mathrm{C}_{\text {stress }}$ applied to a given area and the concentration of vacancies $\mathrm{C}_{\mathrm{o}}$ in that area can be defined by the following equation [57]:

$$
\mathrm{C}_{\text {stress }}=\left(1+\frac{\mathrm{V}_{\mathrm{m}} \sigma_{\mathrm{b}}}{\mathrm{RT}}\right) \mathrm{C}_{\text {。 }}
$$

where $\sigma_{\mathrm{b}}$ is the effective stress at the boundary due to the applied stress, $\mathrm{V}_{\mathrm{m}}$ is the molar volume, $\mathrm{R}$ is the gas constant and $\mathrm{T}$ is the temperature.

Hot Pressing $(H P)$ is sintering while pressure is applied uniaxially. Barsoum et al. [58] were able to obtain $\mathrm{Ti}_{3} \mathrm{SiC}_{2}$ of more than $99 \%$ of the theoretical density using the hot pressing technique. This technique also results in a more uniform microstructure and finer grain size compared to sintering technique. The pressure can also be applied uniformly from all directions; in that case, the technique is called HIP. In HIP, the sample is surrounded by a low melting glass and heated up to above the melting point of the glass (in vacuum), and then pressure is applied by purging Ar gas. The pressure of the Ar gas creates a uniform pressure force on the molten glass and the sample inside it. This technique was used to produce $\mathrm{Ti}_{3} \mathrm{AlC}_{2}$, the precursor for obtaining single flakes of $\mathrm{Ti}_{3} \mathrm{C}_{2} \mathrm{~T}_{\mathrm{x}}$ in paper II.

\subsubsection{Thin film synthesis techniques}

Thin film is a term usually referred to films that have a thickness ranging from several ångströms to tens of microns. They are usually deposited onto surfaces of bulk materials to provide protection against corrosion, to wear resistance, or to act as a barrier against gas penetration, among other functionalities. Also, thin films can be used for their own properties, rather than to enhance the properties of a bulk material, when size reduction is required in the out-of-plane direction, such as in memory chips and transistors.

Among the techniques used for MAX thin film synthesis, Physical Vapor Deposition (PVD), especially sputtering, is the most common [42]. Unlike bulk synthesis techniques, sputter-deposition is a non-equilibrium process. Thus, it can deposit films of compositions and phases that are not constrained by thermodynamic phase diagrams. This can allow for the synthesis of MAX phase thin films that are not readily achievable in bulk form. 
Sputtering is the ejection of atoms by the bombardment of a solid or liquid target by energetic particles, such as ions [59]. A negative voltage is applied to the target (material source), which attracts the ions (Figure 6). These ions bombard the target atoms, which are ejected from the target leading to condensation on a substrate forming the thin film of the desired material.

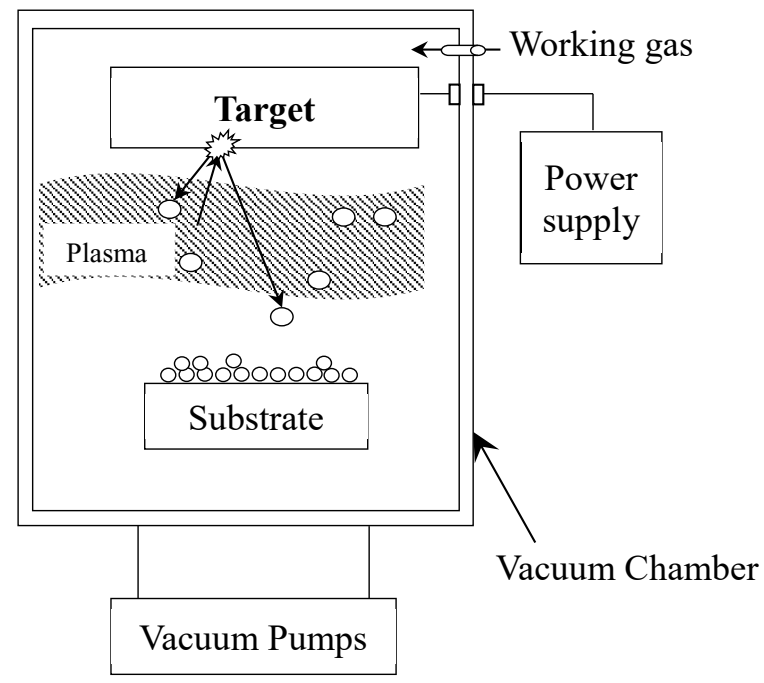

Figure 6. Sputter deposition setup.

The sputter yield $(Y)$ is the ratio between the number of sputter-ejected atoms and the number of incident projectiles. The sputter yield is an important factor, as it determines when a target is consumed and would need to be replaced, and it also affects the deposition rate. The yield depends on many factors such as the ion energy and the target material. The $\mathrm{Y}$ for a certain material increases as the ion energy for a given ion size increases. Below a certain ion energy (threshold energy) the sputter yield is almost negligible.

The sputter yield at low ion energy (near threshold) can be calculated from equation (2.3), which is based on the theory introduced by Sigmund [60]:

$$
Y=\frac{3}{4 \pi^{2}} \alpha \frac{4 M_{1} M_{2}}{\left(M_{1}+M_{2}\right)^{2}} \frac{E}{U_{s}}
$$

where: $E$ is the energy of the projectile

$M_{1}$ is the mass of the projectile atom

$\mathrm{M}_{2}$ is the mass of the target atom

$\mathrm{U}_{\mathrm{s}}$ is the surface binding energy,

$\alpha$ is a dimensionless parameter that depends on the mass ratio and the ion energy. 
At low energy and $\mathrm{M}_{2} / \mathrm{M}_{1}$ ratios $<1, \alpha$ is of the order of 0.2 . Equation (3) can be explained as follows: when an ion hits the surface of the target, its momentum transfers to the target atoms, as expressed in the term $\frac{4 M_{1} M_{2}}{\left(M_{1}+M_{2}\right)^{2}}$. The transferred momentum reaches a maximum when $M_{1}=M_{2}$. For an atom to be removed from the surface of the target, the momentum transfer must overcome the surface binding energy $U_{s}$. Thus, as $U_{s}$ decreases, $Y$ increases. Also, based on Eq. (2.3), the sputter yield increases linearly with increasing ion energy.

As mentioned previously, sputtering is based on ion bombardment of the target to eject the surface atoms of the target. The most widely used ion source is plasma, which is composed of free electrons and positively charged ions. A plasma-based sputter deposition apparatus is composed of a cathode (target) and anode placed opposite to each other in a vacuum chamber of a base pressure typically lower than $10^{-4} \mathrm{~Pa}$ (or with the chamber itself acting as an anode). Various pumps are used to reach that pressure; for example, a rotary pump is used to lower the pressure from atmospheric pressure $\left(10^{5} \mathrm{~Pa}\right)$ to $1 \mathrm{~Pa}$, followed by a turbomolecular pump, which is used to bring the chamber to the desired pressure, i.e. less than $10^{-4} \mathrm{~Pa}$ [61]. A noble gas, such as $\mathrm{Ar}$, is introduced to the chamber after reaching the desired base pressure. The Ar is ionized by applying a high potential difference of about several hundred volts between cathode and anode, and a glow discharge is ignited.

The electric circuit creating the discharge contains an external ohmic resistance described by the following equation:

$$
\mathrm{EMF}=\mathrm{V}+\mathrm{RI}
$$

where EMF is the electromotive force in volts,

$\mathrm{V}$ is the voltage of the gas discharge in volts,

$\mathrm{R}$ is the external ohmic resistance in ohms,

I is the current in amperes.

This equation is also represented in Figure 7, by the straight line called the load line which upon intersecting the I-V characteristics, gives the actual I and V values in a discharge. 


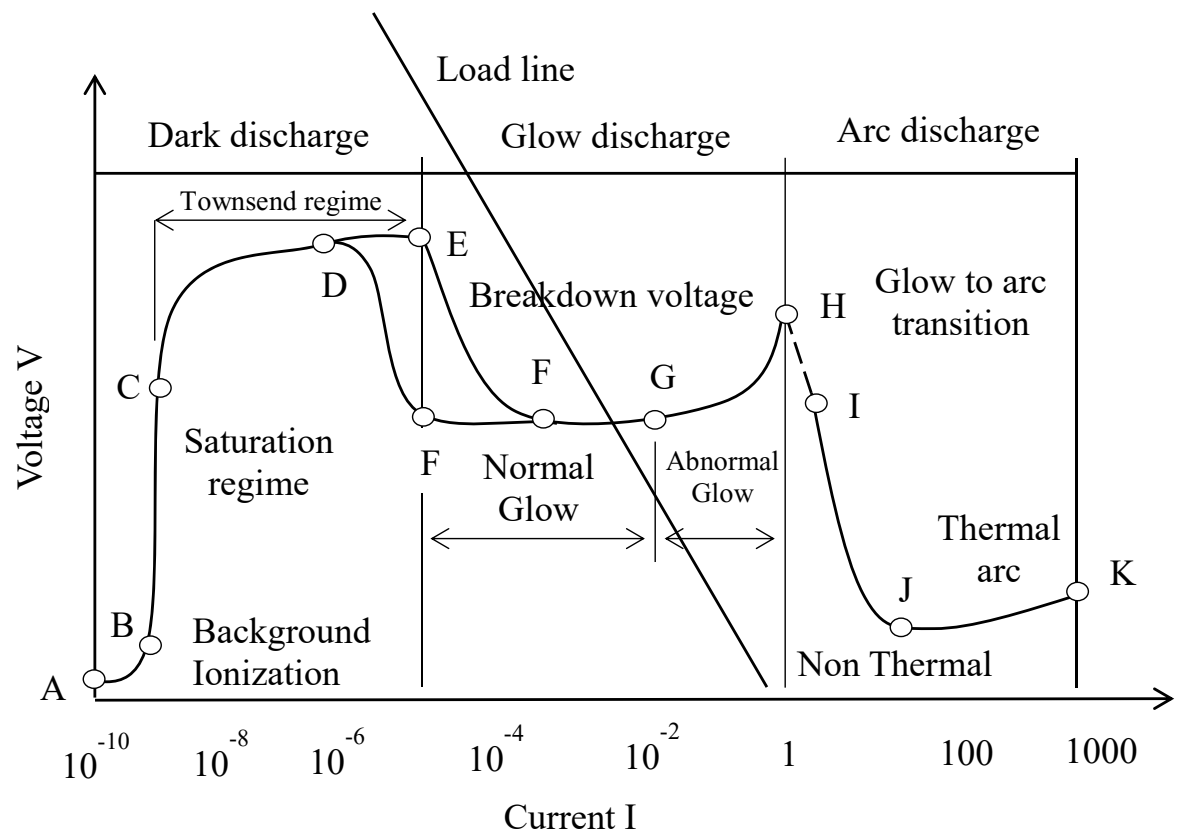

Figure 7. Three primary regions of a gas discharge. The straight line is a typical load line.

The glow discharge can be discussed through the characteristic I-V diagram shown in Figure 7. The I-V diagram can be divided into three regions as follows:

(1) The first regime (Dark discharge): In this region, there is no visible light from the discharge except for the corona and the breakdown voltage. From A to B there is a slight increase in the current as the voltage is increased, which is due to the movement of the ions and electrons formed by the background ionization towards the electrodes. After the voltage reaches point $\mathrm{B}$, the current is constant as all ions and electrons reach the electrodes; this region is called the saturation regime. Then the current increases again when the voltage reaches a value higher than point $\mathrm{C}$, as more ions receive enough energy to collide with the electrodes, producing even more ions. The region $\mathrm{C}$ to $\mathrm{E}$ is called the Townsend regime. The corona discharge takes place from the middle of the Townsend regime to its ending ( $D$ to $E$ ). Corona discharge occurs in regions of high electric fields, such as sharp points and edges. The visibility of the corona depends on the electric current. If the electric current is low, the corona is not visible to the eye; however, if the electric current is high enough, the corona becomes visible to the eye and, in that case, it is more or less a glow discharge. When ions and photons collide, secondary electrons are emitted from the cathode; thus, the gas 
becomes electrically conductive, i.e. a breakdown voltage occurs. The breakdown voltage is described by Paschen's law as follows [59]:

$$
V_{\text {breakdown }}=\frac{B P d}{\ln (\text { APd })+\ln \left(\ln \left[\frac{1}{\gamma}+1\right]\right)}
$$

where $\mathrm{P}$ is the pressure inside the chamber,

$\mathrm{d}$ is the gap distance between the electrodes,

$\gamma$ is the electron emission yield induced by photon and ion bombardment,

$\mathrm{A}$ and $\mathrm{B}$ are constants which depend on the gas used.

Based upon Paschen's law, the breakdown voltage for a certain gas and electrode material depends on the product of the pressure and the distance between the electrodes. Thus, the larger that product, the higher the breakdown voltage.

(2) The second regime (glow discharge): In this regime, the plasma is visible to the eye. The glow discharge regime is divided into two modes. The first region is called the normal glow discharge, which takes place when the glow discharge covers a part of the cathode. In this mode, the current density is independent of the discharge voltage. Thus, by increasing the current density, the plasma region increases covering more area of the cathode, while the voltage remains constant as shown from point $F$ to $G$. As soon as the plasma covers the entire area of the cathode the second mode (abnormal glow discharge) begins, which is characterized by the dependence of the voltage on the current density, i.e. as the current density increases, the voltage increases as well. Sputtering is performed in the abnormal glow discharge mode from $\mathrm{G}$ to $\mathrm{H}$.

(3) The third regime (arc discharge): In this regime, the cathode becomes hot enough that electrons are emitted thermionically, and the discharge changes from glow to arc.

The main drawback of DC (diode) glow discharge sputtering is the inability to ensure that electrons accelerated from the cathode will ionize enough gas atoms to sustain the glow discharge. One way to overcome this drawback is by introducing a magnetic field that will trap the electrons in the discharge region longer, thus increasing the probability of ionizing the gas atoms while the electron is travelling from the cathode to the anode. In this way, enough gas atoms can be ionized and in the same time, the ions will reach the substrate with no loss of energy and with very few collisions (Figure 8). This technique is called magnetron sputtering. 


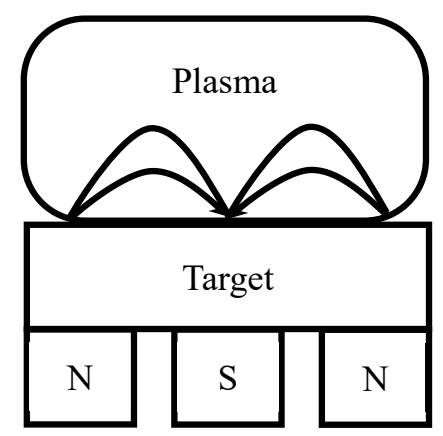

Figure 8. Schematic drawing of plasma confinements in magnetron sputtering Adopted from Ref.[62] with permission from Elsevier, Vacuum, copyright (2000).

In magnetrons, the magnetic field, $\vec{B}$, is applied parallel to the target and perpendicular to the electric field. The electrons emitted from the target due to the ion collision are forced to move in cycloidal orbits as a result of the applied magnetic field. The electron path is described by the Lorenz equation as follows:

$$
\vec{F}=q(\vec{E}+\vec{v} \times \vec{B})
$$

where $\overrightarrow{\mathrm{F}}$ is the Lorenz force,

$\mathrm{q}$ is the electron charge,

$\vec{v}$ is the velocity of electrons,

$\overrightarrow{\mathrm{B}}$ is the magnetic field,

$\overrightarrow{\mathrm{E}}$ is the electric field.

According to Eq. (2.6), the Lorenz force on the electron depends on both its $\vec{v}$ and the $\overrightarrow{\mathrm{B}}$ and is perpendicular to both.

The electron motion consists of three components; the first component is the movement of the electron along the magnetic field. The second component is the rotation of the electron around the magnetic field, where the radius of rotation (Larmor radius) depends on the mass of the electron $\mathrm{m}$, the velocity component perpendicular to the magnetic field and the target $v_{\perp}$, the electron charge $\mathrm{q}$ and the magnetic field $\overrightarrow{\mathrm{B}}$.

$$
\mathrm{r}_{\mathrm{L}}=\frac{\mathrm{mv} \mathrm{\nu}_{\perp}}{\mathrm{qB}}
$$

The third and final component is due to the effect of both $\vec{B}$ and $\vec{E}$ (Hall Effect), where the electron moves in a helical orbit perpendicular to both the electric and magnetic fields. 
There are several methods for powering the target, such as direct current (DC) which is used for conductive targets, and radio frequency (RF), which is used for non-conductive targets. Moreover, a reactive gas can be added to the plasma to deposit a thin film of a compound containing the species found in that gas, such as the deposition of TiN thin films using a DC magnetron sputtering system, titanium target and nitrogen gas [63]. A three-target DC magnetron sputtering system was used for synthesis of $\mathrm{Ti}_{3} \mathrm{AlC}_{2}$ thin films reported in papers I and III. The main reason for using a three-target deposition system is to have control over the flux of each element which helps in controlling the deposited film composition.

The deposition parameters have a strong influence on the film morphology and microstructure. Thus, it is essential to know how such parameters affect the morphology and microstructure of the deposited film in order to grow films of desired morphologies. Structure zone models (SZM) have been developed to show the effect of the deposition parameters on the morphologies and microstructures of deposited films. The SZM published by Thornton in 1974 [64] has been used as a base for many later studies (Figure 10). SZMs are usually represented as a function of the ratio between the substrate temperature $\mathrm{T}$ and the melting temperature of the deposited material $\mathrm{T}_{\mathrm{m}}$. This ratio is called "homologous temperature".

Zone I occurs when $\mathrm{T} / \mathrm{T}_{\mathrm{m}}$ is low, about 0.1 . Sputtered particles will simply stick to the growing film at the place they arrive. That is because the particles do not have enough energy to cross the diffusion barrier. This phenomenon is often referred to as "hit and stick" growth. The only factor affecting the structure of the growing film is the direction of the incoming particles. Due to the inability of the particles to move, only small crystallites or amorphous-like structures will form. After adequate time of deposition, the crystallites will grow into columns separated by voids. Such a morphology will make the deposited film of lower density compared to the bulk material due to the voids. 
$\begin{array}{ccc} & \text { Zone } \mathrm{T} & \text { Zone II } \\ \text { Zone I } & \text { Competitive texture } & \text { restructuration texture }\end{array}$

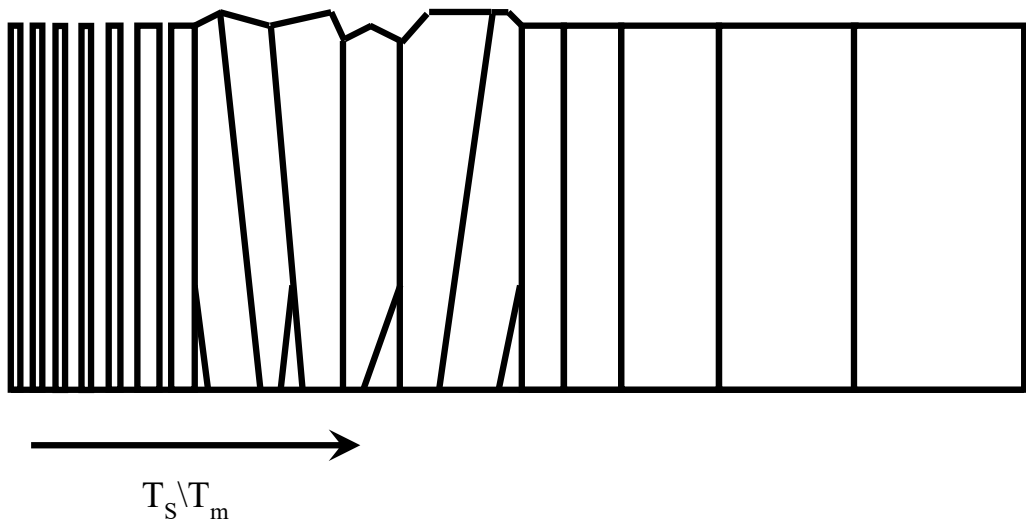

Figure 10. Schematic of the Thornton structure zone model (SZM). Adopted from Ref. [64] with permission of AIP Publishing, Journal of Vacuum Science \& Technology, copyright (1974).

The same structure can also be obtained at high temperatures provided that the deposition rate is high. In that case, the adparticles will not have enough time to diffuse to a more stable site. Although they have enough energy to cross the diffusion barrier, they are hindered by the incoming adparticles that are deposited over them. In that situation, the process is called burial growth process where a zone I structure is still obtained but through a different mechanism.

Zone $\mathrm{T}$ takes place at higher temperatures when the adatoms have enough energy to diffuse from one grain to another. This allows for a denser columnar structure to form compared to that of zone I.

In zone II, the temperature is high enough to enable the mobility of incorporated atoms in the growing films which was prohibited in all the previously discussed zones because the temperature was not high enough for such mobility to occur. The mobility of the incorporated atoms leads to recrystallization or restructuring of the formed islands. Less stable islands will get merged into more stable islands by ripening, cluster diffusion or grain boundary migration. A columnar structure will be formed with nearly straight columns through the entire film thickness. Increasing the temperature increases the width of the columns. Thus, for growing epitaxial films, besides the necessity of lattice match 
between film and substrate, higher temperatures favor the growth of denser films with larger grain sizes.

\subsection{Properties of MAX phases}

The properties of MAX phases are a unique combination of metallic and ceramic properties. They are thermally and electrically conductive, thermal-shock-resistant, machinable and damage-tolerant like metals. Some also have low densities and high elastic stiffness values and exhibit oxidation resistance like ceramics. For instance, $\mathrm{Ti}_{3} \mathrm{SiC}_{2}$ and $\mathrm{Ti}_{2} \mathrm{AlC}$ show a substantial resistance to creep, fatigue and oxidation [65-68].

The MAX phases are layered materials where mechanical deformation takes place by ripplocations and is very anisotropic - it can lead to partial delamination and the formation of lamellae with thicknesses ranging from tens to hundreds of nanometers, as shown in Figure 11 [69]. Therefore, one would assume that exfoliation of MAX crystals to monolayers is possible, similar to graphene. However, mechanical exfoliation of MAX crystals into single layers is difficult because of the nature of bonding between the elements forming MAX crystals. In the case of graphene, layers are bonded to each other by the means of van der Waals forces that are relatively weak [70].

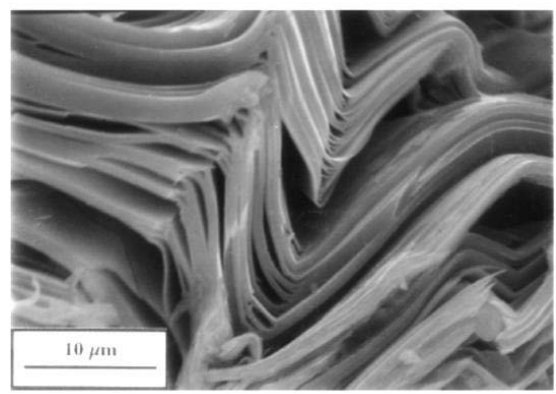

Figure 11. Scanning Electron Microscopy (SEM) micrograph of $\mathrm{Ti}_{3} \mathrm{SiC}_{2}$ sample; its surface was scribed by a sharp metal blade showing partial delamination. Reprinted by permission from Springer Nature, Metallurgical and Materials Transactions A (Ref. [69]), copyright (1999).

In the MAX phase, there is a mixture of ionic, metallic and covalent bonds between the $\mathrm{M}$ and $\mathrm{X}$ elements, while the $\mathrm{M}$ element is bonded to the A element layer via metallic bond, which is weaker than the bond between the $M$ and $X$ elements [43, 71]. Thus, the A layers are more chemically reactive. This is manifested, for example, when heating the MAX phases to high temperatures: they decompose into $M_{n+1} X_{n}$ and $A$. The former recrystallizes, forming binary carbides and/or nitrides [72]. 
Reacting the MAX phases with chlorine gas at high temperatures results in the removal of both $\mathrm{M}$ and A elements, leaving only carbon, which is named carbide derived carbon (CDC) [73-75]. 



\section{2D TRANSITION METAL CARBIDES (MXENES)}

\subsection{Synthesis of MXenes}

Taking advantage of the fact that the A element in MAX phase is more chemically reactive than the MX, Naguib et al. [24] were able to chemically etch the A element (Al) from $\mathrm{Ti}_{3} \mathrm{AlC}_{2}$ powders using aqueous solution of $\mathrm{HF}$. This resulted in exfoliated $\mathrm{M}_{\mathrm{n}+1} \mathrm{X}_{\mathrm{n}}$ $\left(\mathrm{Ti}_{3} \mathrm{C}_{2}\right)$ layers, which they named MXenes. The reactions of $\mathrm{HF}$ with $\mathrm{Ti}_{3} \mathrm{AlC}_{2}$ have been proposed to be as follows [24]:

$$
\begin{aligned}
& \mathrm{Ti}_{3} \mathrm{AlC}_{2}+3 \mathrm{HF}=\mathrm{AlF}_{3}+3 / 2 \mathrm{H}_{2}+\mathrm{Ti}_{3} \mathrm{C}_{2} \\
& \mathrm{Ti}_{3} \mathrm{C}_{2}+2 \mathrm{H}_{2} \mathrm{O}=\mathrm{Ti}_{3} \mathrm{C}_{2}(\mathrm{OH})_{2}+\mathrm{H}_{2} \\
& \mathrm{Ti}_{3} \mathrm{C}_{2}+2 \mathrm{HF}=\mathrm{Ti}_{3} \mathrm{C}_{2} \mathrm{~F}_{2}+\mathrm{H}_{2}
\end{aligned}
$$

When HF reacts with $\mathrm{Ti}_{3} \mathrm{AlC}_{2}, \mathrm{Al}$ and $\mathrm{F}$ form $\mathrm{AlF}_{3}$ (reaction 1), which is removed while washing the powder from $\mathrm{HF}$ with deionized water. The $\mathrm{Al}$ in $\mathrm{Ti}_{3} \mathrm{AlC}_{2}$ is replaced by $\mathrm{OH}, \mathrm{O}$ and/or $\mathrm{F}$ (reaction 2 and 3), referred to as surface-terminating functional groups [32-33]. Thus, the general formula of MXenes containing these functional groups is $\mathrm{M}_{\mathrm{n}+1} \mathrm{X}_{\mathrm{n}} \mathrm{T}_{\mathrm{x}}$, where $\mathrm{T}$ stands for the surface-terminating groups. Figure 12 is a schematic of the production process of MXene from MAX.

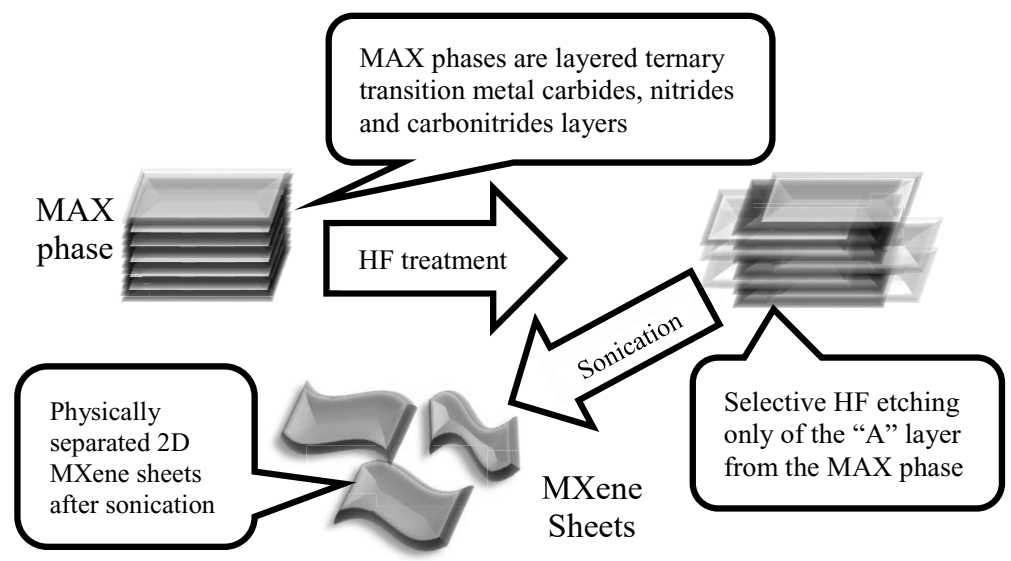

Figure 12. Schematic diagram of the production of MXenes from MAX phases. Adopted with permission from Ref. [25], American Chemical Society, ACS Nano, Copyright (2012). 


\subsubsection{Factors Influencing the Production of MXenes}

Following the success in obtaining the first MXene, $\mathrm{Ti}_{3} \mathrm{C}_{2} \mathrm{~T}_{\mathrm{z}}$, more MXene compounds have been synthetized. Twenty-two MXene compounds, obtained from MAX phases and MAX related phases, have been reported so far. They are: $\left(\mathrm{Ti}_{2} \mathrm{CT}_{\mathrm{z}}\right.$ [25], $\mathrm{Nb}_{2} \mathrm{CT}_{\mathrm{z}}$ [23] $\mathrm{V}_{2} \mathrm{CT}_{\mathrm{z}}$ [23], $\mathrm{Mo}_{2} \mathrm{CT}_{\mathrm{z}}$ (obtained from $\mathrm{Mo}_{2} \mathrm{Ga}_{2} \mathrm{C}$ ) [31], $\left(\mathrm{Ti}_{0.5} \mathrm{Nb}_{0.5}\right)_{2} \mathrm{CT}_{\mathrm{z}}$ [25], $\mathrm{Mo}_{1.33} \mathrm{CT}_{\mathrm{z}}$ [39], $\mathrm{W}_{1.33} \mathrm{CT}_{\mathrm{z}}$ [37-38], $\mathrm{Nb}_{1.33} \mathrm{CT}_{\mathrm{z}}$ (presented in paper $\mathrm{VI}$ ), $\mathrm{Ti}_{3} \mathrm{CNT}_{\mathrm{z}}$ [25], $\mathrm{Ti}_{3} \mathrm{C}_{2} \mathrm{~T}_{\mathrm{z}}$ [24], $\mathrm{Zr}_{3} \mathrm{C}_{2} \mathrm{~T}_{\mathrm{Z}}$ (obtained from $\mathrm{Zr}_{3} \mathrm{Al}_{3} \mathrm{C}_{5}$ ) [76], $\mathrm{Hf}_{3} \mathrm{C}_{2} \mathrm{~T}_{\mathrm{z}}$ (obtained from $\mathrm{Hf}_{3}[\mathrm{Al}(\mathrm{Si})]_{4} \mathrm{C}_{6}$ ) [77], $\mathrm{Ta}_{4} \mathrm{C}_{3} \mathrm{~T}_{\mathrm{z}}$ [25], $\left(\mathrm{V}_{0.5} \mathrm{Cr}_{0.5}\right)_{3} \mathrm{C}_{2} \mathrm{~T}_{\mathrm{z}}$ [25], $\mathrm{Ti}_{4} \mathrm{~N}_{3} \mathrm{~T}_{\mathrm{z}}$ [27], $\mathrm{Nb}_{4} \mathrm{C}_{3} \mathrm{~T}_{\mathrm{z}}$ [78], $\mathrm{V}_{4} \mathrm{C}_{3} \mathrm{~T}_{\mathrm{z}}$ [79], $\left(\mathrm{Nb}_{0.8} \mathrm{Ti}_{0.2}\right)_{4} \mathrm{C}_{3} \mathrm{~T}_{\mathrm{z}},\left(\mathrm{Nb}_{0.8}, \mathrm{Zr}_{0.2}\right)_{4} \mathrm{C}_{3} \mathrm{~T}_{\mathrm{z}}[80], \mathrm{Mo}_{2} \mathrm{TiC}_{2} \mathrm{~T}_{\mathrm{z}}$, and $\mathrm{Mo}_{2} \mathrm{Ti}_{2} \mathrm{C}_{3} \mathrm{~T}_{\mathrm{z}}$, (where Mo and $\mathrm{Ti}$ form an ordered layer structure, with Mo occupying the outer M layers, bonded to the surface termination groups, and $\mathrm{Ti}$ occupying the inner $\mathrm{M}$ layers, similarly, $\operatorname{in} \mathrm{Cr}_{2} \mathrm{TiC}_{2} \mathrm{~T}_{\mathrm{z}}$, the Cr occupies the outer layers [81]).

This list shows that MAX phases of different number of layers, $n=1,2$ and 3 , different M elements Ti, Nb, V, Mo, W, and Ta, different A elements, Al, Si [30] or Ga [31], and different $\mathrm{X}$ elements $\mathrm{C}$ and/or $\mathrm{N}$ can be converted to MXenes. In addition, MAX phases can contain two alloyed different $\mathrm{M}$ elements either ordered such as Mo and Ti or randomly distributed such as $\mathrm{V}$ and $\mathrm{Cr}$. Also, selectively etching one of the alloyed $\mathrm{M}$ elements can create MXene with vacancies either randomly distributed, as with $\mathrm{Nb}_{1.33} \mathrm{CT}_{\mathrm{x}}$ (paper VI), or ordered, such as $\mathrm{Mo}_{1.33} \mathrm{CT}_{\mathrm{z}}$ and $\mathrm{W}_{1.33} \mathrm{CT}_{\mathrm{z}}$.

The process of synthesizing MXenes depends on many factors, such as the particle size of the starting MAX phase powder, etching time, temperature, and HF concentration [23]. Thus, tuning these factors leads to increased yields, reduced etching times and improved quality of the produced MXenes. For example, reducing the particle size of $\mathrm{Ti}_{3} \mathrm{AlC}_{2}$ from above $53 \mu \mathrm{m}$ to less than $38 \mu \mathrm{m}$ resulted in the decrease in the time needed for its complete conversion to $\mathrm{Ti}_{3} \mathrm{C}_{2} \mathrm{~T}_{\mathrm{z}}$ in a $50 \% \mathrm{HF}$ solution from $19 \mathrm{~h}$ to only $2 \mathrm{~h} \mathrm{[82].}$ The same holds true for $\mathrm{V}_{2} \mathrm{AlC}$ : it was shown that decreasing the particle size by attrition milling instead of using a titanium-nitride-coated milling bit led to the reduction of etching time from 90 to $8 \mathrm{~h}$ [23].

Several other factors affect the etching procedures. These factors are related to the chemistry and structure of the MAX phase. Among them is the effect of changing the M element, as well as changing $n$. MAX phases of different M element possess different $\mathrm{M}-\mathrm{Al}$ binding energies which affect the etching conditions needed to convert them to their MXenes. For example, conversion of $\mathrm{Ti}_{2} \mathrm{AlC}$ to $\mathrm{Ti}_{2} \mathrm{CT}_{\mathrm{z}}$ needs shorter etching times and lower HF concentrations than those needed for converting $\mathrm{Nb}_{2} \mathrm{AlC}$ to $\mathrm{Nb}_{2} \mathrm{CT}_{\mathrm{z}}$ (Table 1). This can be explained by comparing the binding energy of $\mathrm{Ti}-\mathrm{Al}$ to that of $\mathrm{Nb}-\mathrm{Al}$ in $\mathrm{Ti}_{2} \mathrm{AlC}$, and $\mathrm{Nb}_{2} \mathrm{AlC}$, respectively. Ti-Al has a lower binding energy of $0.98 \mathrm{eV}$ compared to that for $\mathrm{Nb}-\mathrm{Al},(1.21 \mathrm{eV})$ and $\mathrm{V}-\mathrm{Al}(1.09 \mathrm{eV})$ [83]. More interestingly, as $n$, increases, the chemical stability of the MXenes increases. For example, $\mathrm{Ti}_{3} \mathrm{C}_{2} \mathrm{~T}_{\mathrm{z}}$, etched in $50 \mathrm{wt} . \%$ 
$\mathrm{HF}$, has a yield of $100 \%$ whereas, $10 \mathrm{wt} \%$ of $\mathrm{HF}$ is sufficient to produce $\mathrm{Ti}_{2} \mathrm{CT}_{\mathrm{z}}$ of a 60 $\%$ yield [24-25]. In addition, the bond strength of both M-X and M-A plays an important role in determining which MAX phases can be converted into MXene by selectively etching the A layer and which MAX phases will simply fully dissolve in the etchant [84]. For a MAX phase to be converted into MXene the M-A bonds must be weaker than the $\mathrm{M}-\mathrm{X}$ bonds. For example, in $\mathrm{Ti}_{3} \mathrm{AlC}_{2}$ and $\mathrm{Nb}_{2} \mathrm{AlC}$, both the $\mathrm{Ti}-\mathrm{Al}$ and $\mathrm{Nb}-\mathrm{Al}$ bonds are weaker than the Ti-C and $\mathrm{Nb}-\mathrm{C}$ bonds [84]. On the other hand, when the M-A and M-X bonds are of comparable strength, the MAX phase can dissolve in the etchant or remain as is. For example, in hypothetical $\mathrm{Sc}_{2} \mathrm{AlC}$ and $\mathrm{Cr}_{2} \mathrm{AlC}$, the $\mathrm{Sc}-\mathrm{Al}$ and $\mathrm{Cr}-\mathrm{Al}$ bonds are of comparable strengths to those for Sc-C and $\mathrm{Cr}-\mathrm{C}$ [84]. Therefore, other approaches would be needed to synthesize $\mathrm{Sc}_{2} \mathrm{CT}_{\mathrm{z}}$ or $\mathrm{Cr}_{2} \mathrm{CT}_{\mathrm{z}}$. This rule can also be used to selectively etch one of the $\mathrm{M}$ elements in a quaternary MAX phase forming either ordered or randomly distributed vacancies in the produced MXene, such as in etching $\left(\mathrm{Mo}_{2 / 3} \mathrm{Sc}_{1 / 3}\right)_{2} \mathrm{AlC}$ to form $\mathrm{Mo}_{1.33} \mathrm{CT}_{\mathrm{z}}$ with ordered vacancies [37] or in etching $\left(\mathrm{Nb}_{2 / 3} \mathrm{Sc}_{1 / 3}\right)_{2} \mathrm{AlC}$ to form $\mathrm{Nb}_{1.33} \mathrm{CT}_{\mathrm{z}}$ with disordered vacancies as shown in paper VI.

Apart from $\mathrm{HF}$, other etchants were used to selectively etch the A layers and produce MXenes. Most of them comprised an acid and a source of fluoride ions, such as $\mathrm{NH}_{4} \mathrm{HF}_{2}$ (used in paper I), $\mathrm{LiF}+\mathrm{HCl}$ (used in paper II), $\mathrm{NaBF}_{4}+\mathrm{HCl}$ [85], molten baths of $\mathrm{KF}$, $\mathrm{LiF}$ and $\mathrm{NaF}$ in the case of $\mathrm{Ti}_{4} \mathrm{AlN}_{3}$ to produce $\mathrm{Ti}_{4} \mathrm{~N}_{3} \mathrm{~T}_{2}$ [27]. Whereas, for selectively removing $\mathrm{Si}$ layers from $\mathrm{Ti}_{3} \mathrm{SiC}_{2}$ and producing $\mathrm{Ti}_{3} \mathrm{C}_{2} \mathrm{~T}_{\mathrm{z}}$, a mixture of $\mathrm{HF}$ and an oxidant such as $\mathrm{H}_{2} \mathrm{O}_{2},\left(\mathrm{NH}_{4}\right)_{2} \mathrm{~S}_{2} \mathrm{O}_{8}, \mathrm{HNO}_{3}, \mathrm{KMnO}_{4}, \mathrm{FeCl}_{3}$ was used [30]. A fluorine-free synthesis route has been reported to produce $\mathrm{Ti}_{3} \mathrm{C}_{2} \mathrm{~T}_{\mathrm{z}}$ by etching $\mathrm{Ti}_{3} \mathrm{AlC}_{2}$ using a hydrothermal process containing a $27.5 \mathrm{M} \mathrm{NaOH}$ solution at $270{ }^{\circ} \mathrm{C}$ [86].

\subsection{Exfoliation, Intercalation and Delamination of MXenes}

Delamination trials for the exfoliated MXenes have been carried out to separate the stacked multilayers, MLs, into single flakes. The first approach was to sonicate the exfoliated MXenes in water, isopropanol or methanol. This process resulted in a low yield of single flakes that had relatively small lateral sizes $(<1 \mu \mathrm{m})$ [25].

After the removal of the Al layers by HF alone, the bond between the MXene layers becomes weaker. However, it is still not weak enough to be broken by sonication alone, which is the reason behind the low yield of delaminated flakes after sonication. One approach commonly used for obtaining 2D layers is intercalation of a compound between the layers, which breaks the bonds between the layers and isolates the layers from each other. This method was used decades ago to exfoliate vermiculite [87], as well as other 
clays [88]; nowadays, it is one of the methods used to obtain single layers of 2D materials such as graphene [89] and $\mathrm{MoS}_{2}[90]$.

Using this technique, Mashtalir et al. [91] intercalated multi-layered MXene (ML- $\mathrm{Ti}_{3} \mathrm{C}_{2} \mathrm{~T}_{\mathrm{z}}$ ) with dimethylsulfoxide (DMSO). Immersion of $\mathrm{Ti}_{3} \mathrm{C}_{2} \mathrm{~T}_{\mathrm{z}}$ in DMSO resulted in an increase in the $c$ lattice parameter from 19.5 to $35 \AA$, which is clear evidence of intercalation. After sonication in water, a stable colloidal suspension of delaminated flakes $\left(d-\mathrm{Ti}_{3} \mathrm{C}_{2} \mathrm{~T}_{\mathrm{z}}\right)$ was obtained. Other compounds, such as tetrabutyalammonium hydroxide (TBAOH) used in papers IV, $\mathbf{V}$ and VI and in Refs. [37, 39, 92], tetramethylammonium hydroxide (TMAOH), [30, 93-94] and isopropylamine [95] have been used to delaminate $\mathrm{Ti}_{3} \mathrm{C}_{2} \mathrm{~T}_{\mathrm{x}}$ and other MXenes as well as $\mathrm{Nb}_{2} \mathrm{CT}_{\mathrm{z}}, \mathrm{Ti}_{3} \mathrm{CNT}_{\mathrm{z}}, \mathrm{V}_{2} \mathrm{CT}_{\mathrm{z}}$, $\mathrm{Mo}_{2} \mathrm{CT}_{\mathrm{z}}$ and $\mathrm{Mo}_{1.33} \mathrm{CT}_{\mathrm{z}}$. Figure 15 is a schematic of the entire process, starting from a MAX phase to delaminated MXene along with SEM micrographs of the materials after each process.

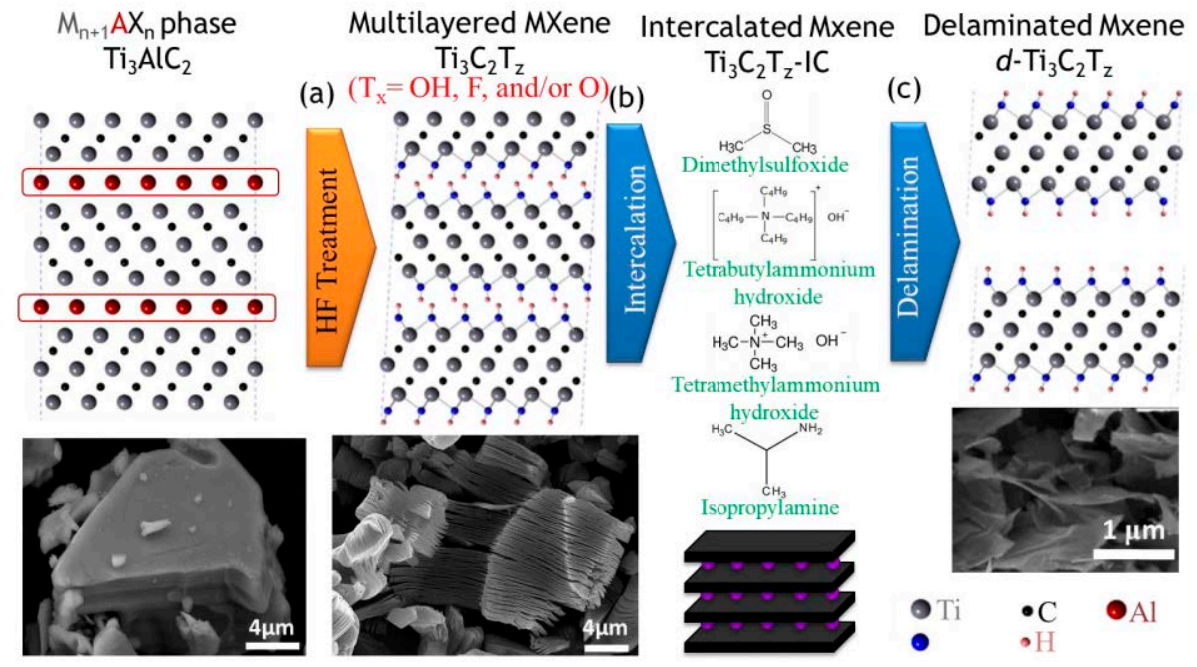

Figure 15. Synthesis of MXenes $\left(\mathrm{Ti}_{3} \mathrm{C}_{2} \mathrm{~T}_{\mathrm{z}}\right)$ from MAX phase $\left(\mathrm{Ti}_{3} \mathrm{AlC}_{2}\right)$ : (a) $\mathrm{Ti}_{3} \mathrm{AlC}_{2}$ powders immersed in $\mathrm{HF}$, resulting in (b) selective etching of the Al layers and formation of multilayered exfoliated MXene (ML- $\mathrm{Ti}_{3} \mathrm{C}_{2} \mathrm{~T}_{\mathrm{z}}$ ), (c) intercalation of the ML- $\mathrm{Ti}_{3} \mathrm{C}_{2} \mathrm{~T}_{\mathrm{z}}$ by various compounds: dimethylsulfoxide (DMSO), tetrabutylammonium hydroxide (TBAOH), tetramethylammonium hydroxide (TMAOH) or isopropylamine leading to delamination by sonication in water to produce single flakes $\left(d-\mathrm{Ti}_{3} \mathrm{C}_{2} \mathrm{~T}_{\mathrm{z}}\right)$. The schematics of the $\mathrm{Ti}_{3} \mathrm{AlC}_{2}, \mathrm{ML}-\mathrm{Ti}_{3} \mathrm{C}_{2} \mathrm{~T}_{\mathrm{z}}$, intercalation and delamination process of $\mathrm{Ti}_{3} \mathrm{C}_{2} \mathrm{~T}_{\mathrm{x}}$ flakes is accompanied by SEM for $\mathrm{Ti}_{3} \mathrm{AlC}_{2}, \mathrm{ML}-\mathrm{Ti}_{3} \mathrm{C}_{2} \mathrm{~T}_{\mathrm{z}}$, and $d-\mathrm{Ti}_{3} \mathrm{C}_{2} \mathrm{~T}_{\mathrm{z}}$. Adopted from Ref. [96] with permission from American Chemical Society (Ref. [25]), copyright (2012) and from Nature Publishing Group (Ref. [91]), copyright (2013), Nature Communications. 
The other approach is to combine etching, exfoliation and delamination in one step. Ghidiu et al. [97] showed that immersing $\mathrm{Ti}_{3} \mathrm{AlC}_{2}$ in a solution of $\mathrm{LiF}+\mathrm{HCl}$, not only etched the $\mathrm{Al}$ layers producing $\mathrm{Ti}_{3} \mathrm{C}_{2} \mathrm{~T}_{\mathrm{z}}$, but also resulted in the MLs spontaneously delaminating in water. The reason for the spontaneous delamination is that $\mathrm{Li}^{+}$ions are intercalated between the layers during etching. These ions are also accompanied by hydration shells of $\mathrm{H}_{2} \mathrm{O}$. The intercalation of both the $\mathrm{Li}^{+}$ions and the water layers weaken the bonding between the flakes sufficiently, facilitating the delamination process.

MXenes can be intercalated by other molecules, such as hydrazine, urea, along with cations other than $\mathrm{Li}^{+}$, such as $\left(\mathrm{Na}^{+}, \mathrm{K}^{+}, \mathrm{Rb}^{+}, \mathrm{Mg}^{+2}\right.$ and alkylammonium cations) [91, 9899]. Furthermore, the exchange of intercalant cations was reported for $\mathrm{Ti}_{3} \mathrm{C}_{2} \mathrm{~T}_{\mathrm{z}}$ [100], where $\mathrm{Li}^{+}$cations were first intercalated, then exchanged by $\mathrm{K}^{+}, \mathrm{Rb}^{+}, \mathrm{Na}^{+}, \mathrm{Mg}^{2+} \mathrm{Or} \mathrm{Ca}^{2+}$.

\subsection{Structure of MXenes}

The first proposed models for $\mathrm{ML} \mathrm{Ti}_{3} \mathrm{C}_{2} \mathrm{~T}_{\mathrm{x}}$ were based on density functional theory, (DFT), simulations [24]. In those models, all $\mathrm{T}_{\mathrm{z}}$ were assumed to be either $\mathrm{OH}$ or $\mathrm{F}$. Simulated XRD diffraction patterns were obtained from these models and compared with XRD diffraction patterns obtained experimentally for $\mathrm{Ti}_{3} \mathrm{C}_{2} \mathrm{~T}_{\mathrm{x}}$ as shown in Figure 13. The $\mathrm{Ti}_{3} \mathrm{C}_{2}(\mathrm{OH})_{2}$ is the closest to the experimental one; however, experimental results obtained from XPS and NMR analysis show the presence of $\mathrm{OH}, \mathrm{O}$ and $\mathrm{F}$ terminations [32-33]. The ratios of $\mathrm{OH}+\mathrm{O}$ to $\mathrm{F}$ terminations can vary according to the concentration of $\mathrm{HF}$ used in etching. For example, $\mathrm{Ti}_{3} \mathrm{AlC}_{2}$ etched using $50 \% \mathrm{HF}$ would have an $\mathrm{OH}+\mathrm{O}$ to $\mathrm{F}$ ratio of $0.5: 1.0$, while using $10 \% \mathrm{HF}$ increases the ratio to $\approx 1: 1$ [96].

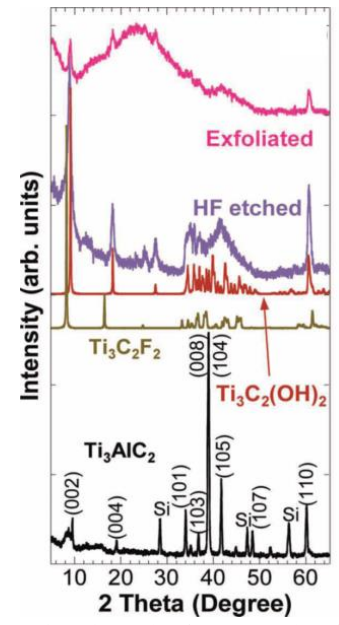

Figure 13. XRD patterns for $\mathrm{Ti}_{3} \mathrm{AlC}_{2}$ before and after $\mathrm{HF}$ treatment, $\mathrm{Ti}_{3} \mathrm{C}_{2} \mathrm{~T}_{\mathrm{Z}}$ after sonication in water (exfoliated) and simulated XRD patterns of $\mathrm{Ti}_{3} \mathrm{C}_{2} \mathrm{~F}_{2}, \mathrm{Ti}_{3} \mathrm{C}_{2}(\mathrm{OH})_{2}$ structure models. Reprinted with permission from John Wiley and Sons, Advanced Materials (Ref. [24]), copyright (2011). 
Later on, the theoretical work on MXenes focused on solving a fundamental problem: finding the most energetically favorable position for T. Enyashin et al. [101] proposed and studied three configurations (Figure 14). Configuration I: OH groups are positioned in the empty space between the three carbon atoms on the two sides of the MXene layer (Figure 14b, and e). Configuration II: OH groups are located right above the $\mathrm{C}$ atoms on both sides of the MXene layer (Figure 14c, and f). Configuration III (Figure 14d) is a combination of configurations I and II, where each configuration I and II occupy one side of the MXene layer. It was found by comparing the relative total energies for the three configurations that the least stable is configuration I, while the most stable is configuration II. The same results were also obtained for $\mathrm{Ti}_{3} \mathrm{C}_{2} \mathrm{~F}_{2}$ [102].

(a)

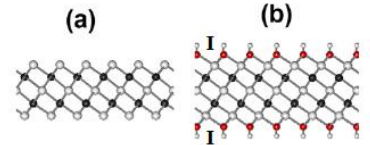

(e)

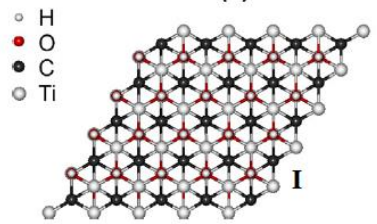

(c)

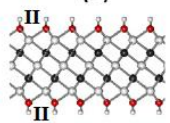

(f)

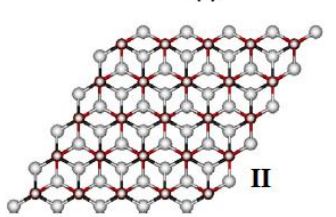

(d)

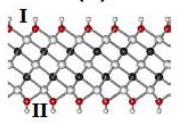

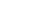

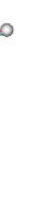

\section{(1)}

Figure 14. Atomic structures of: (a) $\mathrm{Ti}_{3} \mathrm{C}_{2}$ layer without any terminations. (b) $\mathrm{Ti}_{3} \mathrm{C}_{2}$ layer with $\mathrm{OH}$ terminations in configuration $\mathrm{I}$. (c) $\mathrm{Ti}_{3} \mathrm{C}_{2}$ layer with $\mathrm{OH}$ terminations in configuration II. (d) $\mathrm{Ti}_{3} \mathrm{C}_{2}$ layer with $\mathrm{OH}$ terminations in configuration III. (e) Top view of $\mathrm{Ti}_{3} \mathrm{C}_{2}$ layer with $\mathrm{OH}$ termination in configuration I. (f) Top view of $\mathrm{Ti}_{3} \mathrm{C}_{2}$ layer with $\mathrm{OH}$ termination in configuration II. Reprinted with permission from Elsevier (Ref. [101]), Computational and Theoretical Chemistry, copyright 2012.

Persson et al. [103], used in situ STEM and XPS to follow the surface termination groups at the atomic level for $\mathrm{Ti}_{3} \mathrm{C}_{2} \mathrm{~T}_{\mathrm{z}}$, while vacuum annealing. They concluded that at room temperature, both $\mathrm{F}$ and $\mathrm{O}$ surface terminations compete for the thermodynamically preferred site predicted by the DFT calculations mentioned above. At higher temperatures, $\mathrm{F}$ desorbs and is replaced by $\mathrm{O}$.

\subsection{Properties and Applications of MXenes}

Similar to graphene, modifying the surface terminations can result in tuning of the MXene properties to suit specific applications. Much theoretical work using DFT was done to understand the electronic structure of MXenes, how they change by varying the surface 
terminations and what the influence of that variation is on their properties $[24,102,104-$ $108]$.

For example, DFT calculations predict that MXene monolayers without surface terminations are metallic and that their electron density of states, DOS, near the Fermi level, $E_{f}$, are higher than that of their parent MAX phases [24, 102, 104-105]. In MAX phases, taking $\mathrm{Ti}_{2} \mathrm{AlC}$ as an example, the valence states below $\mathrm{E}_{\mathrm{f}}$ are divided into two sub-bands. One of them, which is the nearest to $\mathrm{E}_{\mathrm{f}}$, is mainly composed of a hybridization between Ti 3d and Al 3p orbital; this sub-band is denoted sub-band A (Figure 16). The other sub-band, denoted $\mathrm{B}$, is located further away from $\mathrm{E}_{\mathrm{f}}$ between -10 and $-3 \mathrm{eV}$ and is formed from the hybridization between Ti $3 \mathrm{~d}$ and $\mathrm{C} 2 \mathrm{p}$ orbitals. In MXenes, the removal of the A element leads to the reformation of sub-band A due to the removal of $\mathrm{Al} \mathrm{3p}$ orbitals. Thus sub-band A will be composed of only Ti $3 \mathrm{~d}$ orbitals meaning that the nature of the bonding becomes a metallic Ti-Ti bonding, resulting in the increase of DOS near the $\mathrm{E}_{\mathrm{f}}$ of $\mathrm{Ti}_{2} \mathrm{C}$ compared to $\mathrm{Ti}_{2} \mathrm{AlC}$ [106].

These findings can also influence the magnetic properties of MXenes. The increase in the electron DOS near the $\mathrm{E}_{\mathrm{f}}$ caused by the $\mathrm{d}$ orbitals of $\mathrm{M}$ could potentially lead to magnetic properties [104-105, 109]. For example, DFT calculations predict that $\mathrm{Cr}_{2} \mathrm{C}$, $\mathrm{Cr}_{2} \mathrm{~N}$ [105] and $\mathrm{Ta}_{3} \mathrm{C}_{2}$ [109] are ferromagnetic, while $\mathrm{Ti}_{3} \mathrm{C}_{2}$ and $\mathrm{Ti}_{3} \mathrm{~N}_{2}$ [104] are antiferromagnetic. Such magnetic properties disappear as soon as the MXenes are terminated with any functional groups due to changes in the sub-band A from M-M bonding to $\mathrm{M}-\mathrm{T}$ bonding, causing a reduction in electron DOS near the $\mathrm{E}_{\mathrm{f}}$. That is not true for $\mathrm{Cr}_{2} \mathrm{C}$ and $\mathrm{Cr}_{2} \mathrm{~N}$, where theoretical calculations show that $\mathrm{Cr}_{2} \mathrm{CT}_{\mathrm{z}}$ will stay magnetic up to almost room temperature[105]. It is worth noting that so far, no one has reported the production of $\mathrm{Cr}_{n+1} \mathrm{X}_{\mathrm{n}} \mathrm{T}_{\mathrm{z}}$ experimentally.

Surface terminations also influence whether a particular MXene compound is a metal, semiconductor or insulator. Through theoretical calculations, the band gaps of bare MXenes and MXenes with various surface terminations were predicted. As stated above, bare MXenes surfaces are predicted to be metallic-like conductors, and most surface terminated MXenes are metallic. However, some surface terminated MXenes vary from being semiconductors with a small band gap to large direct or indirect band gap, as shown in Table 1. The key to understanding the reason behind the changes in band gap is how the electron DOS near $E_{f}$ changes when MXenes are surface terminated, as shown in Figure $16[4,37,44,45]$. The existence of the surface terminations results in the formation of a third sub-band, sub-band $\mathrm{C}$, located below sub-band $\mathrm{B}$. The latter is formed due to the M-T bonds moving the gap between sub-band A and B to lower energies. 
Table 1. Band gap values calculated theoretically for various MXenes with different surface terminations.

\begin{tabular}{|c|c|c|}
\hline Compound & Band gap, eV & Ref. \\
\hline $\mathrm{Ti}_{3} \mathrm{C}_{2}(\mathrm{OH})_{2}$ & 0.05 & {$[24]$} \\
\hline $\mathrm{Ti}_{3} \mathrm{C}_{2}(\mathrm{~F})_{2}$ & 0.10 & {$[24]$} \\
\hline $\mathrm{Ti}_{2} \mathrm{CO}_{2}$ & $1.03^{*}$ & {$[105]$} \\
\hline $\mathrm{Sc}_{2} \mathrm{C}(\mathrm{OH})_{2}$ & $0.45^{* *}$ & {$[105]$} \\
\hline $\mathrm{Sc}_{2} \mathrm{C}(\mathrm{F})_{2}$ & $1.80^{*}$ & {$[105]$} \\
\hline $\mathrm{Sc}_{2} \mathrm{CO}_{2}$ & $0.24^{*}$ & {$[105]$} \\
\hline $\mathrm{Zr}_{2} \mathrm{CO}_{2}$ & $0.88^{*}$ & {$[105]$} \\
\hline $\mathrm{Hf}_{2} \mathrm{CO}_{2}$ & $1.00^{*}$ & {$[105]$} \\
\hline
\end{tabular}

${ }^{*}$ indirect band gap. ${ }^{* *}$ direct band gap

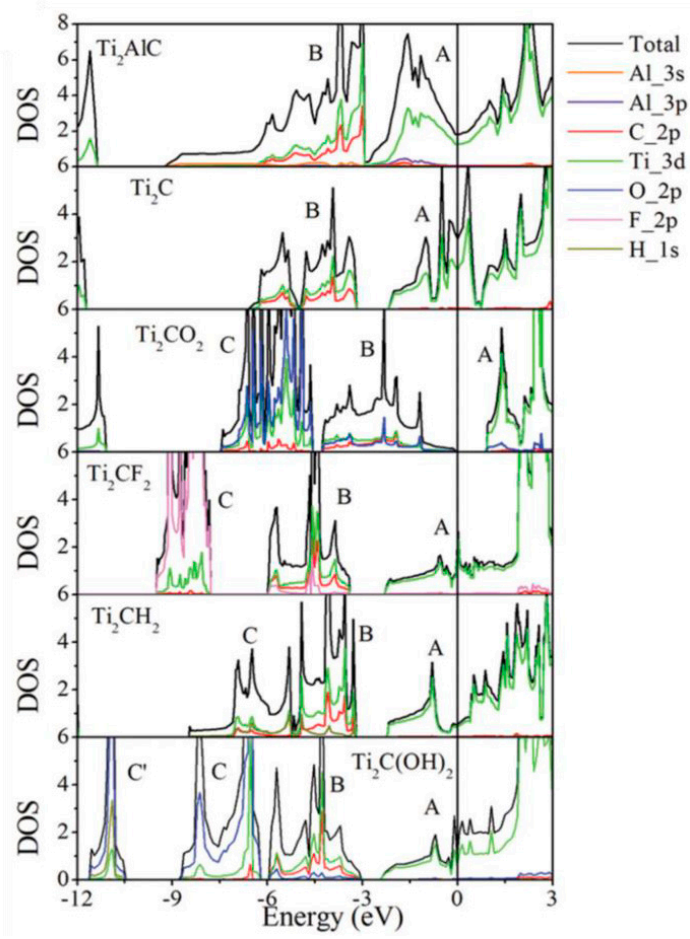

Figure 16. Partial density of states of $\mathrm{Ti}_{2} \mathrm{AlC}$, and $\mathrm{Ti}_{2} \mathrm{CT}_{\mathrm{z}}$, where $\mathrm{T}_{\mathrm{z}}$ is $\mathrm{O}_{2}, \mathrm{~F}_{2}, \mathrm{H}_{2}$ or $(\mathrm{OH})_{2}$. Reprinted with permission from American Physical Society, Physical Review B (Ref. [106]), copyright (2013).

Most of the theoretical results obtained for different MXenes cannot be directly implemented on the MXenes produced experimentally, due to the lack of a structure model that takes into consideration the fact that the surface terminating groups, $\mathrm{T}$, in MXenes are not composed of one functional group, but more than one. Another problem with the theoretical studies is that they only predict properties for isolated layers while 
MXenes are experimentally produced in the form of MLs. Recently a few theoretical researchers started to address these two issues. Among them is Caffrey [110], who reported the predicted DOS of $\mathrm{Ti}_{3} \mathrm{C}_{2} \mathrm{~T}_{2}$ and $\mathrm{V}_{2} \mathrm{CT}_{2}$ assuming mixed surface terminations of $-\mathrm{O},-\mathrm{OH}$ and $-\mathrm{F}$ and also assuming MLs to reflect a typical experimental composition and form. The DOS for multi-layered $\mathrm{Ti}_{3} \mathrm{C}_{2} \mathrm{~T}_{2}$ was found to predominantly comprised the contributions from the $\mathrm{Ti}$ and $\mathrm{C}$ atoms in the range from -4 to $+2 \mathrm{eV}$. For $\mathrm{V}_{2} \mathrm{CT}_{2}$, the contributions from $\mathrm{V}$ and $\mathrm{C}$ were found to dominate the energy region from -2 to $+4 \mathrm{eV}$. In both cases, the states associated with surface terminations were located at lower energy regions (below $-2 \mathrm{eV}$ ). It was predicted that $\mathrm{Ti}_{3} \mathrm{C}_{2}(\mathrm{OH})_{2}$ has a low work function of about $2 \mathrm{eV}$, which would allow such material to be an efficient field emitter [111]. However, that low work function increases drastically when the $-\mathrm{OH}$ is replaced with -F, -O or even mixed with them where the percentage of $-\mathrm{OH}$ is less than $60 \%$ [110]. Similar DFT calculations were performed for $\mathrm{Mo}_{2} \mathrm{CT}_{2}$ and $\mathrm{Mo}_{1.33} \mathrm{CT}_{2}$, where $\mathrm{T}$ is $-\mathrm{O}$ or $-\mathrm{F}(-\mathrm{OH}$ terminations were approximated with $-\mathrm{F}$ in this study) [112]. The electronic properties of both MXenes were predicted to strongly depend on the $\mathrm{O}$ to $\mathrm{F}$ ratio. If the $\mathrm{O}$ to $\mathrm{F}$ ratio is $1: 2$ the electronic structure was predicted to be more metallic. If the $\mathrm{O}$ to $\mathrm{F}$ is $2: 1$, the Fermi level is lowered to a non-metallic state. $\mathrm{Mo}_{2} \mathrm{CT}_{\mathrm{z}}$ shows a preference of $-\mathrm{O}$ terminations to $-\mathrm{F}$ as compared to $\mathrm{Mo}_{1.33} \mathrm{CT}_{\mathrm{Z}}$ which prefers $-\mathrm{F}$ to $-\mathrm{O}$ terminations. This prediction is in agreement with the chemical composition of both MXenes obtained experimentally from XPS. The DOS at $\mathrm{E}_{\mathrm{f}}$ was predicted to be dominated mainly by the Mo orbitals, while the orbitals of both $\mathrm{O}$ and $\mathrm{F}$ are located at lower energies, which is the same case as for $\mathrm{Ti}_{3} \mathrm{C}_{2} \mathrm{~T}_{2}$ and $\mathrm{V}_{2} \mathrm{CT}_{2}[110]$.

Similar to the MAX phases, MXenes of different elements and $n$ layers vary in their electrical resistivities [113]. The resistivity of cold pressed freestanding discs for different exfoliated MXenes is about four times higher than that for their parent MAX phases. For example, the resistivity of cold pressed $\mathrm{Ti}_{3} \mathrm{AlC}_{2}$ is $1200 \mu \Omega \mathrm{m}$, while that for $\mathrm{Ti}_{3} \mathrm{C}_{2} \mathrm{~T}_{\mathrm{z}}$ is $5000 \mu \Omega \mathrm{m}$ [25]. The sheet resistance values reported for MXenes are comparable to those for multilayered graphene [1, 114-115]. The etching time as well as intercalation of various compounds in MXenes were found to play an important role in changing the resistivities of cold pressed MXenes discs [82]. Increasing etching time of $\mathrm{Ti}_{3} \mathrm{AlC}_{2}$ results in a significant increase in resistivity of the produced $\mathrm{Ti}_{3} \mathrm{C}_{2} \mathrm{~T}_{\mathrm{z}}$ [82]. Mashtalir et. al [34], reported on the increase of resistivity of cold pressed discs of $\mathrm{Ti}_{3} \mathrm{C}_{2} \mathrm{~T}_{\mathrm{z}}, \mathrm{Ti}_{3} \mathrm{CNT}_{\mathrm{z}}, \mathrm{Nb}_{2} \mathrm{CT}_{\mathrm{z}}$ and $\mathrm{TiNbCT}_{\mathrm{z}}$ after intercalation with hydrazine monohydrate. This behavior is similar to other 2D materials, such as the intercalation of $\mathrm{TaS}_{2}$ with hydrazine [116]. MXenes have also been reported to be hydrophilic based on measurements of the contact angle on cold pressed discs. The hydrophobicity of the MXenes would be an advantage when using MXenes in energy storage devices containing aqueous electrolytes or dispersing them in water or alcohol. 
The mechanical properties of MXenes have been of interest due to their strong $\mathrm{M}-\mathrm{X}$ bonds. Their elastic properties have been predicted by calculating the elastic constant when stretched along the basal planes, $\mathrm{c}_{11}$, using DFT calculations $[24,117]$. MXenes show high values of $c_{11}$ compared to their parent MAX phases; however, these values are lower than those reported for graphene [118]. Very recently, the elastic properties of single and bilayers were reported [119]; the effective Young's modulus for a single flake of $\mathrm{Ti}_{3} \mathrm{C}_{2} \mathrm{~T}_{\mathrm{z}}$ obtained from a solution processed synthesis technique is $330 \pm$ $30 \mathrm{GPa}$. This value is higher than that of other 2D materials such as graphene oxide, reduced graphene oxide and $\mathrm{MoS}_{2}$, but lower than that of h-BN and graphene.

Energy storage applications are considered one of the early explored applications for MXenes especially Li ion batteries (LIBs). Theoretical as well as experimental studies show promising behavior for MXenes as anodes in LIBs [23, 102, 104, 120]. Theoretical calculations predict that $\mathrm{Ti}_{3} \mathrm{C}_{2}$ could achieve a better performance as an anode in LIBs compared to $\mathrm{TiO}_{2}$ because of its higher electrical conductivity stemming from its metallic nature, its lower open circuit potential and its high charge/discharge rates [102]. Although several MXenes $\left(\mathrm{Ti}_{3} \mathrm{C}_{2} \mathrm{~T}_{\mathrm{z}}\right.$ [91], $\mathrm{Ti}_{2} \mathrm{CT}_{\mathrm{z}}$ [120], $\mathrm{V}_{2} \mathrm{CT}_{\mathrm{z}}$ [23] and $\mathrm{Nb}_{2} \mathrm{CT}_{\mathrm{z}}$ [23]) have been experimentally studied for their performance as anodes in LIBs, the most exciting results were obtained for delaminated $\mathrm{Ti}_{3} \mathrm{C}_{2} \mathrm{~T}_{\mathrm{z}}$ [91]. Delaminated $\mathrm{Ti}_{3} \mathrm{C}_{2} \mathrm{~T}_{\mathrm{z}}$ - used as anodes with no additives - showed a reversible capacity 4 times higher than that of exfoliated $\mathrm{Ti}_{3} \mathrm{C}_{2} \mathrm{~T}_{\mathrm{z}}$, as shown in Figure 17. Furthermore, delaminated $\mathrm{Ti}_{3} \mathrm{C}_{2} \mathrm{~T}_{\mathrm{z}}$ free-standing thin film proved to be capable of maintaining good capacity at high rates $\left(110 \mathrm{mAhg}^{-1}\right.$ at $36 \mathrm{C}$ after 700 cycles). Also in the field of energy storage, $\mathrm{Ti}_{3} \mathrm{C}_{2} \mathrm{~T}_{\mathrm{z}}$ rolled into film, produced by etching $\mathrm{Ti}_{3} \mathrm{AlC}_{2}$ by $\mathrm{LiF}+\mathrm{HCl}$ solution, shows a volumetric capacitance exceeding $900 \mathrm{~F} / \mathrm{cm}^{3}$, which is much higher than that of the porous carbon currently used in electrochemical capacitors [97]. MXenes have also been shown to operate at charge rates exceeding those of conventional electrical double-layer capacitors (EDLCs) and still provide higher capacitance of $\approx 200 \mathrm{~F} / \mathrm{Cm}^{3}$ at a scan rate of $10 \mathrm{~V} / \mathrm{s}[121]$.

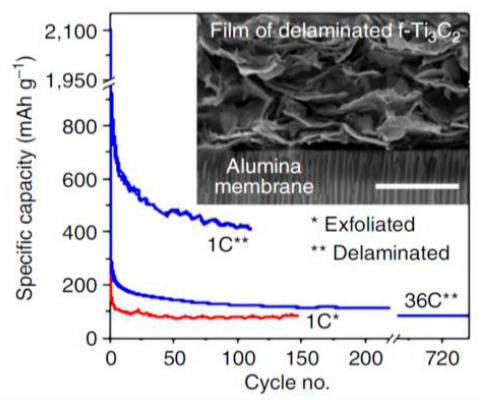

Figure 17. Performance of exfoliated and delaminated $\mathrm{Ti}_{3} \mathrm{C}_{2} \mathrm{~T}_{\mathrm{z}}$ as anodes in LIBs. Inset shows the delaminated $\mathrm{Ti}_{3} \mathrm{C}_{2} \mathrm{~T}_{\mathrm{x}}$ free-standing thin film after filtration through the alumina membrane, scale bar is $4 \mu \mathrm{m}$ long. Reprinted with permission from Nature Publishing Group (Ref. [91]), copyright (2013), Nature Communications. 
$\mathrm{Ti}_{3} \mathrm{C}_{2} \mathrm{~T}_{\mathrm{z}}$ was also used as a supporting material for platinum nanoparticles [122]. The $\mathrm{Ti}_{3} \mathrm{C}_{2} \mathrm{~T}_{\mathrm{z}} / \mathrm{Pt}$ catalysts showed extraordinary stability and durability compared to the conventionally used $\mathrm{Pt} / \mathrm{C}$ catalysts for proton exchange membrane fuel cells. MXenes such as $\mathrm{Mo}_{2} \mathrm{CT}_{\mathrm{z}}, \mathrm{Mo}_{1.33} \mathrm{CT}_{\mathrm{z}}, \mathrm{W}_{1.33} \mathrm{CT}_{\mathrm{z}}, \mathrm{V}_{4} \mathrm{C}_{3} \mathrm{~T}_{\mathrm{z}}$ showed promise as active catalyst candidates for hydrogen evolution reactions $[39,79,123] . \mathrm{Nb}_{2} \mathrm{CT}_{\mathrm{x}}$ has been reported to show promising performance for photothermal cell ablation and as a photocatalyst for hydrogen evolution, besides the good performance for energy storage applications [23, 95, 124-125]. Furthermore, MXenes have shown promise in other applications, such as transparent conducting electrodes (paper I), water treatment, electromagnetic shielding, gas sensors and biosensors [126-132]. Using both DFT calculations and molecular dynamics simulations, the hydrogen storage properties for $\mathrm{Ti}_{2} \mathrm{C}, \mathrm{Sc}_{2} \mathrm{C}$ and $\mathrm{V}_{2} \mathrm{C}$ were studied, showing the possibility of hydrogen storage up to about $3.4 \mathrm{wt}$.\% reversibly at room temperature [133]. In summary, one can say that MXene is a large family of 2D materials with huge promise for many applications. 



\section{ELECTRONIC TRANSPORT PROPERTIES IN DISORDERED SYSTEMS}

Disordered systems are materials which have a disorder in the arrangement of the atoms in the crystal lattice. Disorder can arise from defects, such as atomic vacancies, dislocations, alloying or intercalation. Such materials include ligand-stabilized metal-cluster compounds (e.g. $\left[\mathrm{FeCO}_{3}(\mathrm{CO})_{12}\right]^{-}$anions [134] and $\mathrm{Au}_{55}\left[\mathrm{P}_{(}\left(\mathrm{C}_{6} \mathrm{H}_{5}\right)_{3}\right]_{12} \mathrm{Cl}_{6}$ [135]), ceramic metals (cermets such as $\mathrm{Ni}-\mathrm{SiO}_{2}, \mathrm{Pt}-\mathrm{SiO}_{2134}, \mathrm{Au}-\mathrm{Al}_{2} \mathrm{O}_{3}$ and $\mathrm{W}-\mathrm{Al}_{2} \mathrm{O}_{3}$ ) [136], various other metal-nonmetal composites [137], and doped or amorphous semiconductors [138-139].

Disordered systems can be classified into three categories according to their resistivity ratios $\left(\rho_{r}=\frac{\rho_{1.4 K}}{\rho_{300 K}}\right): 1$. Metallic regime: $\rho_{\mathrm{r}}<2$, critical regime: $2<\rho_{\mathrm{r}}<6$, and 3. insulating regime: $\rho_{r}>6$ [140]. These three regimes can be better characterized by plotting $\ln \mathrm{W}$ vs. $\ln \mathrm{T}$, where $\mathrm{W}$ is defined as the reduced activation energy, $W=-T \frac{d(\ln (\rho))}{d(\ln (T))}[141]$. For disordered systems in the metallic regime, $\mathrm{W}$ decreases with decreasing $\mathrm{T}$. In the critical regime, $\mathrm{W}$ is constant, with decreasing $\mathrm{T}$. In the insulating regime, $\mathrm{W}$ would increase with decreasing T. Figure 18 is an example, plotting $\mathrm{W} v s . \mathrm{T}$ for polyaniline doped with camphor sulfonic acid. These materials exhibit the three regimes depending on the degree of disorder arising from the doping.

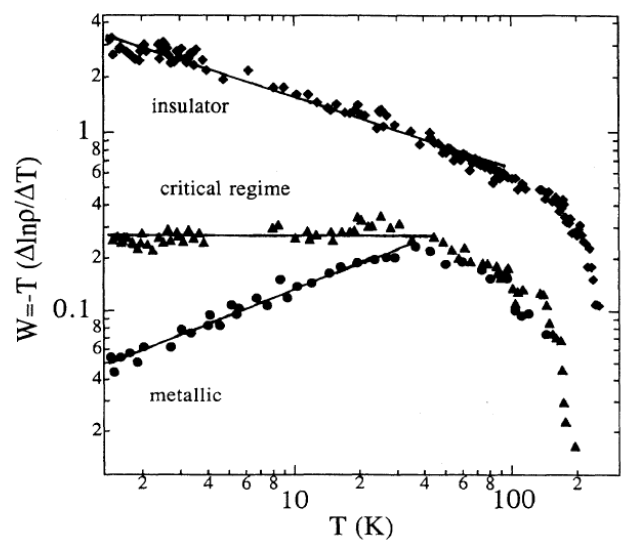

Figure 18. Log-log plot of $\mathrm{W}$ vs. temperature for polyaniline doped with camphor sulfonic acid materials in the metallic, critical and insulting regimes. Reprinted with permission from American Physical Society, Physical Review B (Ref. [140]), copyright (1993). 


\subsection{Conduction mechanisms in disordered systems}

In metals, the conductivity as a function of temperature is described by the scattering of Bloch waves by impurities and defects, which leads to a Boltzmann transport equation [142] written as:

$$
\sigma(T)=\sigma_{0}-A \sigma_{0}^{2} T^{n}
$$

where $\sigma_{0}$ is the residual conductivity due to impurity and defect scattering,

$A$ is a positive constant

$n$ is a positive integer $>2$ ( $n=2$ if the electron-electron interactions are dominant).

The residual conductivity $\sigma_{0}$ increases as $\mathrm{T}$ increases due to the increase of the amount of scattering as the excitation of phonons or electron-electron interactions collision increases. However, this equation does not hold if the disorder is strong. The coefficient $A$ can then be positive or negative, and $n$ is $1 / 2$ for three-dimensional systems [142]. Thus, several theoretical models have been proposed to describe the conduction mechanism in disordered systems. These models address two problems: (1) Dealing with the nature of the wave function of a single electron in the presence of a random potential (Anderson localization) and, (2) The interaction among electrons in the presence of a random potential. A Hamiltonian describing the conductivity of a strongly correlated electron system in interaction with the underlying lattice, would contain the following terms [137]:

$$
\mathscr{H}=\mathscr{H}_{\mathrm{e}}+\mathscr{H}_{\mathrm{ph}}+\mathscr{H}_{\mathrm{e} \text {-e }}+\mathscr{H}_{\mathrm{e} \text {-ph }}+\mathscr{H}_{\mathrm{v}}
$$

The first term describes the non-interacting electron system using a tight binding model, the second is the phonon term, the third is the electron-electron interactions, the fourth is the electron-phonon interaction and the last term is for the potential seen by the electrons as they move through the lattice. The variable-range hopping models discussed later make an approximation of the Hamiltonian, which is called the single-electron approximation where the $\mathscr{H}_{\mathrm{e} \text {-e }}$ is ignored. However, models based on the work of Hubbard, Mott and Anderson consider the electron-electron interaction, $\mathscr{H}_{\mathrm{e}-\mathrm{e}}$, but consider a rigid lattice. 


\subsubsection{Hubbard-Anderson Hamiltonian}

Before describing the Hubbard-Anderson Hamiltonian, the two terms "Anderson localization" and "mobility edge" have to be defined first. The traditional view of how disorder affects crystalline systems was that the random potential would cause the Block waves to lose phase on the length scale of the mean free path $l$. However, the wave would remain extended throughout the sample. Anderson showed that this is not true and the wave function in a random potential may be altered if the randomness or disorder is strong enough [143]. This means that if the disorder is very strong, the wave function may become localized, in that the envelope of the wave function decays exponentially from some point in space. A comparison between the traditional view of the wave function and Anderson localization is demonstrated in Figure 19. Localization can take place due to electron-electron interaction, disorder or electron-phonon interactions.

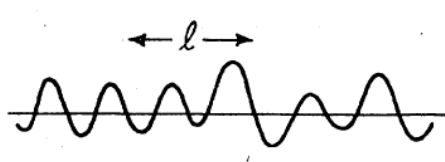

(a)

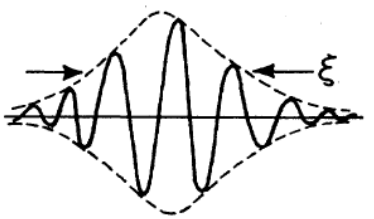

(b)

Figure 19. Wave functions (a) extended throughout the sample with mean free path $l$; (b) localized with localization length $\xi$. Reprinted with permission from American Physical Society, Reviews of Modern Physics (Ref. [137]).

The mobility edge is defined as the amount of energy required to change the character of the states from being localized to being extended [144]. If the Fermi level lies in the region of localized states, the conductivity at $0 \mathrm{~K}$ would be zero and the conductivity at the extended states would have a value at $0 \mathrm{~K}$. Therefore, the mobility edge separates metals from insulators.

Anderson-Hubbard Hamiltonian describes the interactions- or disorder-induced localization as follows [137].:

$$
\mathcal{H}=\sum_{m, \sigma} \varepsilon_{m} n_{m, \sigma}+\sum_{m \neq m^{\prime}, \sigma} J_{m^{\prime}, m} a_{m^{\prime} \sigma}^{+} a_{m, \sigma}+U \sum_{m} n_{m \uparrow} n_{m \downarrow}
$$

where $\varepsilon$ is the energy of site $m$

$J_{m^{\prime}, m}$ is the transfer integral between sites $m^{\prime}$ and $m$,

$U$ is the Hubbard on-site correlation energy,

$a_{m, \sigma}^{+} a_{m, \sigma}$ are quantum-mechanical operators that respectively create and

annihilate an electron at site $m$ with spin $\sigma$, and

$n_{m \sigma}$ is the number of electrons at site $m$ with spin $\sigma$. 
The second term in Eq. (4.3) is the first term in Eq. (4.2), describing a tight-binding band of electrons. The third term, introduced by Hubbard, is to take into account the (on-site) interactions between electrons. However, in the Hubbard model, all sites were assumed to have the same energy, therefore, $\varepsilon$ would be constant and the first term in Eq. (4.3) can be discarded. In this case, the ratio between $U$ and $J_{m^{\prime}, m}$ would be the only factor driving the metal-nonmetal transition. If $U \gg J_{m^{\prime}, m}$ the charges would be localized, while if $J_{m^{\prime}, m} \ll U$ the charges would be delocalized into a band, i.e. extended states would form. If we consider the case where the electron-electron interactions on-site were discarded, i.e. $U=0, J_{m^{\prime}, m}=J_{0}$ and $\varepsilon_{m}$ is distributed randomly over a certain range with a width of $\Gamma$ around zero [143]. In such a case, if $\Gamma=0$, then all the states are extended; if $\Gamma>0$, the electronic states become localized if $\Gamma / \mathrm{z} J_{0}$ (where $\mathrm{z}$ is the number of nearest neighbors) reaches a critical value. This critical value is called the Anderson transition. In general, the states near a band edge are the easiest to localize, i.e., do not need a large disorder to be localized. However, if the disorder is high enough, the valence- and conduction-band tails of a semiconductor may overlap to give a nonzero density of localized states, which originally would have been the energy gap if there were no disorder (semiconductor single band).

It is worth noting that, in the Hubbard-Anderson approach, a rigid lattice is considered. This means that polaronic deformations around the moving charge are not taken into account and quantum mechanical tunneling is the only mechanism of charge transfer between neighboring sites. However, by introducing the phonon contribution, other transport mechanisms can be considered, such as thermally activated hopping at least at sufficiently high temperatures. This has been demonstrated in paper $\mathbf{V}$, where the conduction mechanism for Mo-based MXenes changes from variable range hopping mechanisms at low temperature to a thermally activated mechanism at higher temperatures.

\subsubsection{Weak localization in thin films and $2 D$ materials}

Thin disordered metal films show a deviation from the Boltzmann theory, where at low temperatures the resistivity increases with decreasing temperature. In addition, such thin films experience a decrease in resistivity when magnetic fields perpendicular to the films are applied, i.e. negative magnetoresistance (MR), and the resistance is strongly dependent on the temperature. The value of the negative MR increases with decreasing temperature. An example is a copper thin film with a thickness of $80 \AA$ and a high degree of disorder where its electronic mean free path is of the order of $10 \AA$ [145].

Due to the occurrence of defects and/or impurities, the conduction electrons can be scattered without losing their phase coherence, which would result in multiple scattered waves forming a chaotic pattern. The usual Boltzmann theory neglects the interferences 
between the scattered waves and assumes that the momentum of the electron wave disappears after the time $\tau_{0}$, inelastic lifetime of the electron in an eigenstate of momentum (or $\tau_{\text {tr }}$, transport mean free path). In this case, $\tau_{0}$ is assumed to be equal to $\tau_{\text {tr. }}$. This assumption leads to the Drude formula for the conductivity of free electrons [145]:

$$
\sigma=\frac{n e^{2}}{m} \tau_{o}
$$

where $n$ is the number of electrons, and

$m$ is the mass of an electron.

A correction has to be introduced to account for the interference between the scattered spatial wave. That correction was shown to be [146]:

$$
\Delta L=\frac{-\Delta R}{R_{0}^{2}}=L_{00} \log \left(\tau_{i} / \tau_{0}\right) ; \quad L_{00}=e^{2} /\left(2 \pi^{2} \hbar\right)
$$

where $R$ is the resistance, and

$\tau_{i}$ is the inelastic lifetime, which is the lifetime in an eigenstate of energy.

This correction is temperature-dependent because the inelastic lifetime depends on temperature. Thus, weak localization can be experimentally determined if plotting resistance, R, vs. log $\mathrm{T}$ gives a straight line.

A thin film is considered 2D with respect to weak localization when the diffusion time across its thickness is compared to the characteristic time of the electrons. In the absence of a magnetic field this time is the inelastic lifetime of the conduction electrons [145].

The MR behavior is an important characteristic that helps to differentiate weak localization phenomenon from other conduction mechanisms, such as Coulomb interactions, in disordered materials. The latter also have a linear relationship of resistance with $\log \mathrm{T}$, as seen from its conductance correction [145]:

$$
\Delta L(T)=-\frac{\Delta R}{R_{0}^{2}}=-L_{00}(1-F) \ln (T)
$$

where $\mathrm{F}$ is the screening factor.

The mechanism of Coulomb interaction arises from the fact that the electron-electron interaction in disordered metals is retarded, in other words, a sudden change of the charge distribution in the disordered metal, which cannot be screened immediately. Electrons in this case move by diffusion; thus, they will need time to screen the charge distribution. As indicated above, in the case of weak localization, the MR becomes negative and larger at lower temperatures. This is attributed to the effect of the magnetic field on the quantum interference between forward-scattering events. Both weak localization and Coulomb interaction can simultaneously take place. For example, in Bi-films, they can be separated by applying a high magnetic field, which suppresses the 
temperature dependence of the weak localization, and only the contribution of the Coulomb interaction remains [147].

The weak localization phenomenon has also been also observed in defective $2 \mathrm{D}$ materials that have a metallic behavior, such as chemically doped 2D graphene [148], $\mathrm{Ti}_{3} \mathrm{C}_{2} \mathrm{~T}_{\mathrm{x}}$ in paper $\mathbf{I}$, and $\mathrm{Ti}_{2} \mathrm{CT}_{\mathrm{x}}$ in paper III.

\subsubsection{Variable range hopping (VRH) models}

VRH models are often used to describe the conductivity of systems where charge carriers move from one localized state to another. In addition, the absence of band conduction is assumed either because there are no extended states or because the energies of the extended states present are far from $E_{f}$ and would only be populated at higher temperatures. The VRH conduction follows a universal law given by [137, 149-151]:

$$
\sigma=\sigma_{0} \exp \left[-\left(\frac{T_{0}}{T}\right)^{x}\right]
$$

where $x=(p+1) /(d+p+1)$.

When DOS is constant, $p=0$, and $x=1 / 4$ for $\mathrm{d}=3$; and $x=1 / 3$ for $\mathrm{d}=2$. This corresponds to Mott VRH. However, when the DOS varies in the vicinity of $\mathrm{E}_{\mathrm{f}}$, where charging or Coulomb effects occur, then $x=1 / 2$. The conductivity is then no longer dependent on dimensionality and would correspond to the Efros and Schlovskii (ES) VRH regime.

For a given disordered material, different conduction mechanisms can operate in different temperature regimes. For example, a VRH mechanism where the electronic conduction takes place by hopping from one site to another in the absence of a conduction band can be operative at low temperatures. However, if extended states exist far from $\mathrm{E}_{\mathrm{f}}$ that are activated at high temperatures, then another conduction mechanism, thermal activation, can occur. Such behavior has been observed in several disordered systems, such as 2-D Ag nanoparticle arrays [152] and in Mo-based MXenes presented in paper V. 


\section{CHARACTERIZATION TECHNIQUES}

This chapter describes the most important techniques used in characterizing our MXenes.

\subsection{X-ray Diffraction (XRD)}

$\mathrm{X}$-ray diffraction (XRD) is one of the most common techniques used to characterize the structure of materials, whether in powder, bulk or thin films forms. It is a non-destructive technique, and it does not require extensive sample preparation. The technique is based on the scattering of X-rays by atoms. Constructive interference is achieved at certain angles governed by Bragg's law [153]:

$$
\mathrm{n} \lambda=2 \mathrm{~d} \sin \theta
$$

where $\mathrm{n}$ is an integer,

$\lambda$ is the wavelength of the probing rays,

$\theta$ is the angle between the incident rays and the surface of the crystal, and

$\mathrm{d}$ is the spacing between layers of atoms.

Constructive interference gives peaks at characteristic positions in X-ray diffractograms, from which the lattice parameters, LPs, as well as phase identification, is possible using a mode called $\theta / 2 \theta$ scan. Here, $\theta$ is the angle between the incident beam and the sample, and $2 \theta$ is twice that angle.

The $\theta / 2 \theta$ scans in this thesis were performed for phase identification, as well as for measuring the LPs. The scans were used to determine the conversion of MAX to MXene, as well as whether intercalation of the produced thin MXenes films occurred (see paper I). As shown in Figure 20, the (002) peak for a $\mathrm{Ti}_{3} \mathrm{AlC}_{2}$ thin film etched by HF is shifted to lower $2 \theta$ values compared to the film before etching. This is due to the removal of the Al layers, as well as the exfoliation of the films, resulting in an increase in the $c$-lattice parameter from 18.6 to $19.8 \AA$. The film etched by $\mathrm{NH}_{4} \mathrm{HF}_{2}, \mathrm{Ti}_{3} \mathrm{C}_{2} \mathrm{~T}_{\mathrm{z}}-\mathrm{IC}$, (IC stands for intercalated compound), is shifted further to the left compared to the $\mathrm{Ti}_{3} \mathrm{AlC}_{2}$ thin film etched by HF. This shift is attributed to an increase in the $c$-lattice parameter to $24.7 \AA$, indicating that intercalation took place when etching the thin film using $\mathrm{NH}_{4} \mathrm{HF}_{2}$. 


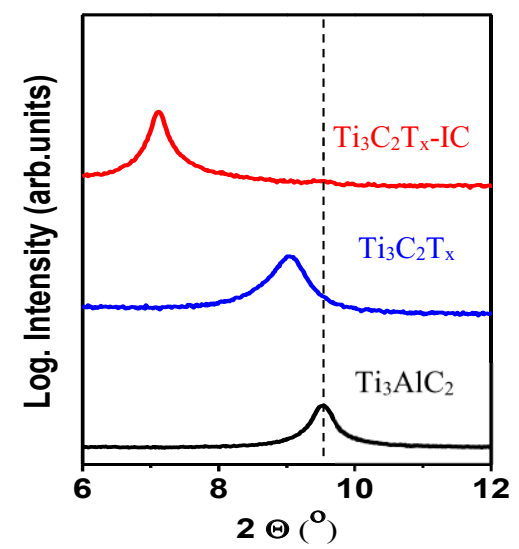

Figure 20. XRD patterns for thin films of $\mathrm{Ti}_{3} \mathrm{AlC}_{2}, \mathrm{Ti}_{3} \mathrm{C}_{2} \mathrm{~T}_{\mathrm{z}}$ and $\mathrm{Ti}_{3} \mathrm{C}_{2} \mathrm{~T}_{\mathrm{x}}-\mathrm{IC}$.

\subsection{X-ray Reflectivity (XRR)}

$\mathrm{X}$-ray reflectivity (XRR) is another non-destructive technique that is used to measure the thickness, roughness, and density of thin films [153]. XRR uses the same $\theta / 2 \theta$ configuration as for phase identification but is performed using parallel beams where beam divergence does not exceed $0.05^{\circ}$ compared to the wide angle beam used for phase identification. Moreover, the $\theta$ angle for XRR is much smaller ( 0 to $10^{\circ}$ ) compared to what is usually used for $\theta / 2 \theta$ scans. However, XRR has several limitations, including the inability to measure film thickness beyond $300 \mathrm{~nm}$. Thickness also cannot be measured for thin films with roughness exceeding $50 \mathrm{~nm}$. The technique itself does not work if there is no difference in electron density between thin film and substrate.

Because XRR is more concerned with the refracted beam, Bragg's law requires modification as follows:

$$
m \lambda=2 d \sin \theta \sqrt{1+\frac{\bar{n}^{2}-1}{\sin \theta^{2}}}
$$

where $m$ is an integer number representing the order of Kiessig fringe (Figure 19),

$\lambda$ is the wave length of the probing rays,

$\mathrm{d}$ is the film thickness,

$\theta$ is the angle at which $\mathrm{m}$ is, and

$\mathrm{n}$ is the refractive index.

The thickness can be deduced from plotting $\sin ^{2} \theta$ vs. $\mathrm{m}^{2}$ and obtaining the slope, then substituting in the following equation:

$$
d=\frac{\lambda}{2 \sqrt{\text { slope }}}
$$




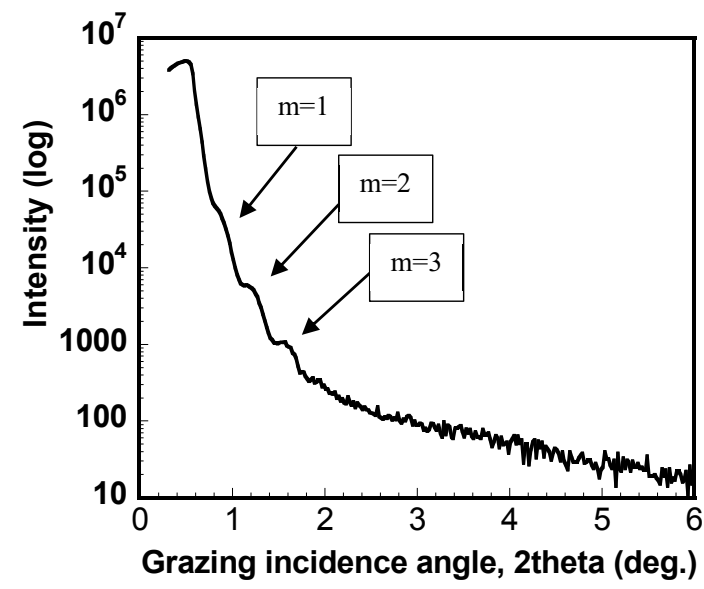

Figure 21. Typical XRR measurements for $\mathrm{Ti}_{3} \mathrm{AlC}_{2}$ thin film sputter-deposited for 10 min, resulting in a thickness of $28 \mathrm{~nm}$.

Figure 21, shows an example of the XRR measurements for a $28 \mathrm{~nm}$ thick $\mathrm{Ti}_{3} \mathrm{AlC}_{2}$ thin film deposited on a sapphire substrate.

\subsection{X-ray Photoelectron Spectroscopy (XPS)}

XPS is a surface sensitive technique used for compositional and chemical state analysis of material surfaces [154]. The basic principle of XPS is the knocking out of electrons from the core level of atoms via photons as shown in Figure 22. The electrons that manage to reach the detector without energy loss result in photoelectron peaks that represent their binding energy (BE). Each element in each specific chemical state has a characteristic binding energy, which is determined from the measured kinetic energy (KE) by the following equation [154]:

$$
\mathrm{BE}=\mathrm{h} v-\mathrm{KE}-\Phi
$$

where $\mathrm{h} v$ is the energy of the $\mathrm{x}$-ray photon,

$\Phi$ is the work function of the spectrometer.

Since the electrons that preserve their energy are the only ones that contribute to the XPS spectrum as peaks, these electrons can only be ejected from the surface of the sample; any electrons that are buried deep in the material would suffer from inelastic 
scattering and would lose energy before reaching the detector. For this reason, XPS analysis is limited to measuring the elemental composition down to 8 to $10 \mathrm{~nm}$ depth in the sample.
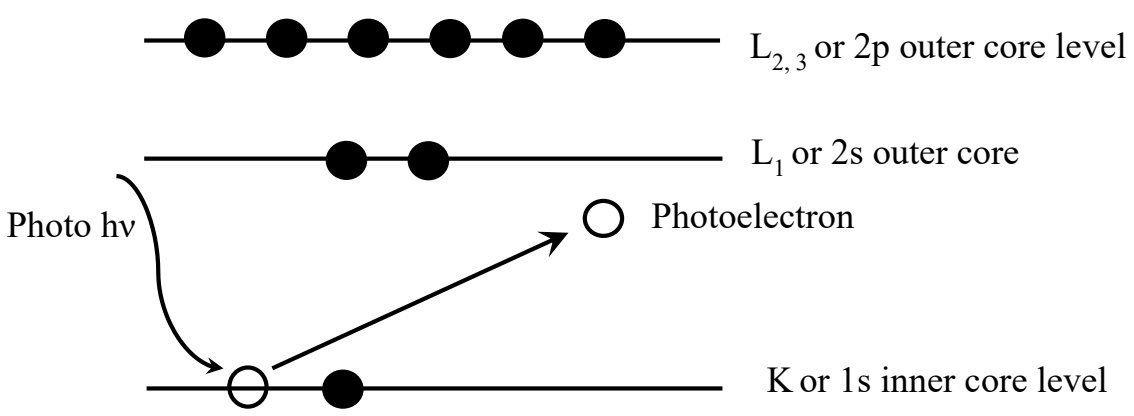

Figure 22. Schematic diagram showing the basic principle of the XPS technique.

For compositional analysis, the survey scans mode is used where the spectrum ranges are $1000 \mathrm{eV}$. However, for chemical state analysis, a high resolution mode is used where the spectrum window is narrower (about $100 \mathrm{eV}$ ), the scanning step is smaller and the time per step is longer than the survey scans.

Surface contamination can strongly affect the XPS results, since the technique is extremely surface sensitive. Thus, the samples have to be either meticulously stored under vacuum, or if that is not practically possible, $\mathrm{Ar}^{+}$sputtering can be used to clean the surface of the sample. However, care should be taken to avoid damage to the structure as well as sputter-inducing chemical changes. Figure 23 shows the effect of sputtering on the $\mathrm{C} 1 \mathrm{~s}$ core level of a $\mathrm{Ti}_{3} \mathrm{C}_{2} \mathrm{~T}_{\mathrm{z}}$ thin film. After sputtering, the BE of Ti-C peak at $282 \mathrm{eV}$ is shifted to higher binding energy, while the intensity of the $\mathrm{C}-\mathrm{C}$ peak at $285 \mathrm{eV}$ is decreased significantly and shifted to lower BE. Furthermore, the organic contamination peak at $289 \mathrm{eV}$ has disappeared after sputtering, indicating the removal of surface contaminations after $\mathrm{Ar}^{+}$sputtering. However, this causes the BE of the Ti-C peak to shift to higher values compared to before sputtering. 


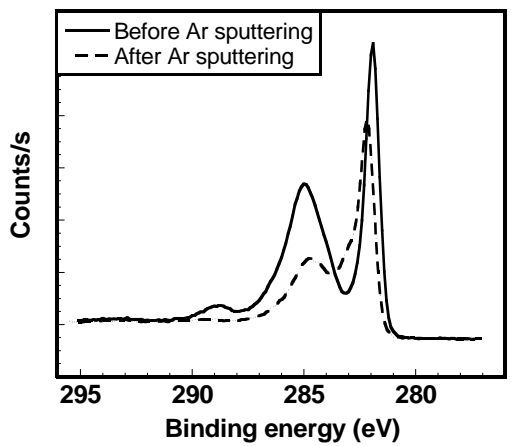

Figure 23. High resolution XPS spectra for $\mathrm{C} 1 \mathrm{~s}$ core level before and after sputtering for a $\mathrm{Ti}_{3} \mathrm{C}_{2} \mathrm{~T}_{\mathrm{Z}}$ thin film.

Besides obtaining information from the core level of the atoms, XPS can be used to determine the density of states (DOS) of the valence band. As expected, valence electrons have lower BE than core level electrons, as they are positioned further from the nucleus. Thus, the photoemissions from the valence electrons are located very close to the Fermi level since the valence band is usually at a $\mathrm{BE}$ in the range of 0 to 15 or even $25 \mathrm{eV}$.

In order to properly identify the chemical species of an element based upon on XPS spectra, calibration is essential. Such calibration can be done by calibrating with respect to the $\mathrm{BE}$ of a certain element, the most common is adventitious $\mathrm{C}$ [154]. However, this method is not accurate when $\mathrm{Ar}^{+}$sputtering is performed, as this species is removed and/or altered due to sputtering effects. The best method in that case, as in Papers I, III, IV, and VI, is to calibrate the XPS spectra with respect to the zero eV Fermi level.

In papers I, III, IV, and VI, XPS was used for compositional analysis, as well as for identification of chemical species through peak fitting of the high resolution spectra and obtaining the chemical formulae of MXenes including the surface termination groups.

More details regarding the XPS peak fitting, analysis and calculations of the amounts of surface terminations can be found in Refs. [32, 96].

\subsection{Electron Microscopy}

Electron microscopes use electrons, which have shorter wavelengths than visible light used in optical microscopy, as a probe. The main reason for using a source with shorter wavelength is to increase resolution and magnification, achieving a resolution of about $1 \AA$. 
A Transmission Electron Microscope (TEM) [155] depends on the transmission of an electron beam through a sample for imaging and acquiring microstructural information. Lattice imaging can be obtained using high-resolution TEM (HRTEM), which is useful for studying the crystal structure and defects at an atomic level. For the electron beam to be transmitted through the sample, the sample has to be quite thin, with thicknesses below $100 \mathrm{~nm}$. TEM and HRTEM were used in papers I, III, IV, and VI for microstructure investigation and atomic resolution imaging.

More information regarding the crystal structure and grain orientation can also be gathered by acquiring selected-area electron diffraction (SAED). SAED was used in papers I, III, and VI for obtaining the LPs of the crystalline regions and identifying if certain regions are crystalline or amorphous.

A scanning transmission electron microscope (STEM) focuses the electron beam into a narrow spot, which is rastered over the sample and the transmitted electrons form the image. Using both modes, the scanning and transmitting of electrons, it is possible to acquire atomic imaging. This technique was used in paper I to image the atomic structure of $\mathrm{Ti}_{3} \mathrm{C}_{2} \mathrm{~T}_{\mathrm{z}}$ thin films. With Electron Dispersive X-ray Spectroscopy (EDS), elemental mapping can be acquired in STEM and TEM.

\subsection{Ultraviolet-Visible Spectroscopy}

Ultraviolet-Visible Spectroscopy (UV-Vis) [156] measures the absorption of light in the visible and ultraviolet ranges by a sample. It measures the intensity of light, I, at a given wavelength after passing through the sample and compares it to the intensity of the original beam $\left(\mathrm{I}_{0}\right)$. The ratio $\mathrm{I} / \mathrm{I}_{\mathrm{o}}$ is called the transmittance and is usually expressed as percentage $(\% \mathrm{~T})$. Absorbance is the negative log of transmittance and is related through the Beer-Lamber-Bouguer Law. UV-Vis was used in paper III to obtain the transmittance for MAX and MXene thin films.

\subsection{Electrical Characterization}

\subsubsection{Four-point probe}

The four-point probe technique is usually used for measuring the electrical resistivity of thin films [157]. This technique consists of four equidistant probes that come in contact with the surface of the film, as shown in Figure 24. The current is applied through the outer two probes while the voltage between the two inner probes is measured. The value obtained is the sheet resistance $\left(R_{s}\right)$, which is the resistivity $(\rho)$ divided by the thickness of the film ( $\mathrm{t}$ ) and multiplied by a geometrical factor to account for the geometry of the 
sample measured. This technique was used to measure the resistivity of the MAX and MXene thin films in paper III.

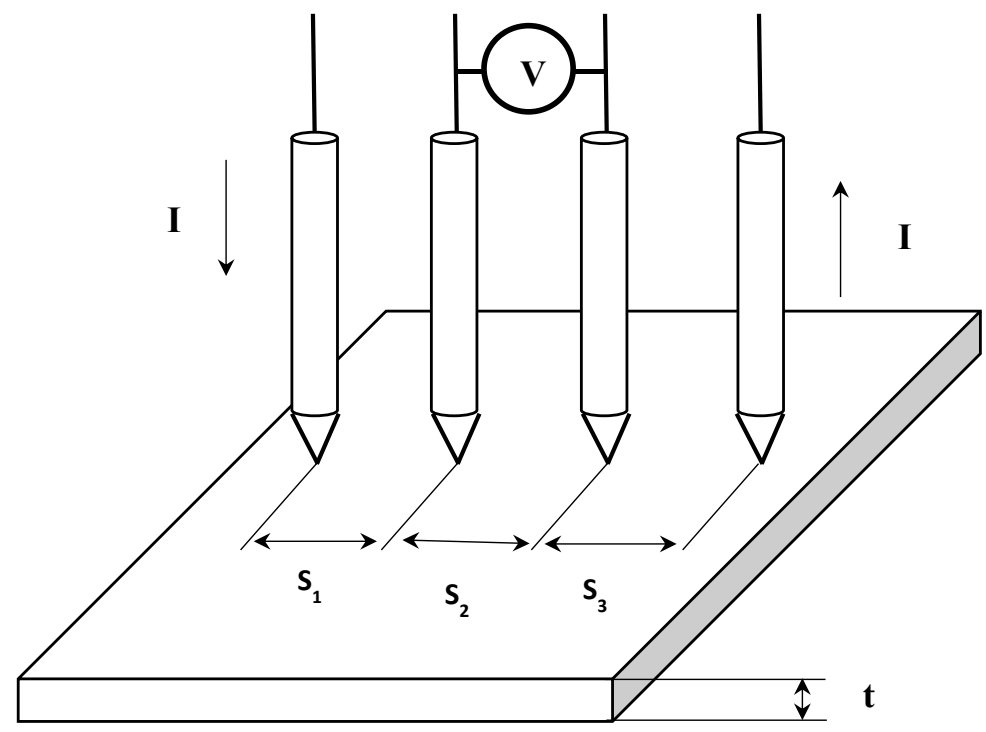

Figure 24. Schematic demonstrating the setup of the four-point probe technique.

\subsubsection{Physical Properties Measurement System (PPMS)}

PPMS is a system for measuring magneto-transport properties, such as: (1) temperature- dependent resistivity, $\rho$. The $\rho$ is measured as a function of temperature which in turn can be used to shed light on the electronic transport in materials. (2) Hall effect: When a magnetic field, $B$, is applied perpendicular to an applied current in a conductor, a potential difference $\left(\mathrm{R}_{\mathrm{H}}\right)$, which is perpendicular to both the applied current and $\mathrm{B}$, is created as a result of the deflection of charge carriers due to their interaction with B. In a single band model, the number of charge carriers and their mobility can be obtained from measuring the $\rho$ and $\mathrm{R}_{\mathrm{H}}$, since in this case the following equations can be used:

$$
\begin{gathered}
\rho=\frac{1}{\sigma}=e([\text { or or } p] \mu) \\
R_{H}=\frac{1}{e n}
\end{gathered}
$$

where $n$ is the number of electrons per unit volume,

$p$ is the number of holes per unit volume, and

$\mu$ is the mobility of such charge carrier. 
mechanisms such as weak localization, where the resistivity decreases with the application of a magnetic field, as in papers I and III.

\subsection{Electrochemical Characterization}

Electrochemical characterizations are used to evaluate the performance of materials for several applications such as batteries, supercapacitors, electrolysis (hydrogen evolution reaction and oxygen evolution reaction) and corrosion resistance. In paper IV, electrochemical characterization was used to evaluate the performance of $\mathrm{Mo}_{2} \mathrm{CT}_{\mathrm{z}}$ as electrodes for both Li-ion batteries and supercapacitors. In this section, I will focus on the characterization for these two applications.

\subsubsection{Li-ion Batteries}

The electrochemical characterization of a given material for Li-ion batteries is usually done by evaluating the behavior of such material as an electrode. In paper IV, the working electrode was a freestanding composite film of $\mathrm{Mo}_{2} \mathrm{CT}_{\mathrm{z}}$ and carbon nanotubes (CNTs). Stainless steel coin cells were assembled inside an Ar-filled glovebox. Li foil was used as a counter electrode. A separator of borosilicate glass fiber paper was used to prevent electrical shorting. The electrolyte used was $1.2 \mathrm{M} \mathrm{LiPF}_{6}$ in ethylene carbonate and dimethyl carbonate (in a mass ratio of 1:2, respectively).

Cyclic voltammetry (CV) was used to evaluate the performance of the working electrode as a Li-ion battery electrode, where the voltage is varied from a $3 \mathrm{~V}$ to $5 \mathrm{mV}$ at a given scanning rate, and the current is recorded. The electrodes are cycled several times between these two values to show the stability of the material. In addition to the $\mathrm{CV}$ measurements, galvanostatic cycling was also performed, where a constant current is applied through the cell and the voltage is recorded. This test helps to evaluate the charge and discharge rates. From both the $\mathrm{CV}$ and galvanostatic tests, the Coulombic efficiency and specific currents, a measure for the amount of charge can be plotted against the number of cycles from which the stability of the electrode can be assessed.

\subsubsection{Supercapacitors}

In batteries, the energy is produced via a chemical reaction that releases electrical current. The charge and discharge of batteries is slow, so they are efficient for storage of energy for long times and its slow release. However, in supercapacitors, the energy is stored electrostatically on the surface of the materials and usually does not involve chemical reactions. They can be charged and discharged quickly relative to batteries, thus having high power densities, and can last for significantly more cycles. However, the amount of charge that can be stored per unit mass is much smaller compared to Li-ion batteries. A three-electrode cell was used to characterize the electrochemical performance of $\mathrm{Mo}_{2} \mathrm{CT}_{\mathrm{z}}$ 
freestanding thin films as supercapacitor electrodes. The counter electrode used was activated carbon; the reference electrode was $\mathrm{Ag} / \mathrm{AgCl}$; the active electrode was a $\mathrm{Mo}_{2} \mathrm{CT}_{\mathrm{z}}$ freestanding thin film; the electrolyte used was $1 \mathrm{M} \mathrm{H}_{2} \mathrm{SO}_{4}$. As with $\mathrm{Li}$-ion battery testing, $\mathrm{CV}$ and galvanostatic measurements were performed to evaluate the materials' performance, stability after a large number of charge/discharge cycles and the capacitance at different scan rates. 



\section{SUMMARY AND CONTRIBUTION TO THE FIELD}

The aim of this thesis was to synthesize MXenes in forms that allow for the characterization of their electronic transport properties. The MXenes presented in this thesis have one of three forms: (1) Epitaxial thin films on sapphire substrate of $\mathrm{Ti}_{3} \mathrm{C}_{2} \mathrm{~T}_{\mathrm{z}}$ (paper I) and $\mathrm{Ti}_{2} \mathrm{CT}_{z}$ (paper III), (2) Single flakes of $\mathrm{Ti}_{3} \mathrm{C}_{2} \mathrm{~T}_{\mathrm{z}}$ on $\mathrm{SiO}_{2}$ (paper II), (3) Delaminated freestanding films of $\mathrm{Mo}_{2} \mathrm{CT}_{\mathrm{z}}$ (paper IV and V), $\mathrm{Mo}_{1.33} \mathrm{CT}_{\mathrm{z}}, \mathrm{Mo}_{2} \mathrm{TiC}_{2} \mathrm{~T}_{\mathrm{z}}$, $\mathrm{Mo}_{2} \mathrm{~T}_{2} \mathrm{C}_{3} \mathrm{~T}_{\mathrm{z}}$ (paper $\mathbf{V}$ ) and $\mathrm{Nb}_{1.33} \mathrm{CT}_{\mathrm{z}}$ (paper VI). Through electronic transport characterization, I was able to study the effect of various parameters, such as the number of MXene layers (thin film vs. single flake), stoichiometry $\left(\mathrm{Ti}_{2} \mathrm{CT}_{\mathrm{z}} \mathrm{vs} . \mathrm{Nb}_{2} \mathrm{CT}_{\mathrm{z}}\right), \mathrm{M}$ element composition (Ti-, Nb- and Mo-based MXenes) and vacancies $\left(\mathrm{Nb}_{1.33} \mathrm{CT}_{\mathrm{z}}\right)$. It is worth noting that before the start of this work, there were no experimental studies published on thin film MXenes or the electronic transport properties of MXenes.

The first step of my study was to synthesize the most common and widely researched MXene, $\mathrm{Ti}_{3} \mathrm{C}_{2} \mathrm{~T}_{\mathrm{z}}$, in thin film form and measure its transport properties. This was done in paper $I$, where epitaxial $\mathrm{Ti}_{3} \mathrm{C}_{2} \mathrm{~T}_{\mathrm{x}}$ thin films were produced from etching magnetron sputter deposited epitaxial $\mathrm{Ti}_{3} \mathrm{AlC}_{2}$ thin films on sapphire substrates using two different etchants, $\mathrm{HF}$ and $\mathrm{NH}_{4} \mathrm{HF}_{2}$. The $\mathrm{Ti}_{3} \mathrm{C}_{2} \mathrm{~T}_{\mathrm{z}}$ films produced by $\mathrm{NH}_{4} \mathrm{HF}_{2}$ etching showed an increase of about $25 \%$ in the $c$ lattice parameter compared to their counterparts that were produced by HF etching. According to the XPS analysis, this significant increase is due to the intercalation of $\mathrm{NH}_{4}{ }^{+}$and $\mathrm{NH}_{3}$ species.

Looking at the electronic transport properties, the $\mathrm{Ti}_{3} \mathrm{C}_{2} \mathrm{~T}_{\mathrm{z}}$ epitaxial thin films were found to be metallic-like conductors at room temperature and down to $100 \mathrm{~K}$, as the $\rho$ decreases with decreasing temperature. Below that temperature, the films' $\rho$ increases with decreasing temperature. This behavior is due to weak localization, which is characteristic of defective 2D materials. MR measurements show a decrease in $\rho$ of such films with increasing magnetic field, again due to weak localization. The films show high transparency - 90\% - in the visible-to-infrared range for films of $19 \mathrm{~nm}$ thick etched by $\mathrm{NH}_{4} \mathrm{HF}_{2}$. These $\mathrm{Ti}_{3} \mathrm{C}_{2} \mathrm{~T}_{\mathrm{z}}$ thin films demonstrated the possibility of using them as transparent conductive electrodes.

To answer the fundamental question of whether MXenes are inherently 2D materials or if their electronic properties are thickness-dependent required the synthesis and isolation of single flakes of $\mathrm{Ti}_{3} \mathrm{C}_{2} \mathrm{~T}_{\mathrm{z}}$ and measuring their transport properties and 
comparing them with those of $\mathrm{ML} \mathrm{Ti}_{3} \mathrm{C}_{2} \mathrm{~T}_{\mathrm{z}}$ thin films previously mentioned. In order for the electronic transport properties for a single flake to be measured, it must have a lateral size of more than $10 \mu \mathrm{m}$. The average flake size produced using either HF etching followed by $\mathrm{DMSO}$ intercalation or with $\mathrm{LiF}+\mathrm{HCl}$ was about 1 to $2 \mu \mathrm{m}$. In order to increase the flake size to the desired dimensions, I started by increasing the grain size of the precursor $\mathrm{Ti}_{3} \mathrm{AlC}_{2}$ phase from about $30 \mu \mathrm{m}$ to about $70 \mu \mathrm{m}$ by changing the synthesis method from pressureless sintering to HIP. In the former, it is not possible to increase the grain size by increasing the heating time, as $\mathrm{TiC}$ would start to precipitate at the grain boundaries and, in turn, suppress grain growth. However, using HIP, the precipitation of TiC was suppressed, and grain coarsening occurred. By etching the HIP-produced $\mathrm{Ti}_{3} \mathrm{AlC}_{2}$ using $\mathrm{LiF}+\mathrm{HCl}$, MLs of lateral sizes $\approx 20 \mu \mathrm{m}$ were produced. The MLs were manually shaken in water to obtain single flakes through delamination. This resulted in flakes with lateral dimensions of $>10 \mu \mathrm{m}$, as shown in paper II. It is worth noting that the etching procedure was modified from the original reported in Ref. [97] by washing the etched solution with $1 \mathrm{M} \mathrm{HCl}$ followed by $1 \mathrm{M} \mathrm{LiCl}$, solution to remove remaining LiF.

The transport measurements of the single flakes showed them to be metallic with a room temperature $\rho$ of $10 \mu \Omega \mathrm{m}$. The density of free carriers was calculated to be about $8 \times 10^{21} \mathrm{~cm}^{-3}$, while their mobility was estimated to be $0.7 \mathrm{~cm}^{2} / \mathrm{Vs}$. The resistivity of the single $\mathrm{Ti}_{3} \mathrm{C}_{2} \mathrm{~T}_{\mathrm{z}}$ flakes appeared to be five times higher than that of a $75 \mathrm{~nm}$ thick $\mathrm{Ti}_{3} \mathrm{C}_{2} \mathrm{~T}_{\mathrm{z}}$ film, which showed the lowest $\rho$ value among all $\mathrm{Ti}_{3} \mathrm{C}_{2} \mathrm{~T}_{\mathrm{z}}$ thin films measured in paper I. However, in later reports, the $\rho$ of $\mathrm{Ti}_{3} \mathrm{C}_{2} \mathrm{~T}_{\mathrm{z}}$ single flake was found to be about $2.2 \mu \Omega \mathrm{m}$, a value similar to that of the best $\mathrm{Ti}_{3} \mathrm{C}_{2} \mathrm{~T}_{\mathrm{z}}$ thin films [158]. The same study reported an increase in $\rho$ when the single flakes were subjected to oxygen or air with relative humidity of $50 \%$. This would explain the high $\rho$ value for the single flake in paper II. Because the flakes were deposited from a colloidal aqueous suspension, if some adsorbate molecules of oxygen or water did not desorb while vacuum annealing, this would lead to an increase in $\rho$.

The effect of the stoichiometry of MXenes on the electronic transport properties is manifested in the comparison of the transport properties between $\mathrm{Ti}_{3} \mathrm{C}_{2} \mathrm{~T}_{\mathrm{Z}}$ (paper I) and $\mathrm{Ti}_{2} \mathrm{CT}_{\mathrm{z}}$ (paper III). The latter follows the same behavior as $\mathrm{Ti}_{3} \mathrm{C}_{2} \mathrm{~T}_{\mathrm{z}}$ thin films, i.e. metallic behavior from RT down to about $40 \mathrm{~K}$, followed by weak localization from 40 $\mathrm{K}$ to $10 \mathrm{~K}$. The RT $\rho$ increases twofold when the stoichiometry, or $n$, is reduced from 2 to 1 for the same film thickness - for $\mathrm{Ti}_{3} \mathrm{C}_{2} \mathrm{~T}_{\mathrm{z}}$ it is $2.3 \mu \Omega \mathrm{m}$ and for $\mathrm{Ti}_{2} \mathrm{CT}_{\mathrm{z}}$ it is $4.4 \mu \Omega \mathrm{m}$. This increase in $\rho$ is most likely due to the absence of a Ti-C core; $\mathrm{Ti}_{3} \mathrm{C}_{2} \mathrm{~T}_{\mathrm{Z}}$ has an extra Ti layer in the center of the Ti-C blocks that is not bonded to surface terminations. However, in $\mathrm{Ti}_{2} \mathrm{CT}_{\mathrm{z}}$, all $\mathrm{Ti}$ layers are bonded to surface terminations. Since the surface termination groups $(-\mathrm{O},-\mathrm{OH}$, and/or $-\mathrm{F})$ are mostly electron acceptors, it is not too 
surprising that $\mathrm{Ti}_{2} \mathrm{CT}_{\mathrm{z}}$ is more resistive. Thus, while decreasing $\mathrm{n}$ for $\mathrm{Ti}_{\mathrm{n}+1} \mathrm{C}_{\mathrm{n}} \mathrm{T}_{\mathrm{z}}$ increased $\rho$, it did not alter the electronic transport mechanism.

In contradistinction, changing the transition metal $\mathrm{M}$, from $\mathrm{Ti}$ in $\mathrm{Ti}_{2} \mathrm{CT}_{\mathrm{z}}$ to $\mathrm{Nb}$ in $\mathrm{Nb}_{2} \mathrm{CT}_{\mathrm{z}}$ epitaxial thin films (paper III) and to $\mathrm{Mo}$ in $\mathrm{Mo}_{2} \mathrm{CT}_{\mathrm{z}}$ in delaminated free-standing thin films (paper IV), obtained from vacuum filtration of a colloidal suspension resulted in a change in transport mechanism. The resistivity-dependent temperature measurements for $\mathrm{Nb}_{2} \mathrm{CT}_{\mathrm{z}}$ and $\mathrm{Mo}_{2} \mathrm{CT}_{\mathrm{z}}$ show an increase in resistivity with decreasing temperature from RT to about $20 \mathrm{~K}$. This behavior was found to be more consistent with variable range hopping (VRH) models. The reason for the different transport behavior of $\mathrm{Ti}_{2} \mathrm{CT}_{\mathrm{z}}$ compared to $\mathrm{Nb}_{2} \mathrm{CT}_{\mathrm{z}}$ and $\mathrm{Mo}_{2} \mathrm{CT}_{\mathrm{z}}$ might be due to the interaction between the $\mathrm{M}$ metal and the surface termination groups, in addition to disorder from the increase in the interlayer distance due to water or cation intercalation. However, the exact reason is not understood at the moment.

The VRH mechanisms evaluated for $\mathrm{Mo}_{2} \mathrm{CT}_{\mathrm{z}}$ (paper IV) were shown to take place at temperatures below $100 \mathrm{~K}$. However, the transport mechanism from $100 \mathrm{~K}$ to RT was not clearly understood. Therefore, paper $\mathbf{V}$ was dedicated to understanding the transport mechanism more thoroughly for Mo-based MXenes. This included four compounds: $\mathrm{Mo}_{2} \mathrm{Ti}_{2} \mathrm{C}_{3} \mathrm{~T}_{\mathrm{z}}, \mathrm{Mo}_{2} \mathrm{TiC}_{2} \mathrm{~T}_{\mathrm{z}}, \mathrm{Mo}_{2} \mathrm{CT}_{\mathrm{z}}$, and $\mathrm{Mo}_{1.333} \mathrm{CT}_{\mathrm{z}}$ (the latter with ordered vacancies). The compounds studied were in the form of delaminated free-standing thin films. From the $\rho$ vs. T measurements, several points were evident: (1) for all samples, $\rho$ increased with decreasing temperature, (2) $\mathrm{Mo}_{2} \mathrm{CT}_{z}$, before annealing, was the least conductive, followed by $\mathrm{Mo}_{1.33} \mathrm{CT}_{\mathrm{z}}$, then $\mathrm{Mo}_{2} \mathrm{TiC}_{2} \mathrm{~T}_{\mathrm{z}}$, and finally, $\mathrm{Mo}_{2} \mathrm{Ti}_{2} \mathrm{C}_{3} \mathrm{~T}_{\mathrm{z}}$ with the highest conductivity, (3) $\rho$ for $\mathrm{Mo}_{2} \mathrm{C}$ increased exponentially with increasing interlayer distance, which is half the $c$-lattice parameter, and (4) Conductivity is enhanced dramatically with increasing annealing temperatures.

The analysis of the $\rho$ vs. T data suggests that there are two transport mechanisms operating in parallel. At high temperatures, $200 \mathrm{~K}$ to RT, a thermally activated process is dominant for all the compounds. This might be due to some extended energy states located far from $\mathrm{E}_{\mathrm{f}}$ that would only contribute to the conductivity at high temperatures. At temperatures $<200 \mathrm{~K}$, all the compounds except $\mathrm{Mo}_{1.33} \mathrm{CT}_{\mathrm{z}}$ exhibit conductivity that is consistent with VRH between individual MXene sheets. As for $\mathrm{Mo}_{1.33} \mathrm{CT}_{\mathrm{z}}$, it is more likely that VRH within the individual flakes is the dominant mechanism. This might be because of the presence of defects inside the flake itself, due to the ordered vacancies, as compared to the other compounds.

MXenes with ordered vacancies have shown promise for several applications such as electrodes for supercapacitors and Hydrogen Evolution Reactions (HER) via water electrolysis, even surpassing the performance of their respective non-vacancy 
compounds, such as in the case of $\mathrm{Mo}_{2} \mathrm{CT}_{\mathrm{z}}$ vs. $\mathrm{Mo}_{1.33} \mathrm{CT}_{\mathrm{z}}$. The latter shows $65 \%$ higher volumetric capacitance when used as an electrode for supercapacitors as compared to $\mathrm{Mo}_{2} \mathrm{CT}_{\mathrm{z}}$ [37]. As stated in Chapter 2, not all quaternary MAX phases can serve as precursors for MXenes with ordered vacancies, and this restricts the synthesis of such MXenes to a few compounds. In paper VI, I explore another method that can extend the family of MXenes with vacancies. I selected $\mathrm{Nb}_{2} \mathrm{C}$ as a proof of concept, taking its precursor, $\mathrm{Nb}_{2} \mathrm{AlC}$, and allowing $1 / 3$ of $\mathrm{Sc}$ on the $\mathrm{M}$ site, forming a $\left(\mathrm{Nb}_{2 / 3}, \mathrm{Sc}_{1 / 3}\right)_{2} \mathrm{AlC}$ solid solution. Etching both the $\mathrm{Sc}$ and $\mathrm{Al}$ produces a MXene, $\mathrm{Nb}_{1.33} \mathrm{CT}_{\mathrm{z}}$, with randomly distributed vacancies. Such a method may be applied to any quaternary MAX phase having solid solution alloying on the $\mathrm{M}$ site, where the minority $\mathrm{M}$ element, that occupies $1 / 3$ of the M position, is more chemically reactive towards HF compared to the other. In other words, its M-C bonds are weaker than those of majority M element. Alloying with $\mathrm{Sc}$ has also led to a decrease of the etching time from $100 \mathrm{~h}$ for $\mathrm{Nb}_{2} \mathrm{AlC}$ to only $30 \mathrm{~h}$ for $\left(\mathrm{Nb}_{2 / 3}, \mathrm{Sc}_{1 / 3}\right)_{2} \mathrm{AlC}$. The electronic transport properties of the freestanding $\mathrm{Nb}_{1.33} \mathrm{CT}_{\mathrm{z}}$ thin film appear to follow VRH models.

In summary, the findings included in this thesis shed valuable light on understanding electronic transport in MXenes, in the form of epitaxial thin films, single flakes and free standing delaminated thin films. In addition, a new method was developed to produce MXenes with random vacancies. Moreover, these results open the door for the use of MXenes in electronic, photonic, and sensing applications. 


\section{REFERENCES}

1. Novoselov, K. S.; Geim, A. K.; Morozov, S. V.; Jiang, D.; Zhang, Y.; Dubonos, S. V.; Grigorieva, I. V.; Firsov, A. A. Science 2004, 306, 666.

2. Brodie, B. C., Philos. Trans. R. Soc. Lond. 1859, 149, 249.

3. Joensen, P.; Frindt, R. F.; Morrison, S. R., Mater. Res. Bull. 1986, $21,457$.

4. Geim, A. K.; Novoselov, K. S., Nat. Mater. 2007, 6, 183

5. Bianco, A.; Cheng, H.-M.; Enoki, T.; Gogotsi, Y.; Hurt, R. H.; Koratkar, N.; Kyotani, T.; Monthioux, M.; Park, C. R.; Tascon, J. M. D.; Zhang, J. Carbon 2013, 65,1 .

6. Nair, R. R.; Blake, P.; Grigorenko, A. N.; Novoselov, K. S.; Booth, T. J.; Stauber, T.; Peres, N. M.; Geim, A. K. Science 2008, 320, 1308.

7. Novoselov, K. S.; Fal'ko, V. I.; Colombo, L.; Gellert, P. R.; Schwab, M. G.; Kim, K. Nature 2012, 490, 192.

8. Lin, Y. M.; Dimitrakopoulos, C.; Jenkins, K. A.; Farmer, D. B.; Chiu, H. Y.; Grill, A.; Avouris, P. Science 2010, 327, 662.

9. Eda, G.; Fanchini, G.; Chhowalla, M., Nat. Nanotechnol. 2008, 3, 270.

10. Kobayashi, T.; Bando, M.; Kimura, N.; Shimizu, K.; Kadono, K.; Umezu, N.; Miyahara, K.; Hayazaki, S.; Nagai, S.; Mizuguchi, Y.; Murakami, Y.; Hobara, D. Appl. Phys. Lett. 2013, 102, 023112.

11. Bonaccorso, F.; Sun, Z.; Hasan, T.; Ferrari, A. C., Graphene photonics and optoelectronics. Nat. Photon 2010, 4, 611.

12. European Graphene Flagship. http://graphene-flagship.eu/.

13. Ribeiro-Soares, J.; Dresselhaus, M. S. Braz. J. Phys. 2014, 44, 278.

14. Son, I. H.; Park, J. H.; Park, S.; Park, K.; Han, S.; Shin, J.; Doo, S.-G.; Hwang, Y.; Chang, H.; Choi, J. W. Nat. commun. 2017, 8, 1561.

15. Zhang, Y.-H.; Zhou, K.-G.; Xie, K.-F.; Zeng, J.; Zhang, H.-L.; Peng, Y. Nanotechnology 2010, $21,065201$.

16. Yan, L.; Zheng, Y. B.; Zhao, F.; Li, S.; Gao, X.; Xu, B.; Weiss, P. S.; Zhao, Y. Chem. Soc. Rev. 2012, 41, 97.

17. Banhart, F.; Kotakoski, J.; Krasheninnikov, A. V. ACS Nano 2010, 5, 26.

18. Boukhvalov, D.; Katsnelson, M. Nano Lett. 2008, 8, 4373.

19. Zhang, Y.-H.; Chen, Y.-B.; Zhou, K.-G.; Liu, C.-H.; Zeng, J.; Zhang, H.-L.; Peng, Y. Nanotechnology 2009, 20, 185504.

20. Pacilé, D.; Meyer, J. C.; Girit, C. O.; Zettl, A. Appl. Phys. Lett. 2008, 92, 133107.

21. Ma, R.; Sasaki, T. Adv. Mater. 2010, 22, 5082. 
22. Coleman, J. N.; Lotya, M.; O'Neill, A.; Bergin, S. D.; King, P. J.; Khan, U.; Young, K.; Gaucher, A.; De, S.; Smith, R. J.; Shvets, I. V.; Arora, S. K.; Stanton, G.; Kim, H. Y.; Lee, K.; Kim, G. T.; Duesberg, G. S.; Hallam, T.; Boland, J. J.; Wang, J. J.; Donegan, J. F.; Grunlan, J. C.; Moriarty, G.; Shmeliov, A.; Nicholls, R. J.; Perkins, J. M.; Grieveson, E. M.; Theuwissen, K.; McComb, D. W.; Nellist, P. D.; Nicolosi, V. Science 2011, 331, 568.

23. Naguib, M.; Halim, J.; Lu, J.; Cook, K. M.; Hultman, L.; Gogotsi, Y.; Barsoum, M. W. J. Am. Chem. Soc. 2013, 135, 15966.

24. Naguib, M.; Kurtoglu, M.; Presser, V.; Lu, J.; Niu, J.; Heon, M.; Hultman, L.; Gogotsi, Y.; Barsoum, M. W. Adv. Mater. 2011, 23, 4248.

25. Naguib, M.; Mashtalir, O.; Carle, J.; Presser, V.; Lu, J.; Hultman, L.; Gogotsi, Y.; Barsoum, M. W. ACS Nano 2012, 6, 1322.

26. Naguib, M.; Mochalin, V. N.; Barsoum, M. W.; Gogotsi, Y. Adv. Mater. 2014, 26, 992.

27. Urbankowski, P.; Anasori, B.; Makaryan, T.; Er, D.; Kota, S.; Walsh, P. L.; Zhao, M.; Shenoy, V. B.; Barsoum, M. W.; Gogotsi, Y. Nanoscale 2016, 8, 11385.

28. Bertolazzi, S.; Krasnozhon, D.; Kis, A. ACS Nano 2013, 7, 3246.

29. Barsoum, M. W., MAX Phases: Properties of Machinable Ternary Carbides and Nitrides. John Wiley \& Sons 2013.

30. Alhabeb, M.; Maleski, K.; Mathis, T. S.; Sarycheva, A.; Hatter, C. B.; Uzun, S.; Levitt, A.; Gogotsi, Y. Angew. Chem. Int. Ed. 2018, 57, 54444.

31. Meshkian, R.; Näslund, L.-Å.; Halim, J.; Lu, J.; Barsoum, M. W.; Rosen, J. Scr. Mater. 2015, 108, 147.

32. Halim, J.; Cook, K. M.; Naguib, M.; Eklund, P.; Gogotsi, Y.; Rosen, J.; Barsoum, M. W. Appl. Surf. Sci. 2016, 362, 406.

33. Hope, M. A.; Forse, A. C.; Griffith, K. J.; Lukatskaya, M. R.; Ghidiu, M.; Gogotsi, Y.; Grey, C. P. Phys. Chem. Chem. Phys. 2016, 18, 5099.

34. Barsoum, M. W.; El-Raghy, T. Am. Sci. 2001, 89, 334.

35. Ingason, A. S.; Mockute, A.; Dahlqvist, M.; Magnus, F.; Olafsson, S.; Arnalds, U. B.; Alling, B.; Abrikosov, I. A.; Hjörvarsson, B.; Persson, P. O. Å.; Rosen, J. Phys. Rev. Lett. 2013, 110, 195502.

36. Kuchida, S.; Muranaka, T.; Kawashima, K.; Inoue, K.; Yoshikawa, M.; Akimitsu, J. Physica C: Superconductivity 2013, 494, 77.

37. Tao, Q.; Dahlqvist, M.; Lu, J.; Kota, S.; Meshkian, R.; Halim, J.; Palisaitis, J.; Hultman, L.; Barsoum, M. W.; Persson, P. O.; Rosen, J. Nat. commun. 2017, 8, 14949.

38. Persson, I.; El Ghazaly, A.; Tao, Q.; Halim, J.; Kota, S.; Darakchieva, V.; Palisaitis, J.; Barsoum, M. W.; Rosen, J.; Persson, P. O. Small 2018, 14, 1703676. 
39. Meshkian, R.; Dahlqvist, M.; Lu, J.; Wickman, B.; Halim, J.; Thörnberg, J.; Tao, Q.; Li, S.; Intikhab, S.; Snyder, J.; Barsoum, M. W.; Yildizhan, M.; Palisaitis, J.; Hultman, L.; Persson, P. O.; Rosen, J. Adv. Mater. 2018, 30, 1706409.

40. Anasori, B.; Halim, J.; Lu, J.; Voigt, C. A.; Hultman, L.; Barsoum, M. W. Scr. Mater. 2015, 101, 5.

41. Anasori, B.; Dahlqvist, M.; Halim, J.; Moon, E. J.; Lu, J.; Hosler, B. C.; El'ad, N. C.; May, S. J.; Hultman, L.; Eklund, P.; Rosen J.; M.W. Barsoum J. Appl. Phys. 2015, $118,094304$.

42. Eklund, P.; Beckers, M.; Jansson, U.; Högberg, H.; Hultman, L. Thin Solid Films 2010, 518, 1851.

43. Barsoum, M. W. Prog. Solid State Chem. 2000, 28, 201-281.

44. Naguib, M.; Bentzel, G.; Shah, J.; Halim, J.; Caspi, E.; Lu, J.; Hultman, L.; Barsoum, M. M. R. L. 2014, 2, 1

45. Dubois, S.; Bei, G. P.; Tromas, C.; Gauthier-Brunet, V.; Gadaud, P. Int. J. Appl. Ceram. Technol. 2010, 7, 719.

46. Radovic, M.; Ganguly, A.; Barsoum, M. J. Mater. Res. 2008, 23, 1517.

47. Dahlqvist, M.; Petruhins, A.; Lu, J.; Hultman, L.; Rosen, J. ACS Nano 2018, 12, 7761.

48. Hu, C.; Lai, C.-C.; Tao, Q.; Lu, J.; Halim, J.; Sun, L.; Zhang, J.; Yang, J.; Anasori, B.; Wang, J. Chem. Commun. (Cambridge, U. K.) 2015, 51, 6560.

49. Sato, K.; Mishra, M.; Hirano, H.; Hu, C.; Sakka, Y. J. Am. Ceram. Soc. 2014, 97, 1407.

50. Zhu, J.; Mei, B.; Liu, J.; Xu, X. J. Mater. Sci. Lett. 2003, 22, 1111.

51. Tzenov, N. V.; Barsoum, M. W. J. Am. Ceram. Soc. 2000, 83, 825.

52. Łopaciński, M.; Puszynski, J.; Lis, J. J. Am. Ceram. Soc. 2001, 84, 3051.

53. Zou, Y.; Sun, Z. M.; Tada, S.; Hashimoto, H., Mater. Res. Bull. 2008, 43, 968.

54. Wang, X.; Zhou, Y., J. Mater. Chem. 2002, 12, 455.

55. Wang, Q.; Hu, C.; Cai, S.; Sakka, Y.; Grasso, S.; Huang, Q., Int. J. Appl. Ceram. Technol. 2014, 11, 911.

56. Hamm, C. M.; Schäfer, T.; Zhang, H.; Birkel, C. S. Z. Anorg. Allg. Chem. 2016, 642, 1397.

57. Barsoum, M. W., Fundamentals of ceramics. CRC Press: 2002.

58. Barsoum, M. W.; El-Raghy, T. J. Am. Ceram. Soc. 1996, 79, 1956.

59. Martin, P. M., Handbook of deposition technologies for films and coatings: science, applications and technology. William Andrew: 2009.

60. Sigmund, P. Physical review 1969, 184, 383.

61. O'Hanlon, J. F., A user's guide to vacuum technology. John Wiley \& Sons: 2005.

62. Kelly, P. J.; Arnell, R. D. Vacuum 2000, 56, 159.

63. Greene, J.; Sundgren, J. E.; Hultman, L.; Petrov, I.; Bergstrom, D. Appl. Phys. Lett. 1995, 67, 2928. 
64. Thornton, J. A. J.V.S.T. 1974, 11, 666.

65. Sun, Z.; Zhou, Y.; Li, M. Corros. Sci. 2001, 43, 1095.

66. Zhen, T.; Barsoum, M.; Kalidindi, S.; Radovic, M.; Sun, Z.; El-Raghy, T. Acta Mater. 2005, 53, 4963.

67. Wang, X.; Zhou, Y. Corros. Sci. 2003, 45, 891.

68. Qian, X.; He, X.; Li, Y.; Sun, Y.; Li, H.; Xu, D. Corros. Sci. 2011, 53, 290.

69. Barsoum, M.; Farber, L.; El-Raghy, T. Metall. Mater. Trans. A 1999, 30, 1727.

70. Singh, V.; Joung, D.; Zhai, L.; Das, S.; Khondaker, S. I.; Seal, S. Prog. Mater. Sci. 2011, 56, 1178.

71. Magnuson, M.; Palmquist, J. P.; Mattesini, M.; Li, S.; Ahuja, R.; Eriksson, O.; Emmerlich, J.; Wilhelmsson, O.; Eklund, P.; Högberg, H.; Hultman, L.; Jansson, U. Phys. Rev. B 2005, 72, 245101.

72. Wang, X. H.; Zhou, Y. C. Journal of Materials Science \& Technology 2010, 26, 385.

73. Gogotsi, Y.; Nikitin, A.; Ye, H.; Zhou, W.; Fischer, J. E.; Yi, B.; Foley, H. C.; Barsoum, M. W. Nat. Mater. 2003, 2, 591.

74. Yushin, G.; Hoffman, E.; Nikitin, A.; Ye, H.; Barsoum, M.; Gogotsi, Y. Carbon 2005, 43, 2075.

75. Yushin, G.; Hoffman, E. N.; Barsoum, M. W.; Gogotsi, Y.; Howell, C. A.; Sandeman, S. R.; Phillips, G. J.; Lloyd, A. W.; Mikhalovsky, S. V. Biomaterials 2006, 27, 5755.

76. Zhou, J.; Zha, X.; Chen, F. Y.; Ye, Q.; Eklund, P.; Du, S.; Huang, Q. Angew. Chem. Int. Ed. 2016, 55, 5008.

77. Zhou, J.; Zha, X.; Zhou, X.; Chen, F.; Gao, G.; Wang, S.; Shen, C.; Chen, T.; Zhi, C.; Eklund, P. ACS Nano 2017, 11, 3841.

78. Ghidiu, M.; Naguib, M.; Shi, C.; Mashtalir, O.; Pan, L.; Zhang, B.; Yang, J.; Gogotsi, Y.; Billinge, S. J. L.; Barsoum, M. W. Chem. Commun. (Cambridge, U. K.) 2014, 50, 9517.

79. Tran, M. H.; Schäfer, T.; Shahraei, A.; Dürrschnabel, M.; Molina-Luna, L.; Kramm,U. I.; Birkel, C. S. ACS Applied Energy Materials 2018, 1, 3908.

80. Yang, J.; Naguib, M.; Ghidiu, M.; Pan, L.-M.; Gu, J.; Nanda, J.; Halim, J.; Gogotsi, Y.; Barsoum, M. W. J. Am. Ceram. Soc. 2015, 99, 660.

81. Anasori, B.; Xie, Y.; Beidaghi, M.; Lu, J.; Hosler, B. C.; Hultman, L.; Kent, P. R.; Gogotsi, Y.; Barsoum, M. W. ACS Nano 2015, 10, 9507.

82. Mashtalir, O.; Naguib, M.; Dyatkin, B.; Gogotsi, Y.; Barsoum, M. W. Mater. Chem. Phys. 2013, 139, 147.

83. Sun, Z.; Li, S.; Ahuja, R.; Schneider, J. M. Solid State Commun. 2004, 129, 589.

84. Khazaei, M.; Ranjbar, A.; Esfarjani, K.; Bogdanovski, D.; Dronskowski, R.; Yunoki, S. Phys. Chem. Chem. Phys. 2018, 20, 8579. 
85. Peng, C.; Wei, P.; Chen, X.; Zhang, Y.; Zhu, F.; Cao, Y.; Wang, H.; Yu, H.; Peng, F. Ceram. Int. 2018, 44, 18886.

86. Li, T.; Yao, L.; Liu, Q.; Gu, J.; Luo, R.; Li, J.; Yan, X.; Wang, W.; Liu, P.; Chen, B. Angew. Chem. Int. Ed. 2018, 57, 6115.

87. Walker, G.; Garrett, W. Science 1967, 156, 385.

88. Ledoux, R. L.; White, J. L. J. Colloid Interface Sci. 1966, 21, 127.

89. Viculis, L. M.; Mack, J. J.; Mayer, O. M.; Hahn, H. T.; Kaner, R. B. J. Mater. Chem. 2005, 15, 974.

90. Eda, G.; Yamaguchi, H.; Voiry, D.; Fujita, T.; Chen, M.; Chhowalla, M. Nano Lett. 2011, 11, 5111.

91. Mashtalir, O.; Naguib, M.; Mochalin, V. N.; Dall'Agnese, Y.; Heon, M.; Barsoum, M. W.; Gogotsi, Y. Nat. commun. 2013, 4, 1716.

92. Naguib, M.; Unocic, R. R.; Armstrong, B. L.; Nanda, J. Dalton Trans. 2015, 44, 9353.

93. Alhabeb, M.; Maleski, K.; Anasori, B.; Lelyukh, P.; Clark, L.; Sin, S.; Gogotsi, Y. Chem. Mater. 2017, 29, 7633.

94. Qin, Y.; Wang, Z.; Liu, N.; Sun, Y.; Han, D.; Liu, Y.; Niu, L.; Kang, Z., Nanoscale 2018, 10, 14000.

95. Mashtalir, O.; Lukatskaya, M. R.; Zhao, M. Q.; Barsoum, M. W.; Gogotsi, Y. Adv. Mater. 2015, 27, 3501.

96. Halim, J. An X-Ray Photoelectron Spectroscopy Study of Multilayered Transition Metal Carbides (MXenes). Drexel University, 2016.

97. Ghidiu, M.; Lukatskaya, M. R.; Zhao, M. Q.; Gogotsi, Y.; Barsoum, M. W. Nature 2014, 516, 78 .

98. Lukatskaya, M. R.; Mashtalir, O.; Ren, C. E.; Dall'Agnese, Y.; Rozier, P.; Taberna, P. L.; Naguib, M.; Simon, P.; Barsoum, M. W.; Gogotsi, Y. Science 2013, 341, 1502.

99. Ghidiu, M.; Kota, S.; Halim, J.; Sherwood, A. W.; Nedfors, N.; Rosen, J.; Mochalin, V. N.; Barsoum, M. W. Chem. Mater. 2017, 29, 1106.

100. Ghidiu, M.; Halim, J.; Kota, S.; Bish, D.; Gogotsi, Y.; Barsoum, M. W. Chem. Mater. 2016, 28, 3507.101.

101. Enyashin, A. N.; Ivanovskii, A. L. Comput. Theor. Chem. 2012, 989, 27.

102. Tang, Q.; Zhou, Z.; Shen, P. J. Am. Chem. Soc. 2012, 134, 16909.

103. Persson, I.; Näslund, L.-Å.; Halim, J.; Barsoum, M. W.; Darakchieva, V.; Palisaitis, J.; Rosen, J.; Persson, P. O. Å. 2D Materials 2017, 5, 015002.

104. Shein, I.; Ivanovskii, A. Comput. Mater. Sci. 2012, 65, 104.

105. Khazaei, M.; Arai, M.; Sasaki, T.; Chung, C. Y.; Venkataramanan, N. S.; Estili, M.; Sakka, Y.; Kawazoe, Y. Adv. Funct. Mater. 2012, 23, 2185.

106. Xie, Y.; Kent, P. Phys Rev B 2013, 87, 235441.

107. Enyashin, A.; Ivanovskii, A., J. Solid State Chem. 2013, 207, 42. 
108. Shein, I. R.; Ivanovskii, A. L. Superlattices Microstruct. 2012, 52, 147.

109. Lane, N. J.; Barsoum, M. W.; Rondinelli, J. M. EPL (Europhysics Letters) 2013, $101,57004$.

110. Caffrey, N. M. Nanoscale 2018, 10, 13520.

111. Khazaei, M.; Arai, M.; Sasaki, T.; Ranjbar, A.; Liang, Y.; Yunoki, S. Phys. Rev. B 2015, 92, 075411.

112. Lind, H.; Halim, J.; Simak, S.; Rosen, J. Phys. Rev. Mater. 2017, 1, 044002.

113. Hettinger, J.; Lofland, S.; Finkel, P.; Meehan, T.; Palma, J.; Harrell, K.; Gupta, S.; Ganguly, A.; El-Raghy, T.; Barsoum, M. Phys. Rev. B 2005, 72, 115120.

114. Blake, P.; Brimicombe, P. D.; Nair, R. R.; Booth, T. J.; Jiang, D.; Schedin, F.; Ponomarenko, L. A.; Morozov, S. V.; Gleeson, H. F.; Hill, E. W. Nano Lett. 2008, $8,1704$.

115. Li, X.; Zhu, Y.; Cai, W.; Borysiak, M.; Han, B.; Chen, D.; Piner, R. D.; Colombo, L.; Ruoff, R. S. Nano Lett. 2009, 9, 4359.

116. Friend, R. H.; Yoffe, A. D. Adv Phys 1987, 36, 1.

117. Kurtoglu, M.; Naguib, M.; Gogotsi, Y.; Barsoum, M. W. MRS Commun. 2012, 2, 133.

118. Klintenberg, M.; Lebègue, S.; Ortiz, C.; Sanyal, B.; Fransson, J.; Eriksson, O., J. Phys.: Condens. Matter. 2009, 21, 335502.

119. Lipatov, A.; Lu, H.; Alhabeb, M.; Anasori, B.; Gruverman, A.; Gogotsi, Y.; Sinitskii, A. Science Advances 2018, 4, 0491.

120. Naguib, M.; Come, J.; Dyatkin, B.; Presser, V.; Taberna, P.-L.; Simon, P.; Barsoum, M. W.; Gogotsi, Y. Electrochem. Commun. 2012, 16, 61.

121. Lukatskaya, M. R.; Kota, S.; Lin, Z.; Zhao, M.-Q.; Shpigel, N.; Levi, M. D.; Halim, J.; Taberna, P.-L.; Barsoum, M. W.; Simon, P. Nat. Energy 2017, 2, 17105.

122. Xie, X.; Chen, S.; Ding, W.; Nie, Y.; Wei, Z. Chem. Commun. (Cambridge, U. K.), 2013, 49, 10112.

123. Seh, Z. W.; Fredrickson, K. D.; Anasori, B.; Kibsgaard, J.; Strickler, A. L.; Lukatskaya, M. R.; Gogotsi, Y.; Jaramillo, T. F.; Vojvodic, A., ACS Energy Letters 2016, $1,589$.

124. Lin, H.; Gao, S.; Dai, C.; Chen, Y.; Shi, J. J. Am. Chem. Soc. 2017, 139, 16235

125. Su, T.; Peng, R.; Hood, Z. D.; Naguib, M.; Ivanov, I. N.; Keum, J. K.; Qin, Z.; Guo, Z.; Wu, Z., ChemSusChem 2017, 11, 688.

126. Ng, V. M. H.; Huang, H.; Zhou, K.; Lee, P. S.; Que, W.; Xu, J. Z.; Kong, L. B., J. Mater. Chem. A 2017, 5, 3039.

127. Peng, Q.; Guo, J.; Zhang, Q.; Xiang, J.; Liu, B.; Zhou, A.; Liu, R.; Tian, Y. J. Am. Chem. Soc. 2014, 136, 4113.

128. Shahzad, F.; Alhabeb, M.; Hatter, C. B.; Anasori, B.; Hong, S. M.; Koo, C. M.; Gogotsi, Y. Science 2016, 353, 1137. 
129. Han, M.; Yin, X.; Wu, H.; Hou, Z.; Song, C.; Li, X.; Zhang, L.; Cheng, L., ACS Appl. Mater. Interfaces 2016, 8, 21011.

130. Römer, F. M.; Wiedwald, U.; Strusch, T.; Halim, J.; Mayerberger, E.; Barsoum, M. W.; Farle, M. RSC Advances 2017, 7, 13097.

131. Lee, E.; VahidMohammadi, A.; Prorok, B. C.; Yoon, Y. S.; Beidaghi, M.; Kim, D.J. ACS Appl. Mater. Interfaces 2017, 9, 37184.

132. Liu, H.; Duan, C.; Yang, C.; Shen, W.; Wang, F.; Zhu, Z. Sensors and Actuators B: Chemical 2015, 218, 60.

133. Hu, Q.; Sun, D.; Wu, Q.; Wang, H.; Wang, L.; Liu, B.; Zhou, A.; He, J. J. Phys. Chem, A 2013, 117, 14253.

134. Chini, P.; Longoni, G.; Albano, V. Adv. Organomet. Chem., 1976, 14, 285.

135. Schmid, G. Chem. Rev. (Washington, DC, U. S.) 1992, 92, 1709.

136. Abeles, B.; Sheng, P.; Coutts, M.; Arie, Y. Adv. Phys. 1975, 24, 407.

137. van Staveren, M. P. J.; Brom, H.; De Jongh, L. Phys. Rep. 1991, $208,1$.

138. Hill, R. physica status solidi (a) 1976, 35, K29.

139. Mott, N.; Kaveh, M. Adv Phys 1985, 34, 329.

140. Menon, R.; Yoon, C.; Moses, D.; Heeger, A.; Cao, Y. Phys Rev B 1993, 48, 17685.

141. Zhang, X.; Manno, M.; Baruth, A.; Johnson, M.; Aydil, E. S.; Leighton, C. ACS Nano 2013, 7, 2781.

142. Lee, P. A.; Ramakrishnan, T. Reviews of Modern Physics 1985, 57, 287.

143. Anderson, P. W. Physical review 1958, 109, 1492.

144. Mott, N. Adv Phys 1967, 16, 49.

145. Bergmann, G. Phys. Rep. 1984, 107, 1.

146. Anderson, P.; Abrahams, E.; Ramakrishnan, T. Phys. Rev. Lett. 1979, 43, 718.

147. Kommik, Y. F.; Bukhshtab, E.; Butenko, A.; Andrievsky, V. Solid State Commun. 1982, 44, 865 .

148. Lherbier, A.; Blase, X.; Niquet, Y.-M.; Triozon, F.; Roche, S. Phys. Rev. Lett. 2008, $101,036808$.

149. Sybous, A.; El Kaaouachi, A.; Hemine, J.; Narjis, A.; Limouny, L.; Dlimi, S.; Abdia, R.; Biskupski, G. Journal of Modern Physics 2012, 3, 521.

150. Pollak, M. J. Non-Cryst. Solids 1972, 8, 486.

151. Efros, A.; Shklovskii, B. Journal of Physics C: Solid State Physics 1975, 8, L49.

152. Beverly, K.; Sampaio, J.; Heath, J. J. Phys. Chem. B 2002, 106, 2131.

153. Birkholz, M., Thin film analysis by X-ray scattering. John Wiley \& Sons: 2006.

154. van der Heide, P., X-ray photoelectron spectroscopy: an introduction to principles and practices. John Wiley \& Sons: 2011.

155. Williams, D. B.; Carter, C. B., The Transmission Electron Microscope. Springer: 1996.

156. Förster, H., UV/vis spectroscopy. In Characterization I, Springer: 2004; pp 337426. 
157. Smits, F. Bell System Technical Journal 1958, 37, 711.

158. Lipatov, A.; Alhabeb, M.; Lukatskaya, M. R.; Boson, A.; Gogotsi, Y.; Sinitskii, A. Adv. Elec. Mater. 2016, 2, 1600255. 


\section{Papers}

The papers associated with this thesis have been removed for copyright reasons. For more details about these see:

http://urn.kb.se/resolve?urn=urn:nbn:se:liu:diva-151666 